OSVALDO LUIS ASATO

REGENERAÇÃO DE SISTEMAS PRODUTIVOS MEDIANTE A REALOCAÇÃO DINÂMICA DE RECURSOS COM FLEXIBILIDADE FUNCIONAL

São Paulo

2015 


\section{REGENERAÇÃO DE SISTEMAS PRODUTIVOS MEDIANTE A REALOCAÇÃO DINÂMICA DE RECURSOS COM FLEXIBILIDADE FUNCIONAL}

Tese apresentada à Escola Politécnica da Universidade de São Paulo para obtenção do título de Doutor em Ciências.

Área de Concentração:

Engenharia de Controle e Automação

Orientador:

Prof. Dr. Paulo Eigi Miyagi

Coorientador:

Prof. Dr. Diolino José dos Santos Filho

São Paulo

2015 
Este exemplar foi revisado e alterado em relação à versão original, sob responsabilidade única do autor e com a anuência de seu orientador.

São Paulo, 06 de julho de 2015.

Assinatura do autor

Assinatura do orientador

\section{Catalogação-na-publicação}

\section{Asato, Osvaldo Luis}

Regeneração de sistemas produtivos mediante a realocação dinâmica de recursos com flexibilidade funcional / O.L. Asato. --ed. rev.--São Paulo, 2015.

$144 \mathrm{p}$.

Tese (Doutorado) - Escola Politécnica da Universidade de São Paulo. Departamento de Engenharia Mecatrônica e de Sistemas Mecânicos.

1.Flexibilidade funcional 2.Realocação de recurso 3.Sistemas produtivos I. Universidade de São Paulo. Escola Politécnica. Departamento de Engenharia Mecatrônica e de Sistemas Mecânicos Il.t. 
Dedico este trabalho à esposa Alice; às minhas filhas, Jaqueline e Letícia; Aos meus pais, Guisho e Luiza; e irmãos, Tereza, Marina, Inês, Sueli, Paulo, Sergio, Edson. 


\section{AGRADECIMENTOS}

Primeiramente agradeço a Deus, agradeço ao orientador, Prof. Dr. Paulo Eigi Miyagi, pela oportunidade, confiança, muita paciência e incentivo em todos os momentos. Agradeço imensamente ao orientador Prof. Dr. Diolino José dos Santos Filho pela ajuda pessoal desde o primeiro dia que o conheci e pelas inúmeras dificuldades que passei, sou muito grato pelos constantes incentivos e muita paciência.

Agradeço aos professores Prof. Dr. Fabricio Junqueira, Prof. Dr. Newton Maruyama, Prof. Dr. Reinaldo Silva, Prof. Dr. Jun Okamoto Jr.

Aos colegas do laboratório de pesquisa da EPUSP, Marcosiris Pessoa, André Cavalheiro, Caio Fattori, Reinaldo Squilante, Edson Watanabe, Mauricio Bloss, Robson Marinho, Jeferson Souza, Edinei Legaspe, Guilherme Dobrianskyj, Lucas Cardozo de Sá, aos Professores do IFSP André Uehara e Vera Silva que sempre estiveram presentes colaborando para o desenvolvimento deste trabalho.

Aos eternos amigos Francisco Yastami Nakamoto, Gilson Kawakame, Lincoln Serikawa e João Ângelo Martine que sempre estiveram presentes compartilhando todos os momentos, os de dificuldades e os de conquistas.

Ao Eng. João Ueda, diretor da empresa CBD Automação Industrial, pelo exemplo de determinação, constante apoio e colaboração.

À Sra. Marisa Lara e Sra. Regianne Amaral, da secretaria da PPGEM, que sempre se empenharam e colaboram. 
Aquele que permanece em mim, e eu nele, esse produz muito fruto; porque sem mim nada podeis fazer.

João 15,5 


\section{RESUMO}

Nos sistemas produtivos contemporâneos, vários processos são executados simultaneamente por meio de um conjunto finito de recursos, que são fortemente compartilhados. No chão de fábrica desses sistemas produtivos, ocorrem também eventos não programados como a quebra de máquina, isto é, indisponibilidade imprevista de recursos que pode dar origem a muitos problemas como o travamento (deadlock) dos processos. Existem várias abordagens para resolver o problema, mas, em geral, elas envolvem o suporte de um sistema computacional especifico para a realocação de recursos. Por outro lado, na prática, os sistemas produtivos já possuem uma arquitetura física de controle dos processos estabelecida por normas internacionalmente aceitas, ou seja, a IEC 61131 e a IEC 61499, que prescrevem as diretrizes para o desenvolvimento de soluções de controle baseadas em CLPs. Nesse contexto, é necessário rever o problema de realocação de recursos para se adequar essa realidade à existência de uma arquitetura baseada em controladores programáveis que compõem o sistema de controle de processos desses sistemas produtivos. No presente trabalho, parte-se de requisitos de uma arquitetura física de controle de sistemas produtivos segundo as normas IEC 61131 e IEC 61499 para implementar uma solução de controle de processos que envolve recursos de uma nova natureza, ou seja, que possuem flexibilidade funcional, não prevista nas correspondentes normas. Além disso, desenvolve-se uma nova arquitetura de controle para realocação de recursos que; mediante a indisponibilidade imprevista de recursos como, por exemplo, a quebra de máquinas; considera a flexibilidade funcional das MFMs (Máquinas-Ferramenta Multifuncionais) como uma característica de seu comportamento a ser explorada em tempo real. Nesse contexto, a arquitetura proposta possui três módulos básicos: Controle de Processo (CP), que é responsável pela execução da sequência de atividades de cada processo, Designação de Funcionalidade (DF), que é responsável pela integração e organização de todas as sequências de funcionalidades dos processos, e Designação de Recurso (DR), que é responsável pela alocação/realocação de recursos, incluindo as MFMs. O trabalho define, também, um método para a 
implementação dos módulos que constituem o novo sistema de controle de alocação de recursos em sistemas produtivos.

Palavras Chave: Flexibilidade funcional, Realocação de recursos, Sistema produtivo. 


\begin{abstract}
In contemporary productive systems, several processes are executed simultaneously through a finite set of resources, which are shared intensively. On the shop floor of these productive systems, unscheduled events also occur, such as machine breakdowns. In other words, unexpected unavailability of resources may give rise to many problems, such as the deadlocking of processes. Several approaches exist to solve this problem, but in general they involve the support of a specific computer system to resolve the reallocation of resources. In practice, however, the productive systems already have a physical architecture for procedural control established by internationally accepted standards, i.e. IEC 61131 and IEC 61499, which prescribe guidelines for the development of control solutions. In this context, the reallocation of resources problem should be reviewed to suit this reality where there exist an architecture based on programmable controllers that make up the process control system of these productive systems. This work starts with the requirements of a physical architecture for the control of productive systems according to the IEC 61131 and IEC 61499 standards to implement a process control solution that involves resources of a new nature. In other words, resources that have a functional flexibility not provided for in the corresponding standards. In this work, a new control architecture was developed for the reallocation of resources that become unavailable because of such events as the breakdown of machinery. This architecture considers the functional flexibility of MMTs (Multifunction Machine Tools) as a characteristic of their behavior to be exploited in real time. In this context, the proposed architecture has three basic modules: Process Control (PC), which is responsible for the execution of the sequence of activities of each process; Functionality Designation (FD), which is responsible for the integration and organization of all functionality sequences of the processes; and Resource Designation (RD), which is responsible for the allocation/reallocation of resources, including the MMTs. This work also defines a method to implement the modules that make up the new resource allocation control system in production systems.
\end{abstract}

Keywords: Functional flexibility, Resource reallocation, Productive system. 


\section{LISTA DE FIGURAS}

Figura 1 - Representa os processos "A" e "B" em grafo MFG

Figura 2 - Representa a ocorrência de um evento inesperado no recurso R1.... 21

Figura 3 - Representa os processos "A" e "B" e compartilhamento da MFM........ 24

Figura 4 - Representa a evolução de uma variável em função do tempo 28

Figura 5 - Evolução de estados em sistemas a eventos discretos 29

Figura 6 - Evolução do centro de torneamento 31

Figura 7 - Exemplo de Máquina Ferramenta Multifuncional 32

Figura 8 - Evolução das máquinas visto através das peças 33

Figura 9 - Estrutura geral de um SP 35

Figura 10 - Ciclo de processamento da informação de produção. 36

Figura 11 - Relação dos blocos do sistema de manufatura holônica. 42

Figura 12 - Arquitetura do sistema de controle de alocação de recurso 51

Figura 13 - Processo para a síntese dos grafos do sistema de controle. 53

Figura 14 - Exemplo de um processo produtivo descrito por seq. de recursos.... 54

Figura 15 - Exemplo de síntese do grafo GSF 55

Figura 16 - Exemplo do refinamento - Passo 1 para construir o GDF 56

Figura 17 - Exemplo de fusão dos boxes controladores - Passo 2 para construir o GDF. 
Figura 18 - Exemplo de grafo de controle do GCP derivado do GSF.

Figura 19 - Comunicação entre os módulos.

Figura 20 - Geração do grafo de sequência de funcionalidade (GSF) 64

Figura 21 - Passo 1 - Geração do (GDF) Processo A. 65

Figura 22 - Passo 1 - Geração do (GDF) Processo B. 65

Figura 23 - Passo 1 - Geração do (GDF) Processo C. 65

Figura 24 - Passo 2- Grafo para Designar Funcionalidade (GDF). 66

Figura 25 - Grafo de Controle do Processo "A" (GCP). 67

Figura 26 - Grafo de Controle do Processo "B" (GCP). 67

Figura 27 - Grafo de Controle do Processo "C" (GCP) 68

Figura 28 - Fluxograma do algoritmo. 68

Figura 29 - Layout da planta 75

Figura 30 - Geração do GSF do processo "A". 76

Figura 31 - Geração do GSF do processo "B". 76

Figura 32 - Geração do GSF do processo "C". 76

Figura 33 - Geração do GSF do processo "D". 76

Figura 34 - Geração do GSF do processo "E". 77

Figura 35 - Geração do GSF do processo "G". 77

Figura 36 - Passo 1 - Geração do GDF.do processo "A". 77

Figura 37 - Passo 1 - Geração do GDF.do processo "B" 78 
Figura 38 - Passo 1 - Geração do GDF.do processo "C"

Figura 39 - Passo 1 - Geração do GDF.do processo "D"

Figura 40 - Passo 1 - Geração do GDF.do processo "E".. 79

Figura 41 - Passo 1 - Geração do GDF.do processo "G" 79

Figura 42 - Passo 2 - Geraçao do GDF global. 80

Figura 43 - Grafo de Controle do Processo "A" (GCP). 80

Figura 44 - Grafo de Controle do Processo "B" (GCP). 81

Figura 45 - Grafo de Controle do Processo "C" (GCP)

Figura 46 - Grafo de Controle do Processo "D" (GCP)

Figura 47 - Grafo de Controle do Processo "E" (GCP)

Figura 48 - Grafo de Controle do Processo "G" (GCP) 82

Figura 49 - llustra a comunicação dos GCPs, GDF e os recursos 83

Figura 50 - Exemplo de transcrição de um trecho do GDF do processo "A" para a linguagem SFC

Figura A1 - Elementos básicos do MFG. 96

Figura A2 - Exemplo de estrutura de uma marca individual.

Figura A3 - Representação de um box controlador alterando o estado de uma marca individual. 99

Figura A4 - Representação de um procedimento de filtragem seletiva 99

Figura A5 - Ilustra as marcas com os respectivos atributos 100 
Figura A6 - Alteração dos atributos das marcas decorrentes do disparo 101

Figura A7 - Interface de transmissão. 102

Figura A8 - interface de recepção. 102

Figura B1 - Representação do caminho das formigas (DORIGO, 1991). 104

Figura C1 - Exemplo de programa SFC 111

Figura C2 - Exemplo de um mesmo código implementado nas 4 linguagens IEC. 112

Figura C3 - Modelo de software proposto pelo padrão IEC 1131-3. 113

Figura C4 - Exemplo da interconexão dos equipamentos de um sistema de controle distribuído segundo a norma IEC

Figura C5 - Esquema básico de um Bloco Funcional padronizado pela norma IEC

Figura C6 - Modularização dos Blocos Funcionais 118

Figura C7 - Exemplo de bloco funcional utilizando bloco sequencial do MFG..... 121

Figura C8 - Diagrama de hierarquia funcional. 125 


\section{LISTA DE TABELAS}

Tabela 5.1 - Descrição da funcionalidade de cada recurso.

61

Tabela 5.2 - Custo inicial atribuído carregando inicial e despacho de peça

do recurso

Tabela 5.3 - Custo para transporte de uma máquina para outra

Tabela 5.4 - Resultado da simulação sem a ocorrência de indisponibilidade de ...

recurso

Tabela 5.5 - Resultado da simulação referente à quebra do recurso R1

Tabela 5.6 - Resultado da simulação referente à quebra do recurso R2

Tabela 5.7 - Resultado da simulação referente à quebra do recurso R3

Tabela 5.8 - Resultado da simulação referente à quebra do recurso R4 71

Tabela 5.9 - Resultado da simulação referente à quebra do recurso R5 72

Tabela 5.10 - Resultado da simulação referente à quebra do recurso R6 72

Tabela 5.11 - Descrição da funcionalidade de cada recurso. 


\section{LISTA DE ABREVIATURAS E SIGLAS}

$\begin{array}{ll}\text { ACS } & \text { Algoritmo Colônia de Formiga } \\ \text { AGV } & \text { Automated Guided Vehicle } \\ \text { AG } & \text { Algoritmo Genético } \\ \text { ANSI } & \text { American National Standards Institute } \\ \text { CLP } & \text { Controlador Lógico Programável } \\ \text { COBASA } & \text { Coalition Based Approach for Shop floor Agility } \\ \text { CP } & \text { Módulo Controle de Processo } \\ \text { DF } & \text { Módulo Designação de Funcionalidade } \\ \text { DR } & \text { Módulo Designação de Recurso } \\ \text { E-MFG } & \text { Enhanced Mark Flow Graph } \\ \text { FBD } & \text { Function Block Diagram } \\ \text { FMS } & \text { Sistema Flexível de Manufatura } \\ \text { GAR } & \text { Grafo de Alocação de Recurso } \\ \text { GDF } & \text { Grafo para Designação de Funcionalidade } \\ \text { GDR } & \text { Grafo para Designação de Recurso } \\ \text { GCP } & \text { Grafo para o Controle de Processo } \\ \text { GSF } & \text { Grafo de Sequência de Funcionalidade } \\ \text { HAPBA } & \text { Holonic Adaptive Plan-Based Architecture } \\ \text { HMS } & \text { Holonic Manufacturing Systems } \\ \text { IEC } & \text { International Electrotechnical Commission } \\ \text { ISA } & \text { International Society of Automation } \\ & \end{array}$




$\begin{array}{ll}\text { MFG } & \text { Mark Flow Graph } \\ \text { MFM } & \text { Máquina Ferramenta Multifuncional } \\ \text { PCP } & \text { Planejamento Controle da Produção } \\ \text { PROSA } & \text { Product Resource Order Staff Architecture } \\ \text { SFC } & \text { Sequential Function Chart } \\ \text { SED } & \text { Sistema a Eventos Discretos } \\ \text { SP } & \text { Sistemas Produtivos } \\ \text { SVC } & \text { Sistema de Variável Continua } \\ \text { RdP } & \text { Rede de Petri }\end{array}$




\section{LISTA DE SÍMBOLOS}

$\begin{array}{ll}T & \text { Intensidade do feromônio } \\ \text { Cn } & \text { conjunto de recursos } \\ r & \text { recurso de origem } \\ S & \text { recurso de destino } \\ \alpha & \text { regula a intensidade de feromônio } \\ \rho & \text { visibilidade de um recurso em relação aos recursos. } \\ \text { dri } & \text { parâmetro (custo ou tempo) } \\ \beta & \text { parâmetro que regula a influência de } \rho \\ P & \text { probabilidade } \\ \Sigma & \text { somatória } \\ \text { uc } & \text { unidade de custo }\end{array}$




\section{SUMÁRIO}

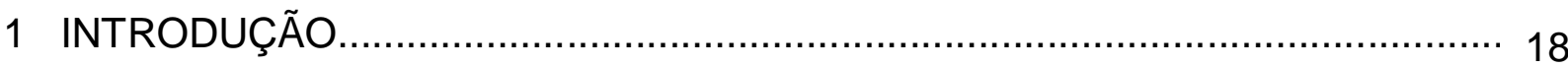

1.1 Motivação do trabalho ................................................................ 19

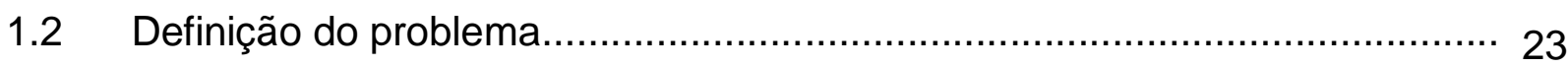

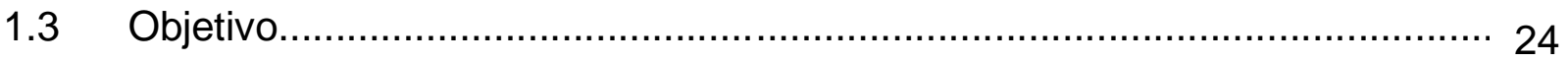

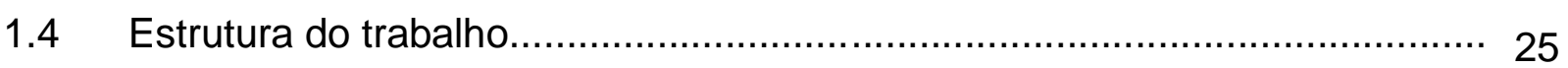

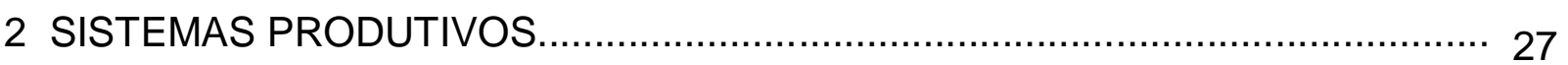

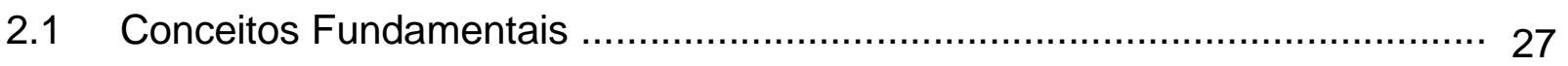

2.2 Flexibilidade do Sistema Produtivo.................................................... 30

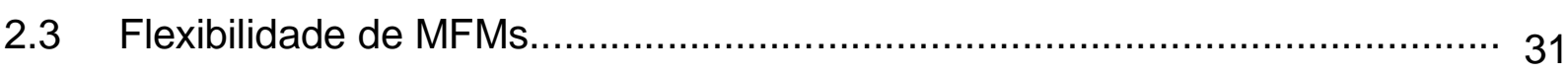

2.4 Complexidade em Sistemas Produtivos.............................................. 33

2.5 Sistema de apoio à produção............................................................ 35

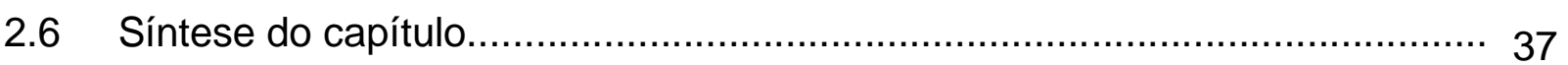

3 CONTROLE DE ALOCAÇÃO DE RECURSOS ........................................ 39

3.1 Dinâmica de alocação de recursos..................................................... 39

3.2 Arquitetura utilizando Sistemas Holônicos.......................................... 40

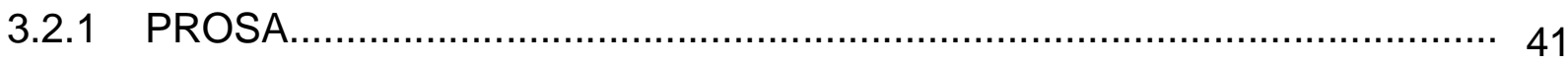

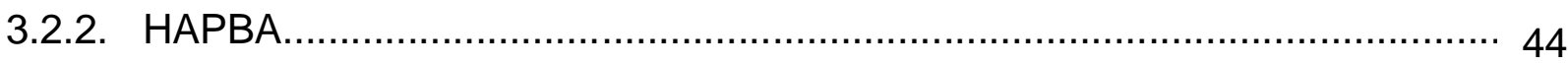

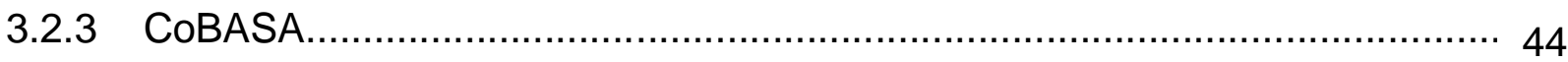

3.2.4 Arquitetura Semi-Heterárquica..................................................... 45

3.3 Limitações das Arquiteturas Holônicas em SPs.................................... 46

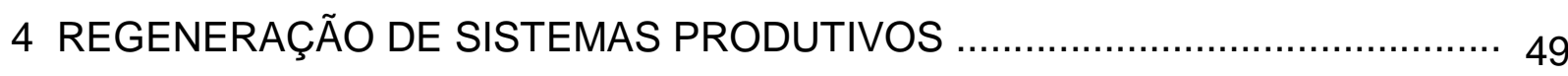

4.1 Arquitetura proposta para a regeneração de SPs................................. 51

4.2 Método para implementar os módulos................................................. 53

4.2.1 Síntese do Grafo Sequência de Funcionalidades (GSF) ........................... 54

4.2.2 Síntese do Grafo para a Designação de Funcionalidades (GDF) ................. 55

4.2.3 Síntese do Grafo para o Controle de Processo (GCP) ............................. 56

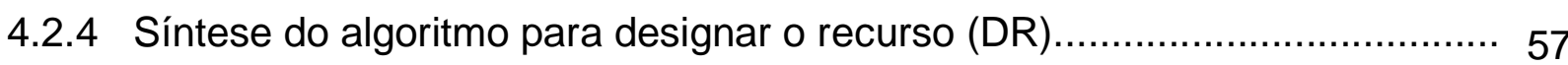


4.3 Comunicações entre os módulos ….............................................. 58

4.4 Observações complementares..................................................... 59

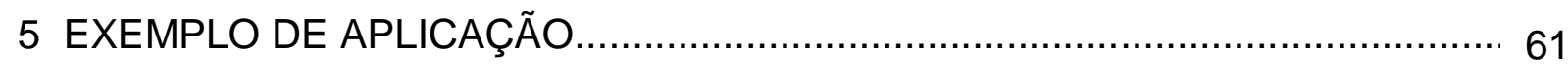

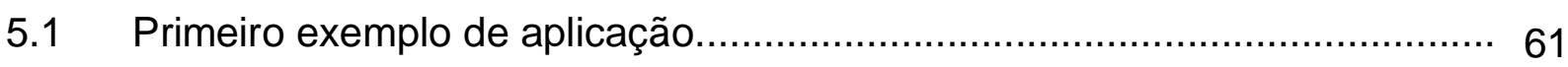

5.2 Segundo exemplo de aplicação................................................... 73

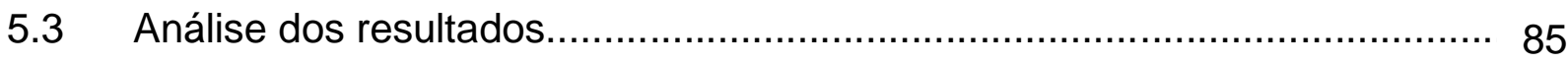

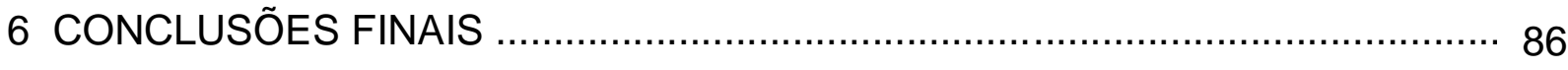

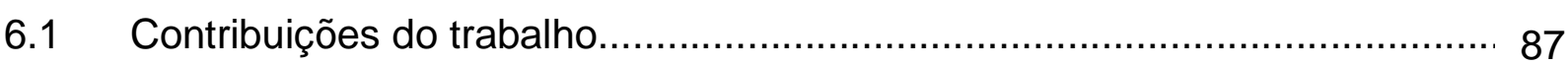

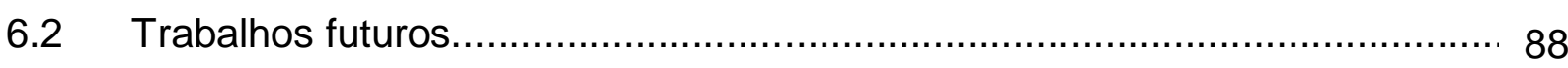

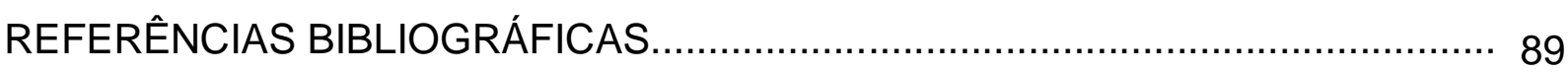

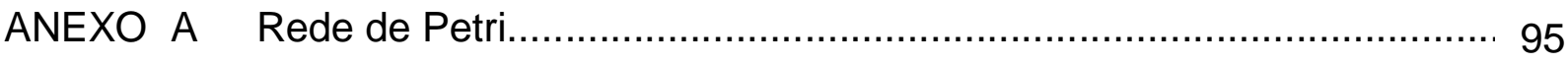

ANEXO B Algoritmo colônia de formigas................................................ 103

ANEXO C Normas IEC 61131-3, IEC 61499, ISA-S95.................................. 109

APÊNDICE Código de programação................................................... 128 


\section{INTRODUÇÃO}

Um sistema produtivo (SP) é visto como um sistema que realiza processos para transformar a matéria-prima (entradas) em produtos úteis (saídas) para a sociedade. Para que isso ocorra, o SP possui um conjunto de recursos como as máquinas operatrizes com capacidade de realizar diferentes tarefas, que estão localizados no chão da fábrica de modo que as alocações desses recursos ocorrem dinamicamente, conforme são executadas as atividades que compõem os processos (YUSO et al., 2014; SANTOS FILHO et al., 2011; QIU, 2009).

Do ponto de vista da teoria de sistemas, os SPs podem ser analisados como uma classe de sistema a eventos discretos (SED), em que é possível usar técnicas derivadas da rede de Petri (LI et al., 2014; GRADISAR, 2007) para a modelagem, análise e controle de acordo com as normas IEC 61131 (IEC, 2003) e IEC 61499 (IEC, 2005).

Em relação à capacidade produtiva dos recursos de um SP, o avanço tecnológico de sistemas mecatrônicos adicionou várias funcionalidades, tais como fresamento, torneamento e perfuração no mesmo recurso, que se denomina de Máquina Ferramenta Multifuncional (MFM) (MORIWAKI, 2008). As MFMs atendem, potencialmente, à necessidade de flexibilidade e produtividade, com o propósito de melhorar a eficiência dos processos de produção, especialmente na produção de produtos personalizados (RAJ et al., 2014; SHIN et al., 2009; GUO et al., 2012).

No contexto de gerenciamento global dos processos produtivos, as atuais arquiteturas de controle, sejam elas baseadas no conceito de sistemas holônicos (BORANGIU et al., 2014; VAN BRUSSEL et al., 1998), sistemas multiagentes (VRBA, 2013; BARATA; CAMARINHA-MATOS, 2003), ou grafos de alocação de recursos - GAR (NAKAMOTO et al., 2008), adotam uma estrutura de controle distribuída em que estão presentes dois níveis semânticos básicos: controle de processos e controle de uso dos recursos para a realização dos processos (SANTOS FILHO, 2000). 


\subsection{MOTIVAÇÃO DO TRABALHO}

Um fato importante a ser destacado é que as soluções apresentadas para o gerenciamento global dos processos produtivos baseiam-se em informações do processo de fabricação com a especificação do recurso a ser utilizado de forma fixa, isto é, estática e não flexível. Portanto, ainda que o paradigma baseado em grafo de alocação de recursos (GAR) seja útil para a solução de problemas de deadlock, não pode ser aplicado para o caso de SP que envolve diferentes funcionalidades para seus recursos. Isso implica em atribuição dinâmica da funcionalidade ao respectivo recurso, de acordo com o estado do SP, não se limitando a uma atribuição previamente fixada que restringe $o$ uso de um determinado recurso a uma determinada atividade, sem considerar alterações na alocação de funcionalidades ao conjunto de recursos disponíveis, que é uma nova circunstância de controle de parâmetros que deve ser realizada para tratar, de forma adequada, a disponibilidade de flexibilidade funcional nesses recursos.

Embora exista a arquitetura holônica (como exemplo, PROSA), que permite utilizar recursos com múltiplas funcionalidades. Essa solução também apresenta 0 problema de confiabilidade e escalabilidade, isto é, segundo Vrba et al., (2011) e Marik; McFarlane (2005), quando aplicado em sistemas de manufatura reais, há dificuldade em lidar com o processamento de milhares de agentes trabalhando em paralelo para gerir a comunicação com a robustez que a indústria requer.

A arquitetura holônica também apresenta dificuldades em aderir às normas IEC 61131 e IEC 61499 (que rege o sistema de controle de sistemas produtivos) no que se refere aos recursos, quando trabalham com o conceito de preempção (interrupção temporária) e, portanto não permite que o sistema gere interrupções nos processos na forma que necessita. Quando se utiliza sistemas altamente descentralizados e distribuídos (como os agentes e holons), a dificuldade está em como controlar as gerações de interrupções e como garantir a confiabilidade nesse sistema de controle.

Por sua vez, as abordagens convencionais sobre arquiteturas de controle de alocação dinâmica de recursos em SPs não preveem a utilização dos recursos com 
múltiplas funcionalidades (MFM). Portanto, para tratar esse caso, é necessário rever o paradigma de alocação de recursos para que o enfoque seja na alocação de funcionalidades e, como consequência, é necessário considerar uma nova arquitetura de controle de processos.

Para facilitar o entendimento do exposto, mostra-se o problema por meio de um exemplo. Considere o exemplo ilustrado na Figura 1, em que um SP possui dois processos "A" e "B", que são descritos usando MFG (Mark Flow Graph) (Anexo A). O processo "A" envolve as atividades de A1, A2 e A3 e o processo "B" envolve as atividades B1, B2 e B3.

O processo "A" utiliza um recurso R1 que possui a funcionalidade F1 para executar a atividade $A 2$, e o processo "B" utiliza um recurso multifuncional, isto é, uma máquina MFM com as funcionalidades F1 e F2, sendo que, neste caso, apenas F2 é considerada para executar a atividade B2.
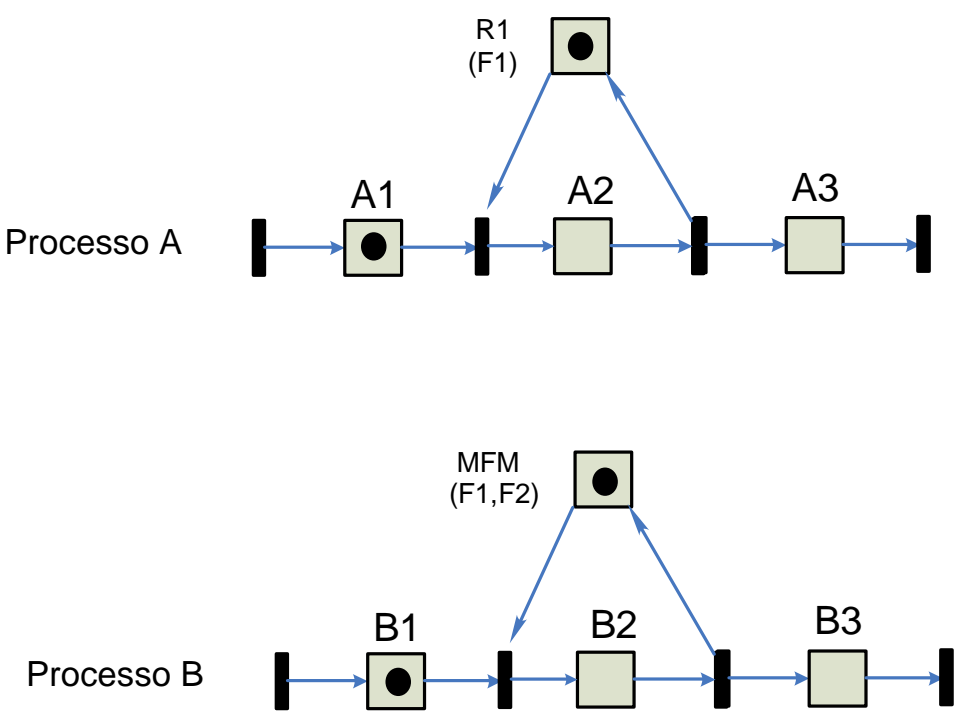

Figura 1 - Representa os processos "A" e "B" em grafos MFG 
Caso ocorra um evento inesperado, por exemplo, a quebra do recurso R1, habilitase a transição (Tq), conforme Figura 2, levando o recurso R1 ao estado inoperante. O sistema pode entrar em deadlock devido à parada do processo "A", mesmo sabendo que a MFM possui a funcionalidade F1 disponível para executar a atividade A2 quando não está executando a atividade B2.

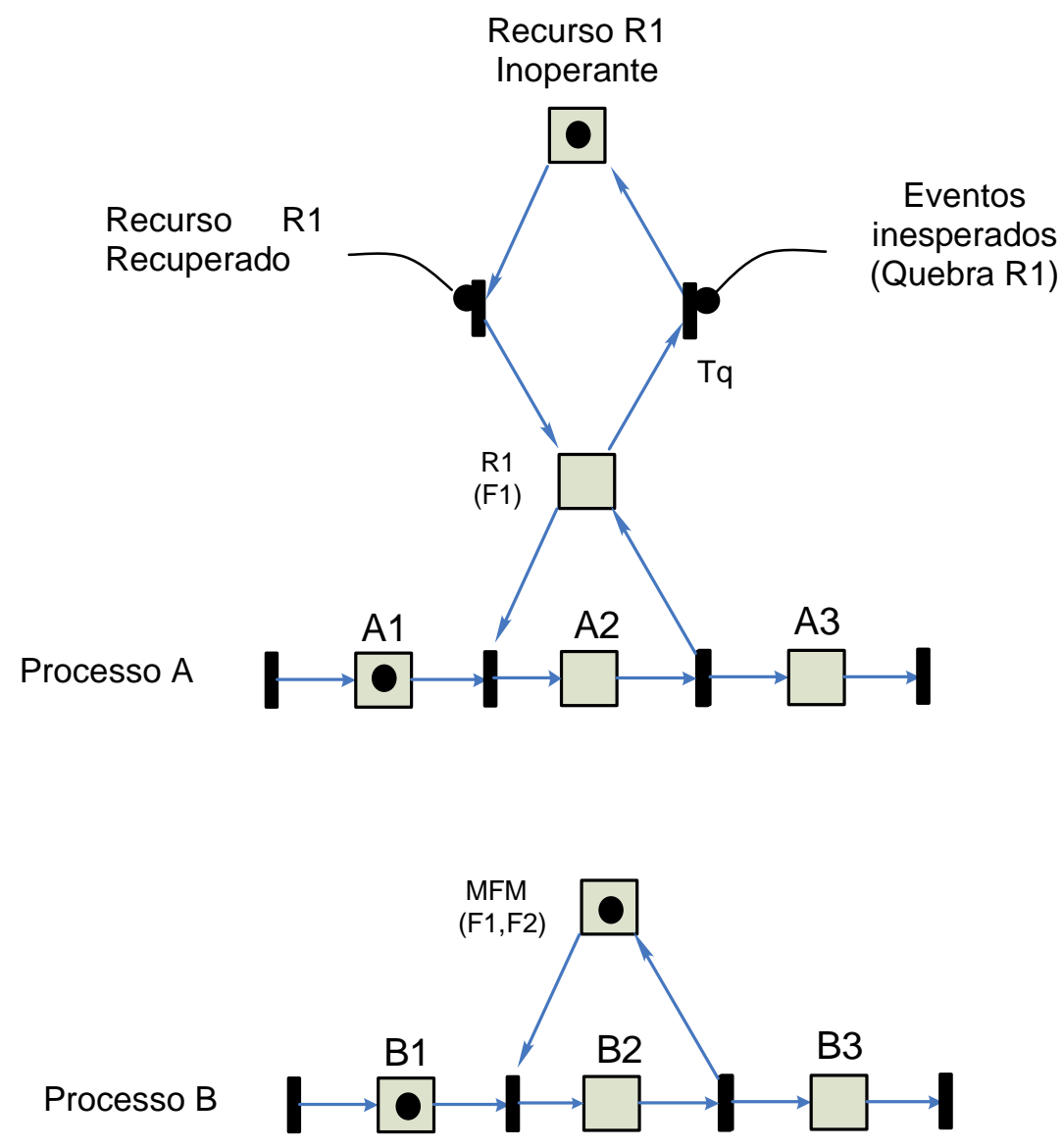

Figura 2. Representa a ocorrência de um evento inesperado no recurso R1.

Esse exemplo ilustra uma limitação da abordagem convencional e, é possível deduzir que o problema é mais complexo no caso de SPs com várias MFMs.

As MFMs introduzem uma flexibilidade funcional adicional para a execução dos processos produtivos, mas esses recursos não podem ser plenamente explorados se a alocação de recursos for baseada apenas numa sequência pré-definida de 
tarefas e que só é revisada quando se realiza uma nova programação global da produção.

Isto é, para explorar o potencial das MFMs e, no caso citado, retirar o sistema do estado de deadlock, o enfoque deve ser em uma solução com base nas demandas de funcionalidade para executar os processos produtivos, ou seja, uma solução com base na alocação de funcionalidades sob uma abordagem dinâmica. Assim, concluise que é necessário rever o sistema de controle para que este realize a alocação de recursos sob uma abordagem dinâmica baseada na alocação de funcionalidades.

Portanto, a questão é que sempre podem ocorrer eventos não esperados, como a quebra de máquina no Sistema Produtivo. Como possível solução, seria necessário executar a realocação de recursos com flexibilidade funcional, mas alocar esse tipo de recurso exige uma mudança de paradigma que permita associar a característica de flexibilidade funcional à tarefa de controle de alocação de recursos que possuem tal propriedade.

Dessa forma, quando ocorre, por exemplo, uma falha no processo causada por uma quebra de máquina no chão de fabrica, o sistema de controle deve reorganizar o processo produtivo considerando o conjunto de funcionalidades inerente a cada recurso para que a funcionalidade requisitada em cada atividade seja usada como parâmetro para realizar a realocação do recurso adequado para a atividade pendente.

Nesse contexto, é necessário não só identificar os recursos disponíveis, mas também definir sequências dinâmicas de uso de recursos fazendo uso de algoritmos de tomada de decisão e/ou busca heurística que permitam auxiliar no procedimento de seleção de recursos de acordo com algum critério (exemplo: menor custo) dentre uma variedade de possibilidades. 


\subsection{DEFINIÇÃO DO PROBLEMA}

Diante da indisponibilidade imprevista de recursos, como por exemplo, a quebra de máquina nos SPs, as atividades podem ficar impedidas de prosseguir porque 0 sistema entra no estado de deadlock. O conceito de deadlock tratado neste trabalho relaciona-se ao evento associado a recursos no chão de fábrica de modo que o Sistema Produtivo entra no estado de travamento (deadlock) e, para retirá-lo deste estado, é necessário realocar outro recurso.

Neste trabalho, a MFM é vista como um recurso parametrizável, isto é, a funcionalidade da MFM passa a ser uma variável do recurso e a regeneração do estado de deadlock ocorre por meio de realocação dinâmica de recursos com flexibilidade funcional.

Essa nova abordagem, explora a flexibilidade funcional das MFMs e muda o paradigma de alocação de recursos porque, convencionalmente, esses recursos são vistos com capacidade de executar apenas uma única funcionalidade.

A premissa é que, diante da eventual indisponibilidade imprevista do recurso que foi programado, o sistema de controle de alocação de recursos agora passa a considerar a funcionalidade que necessita ser atendida.

Dessa forma, o sistema realiza uma busca das funcionalidades disponibilizadas nos recursos e, a partir das máquinas candidatas, designa-se o recurso mais viável para o momento.

Essa mudança da forma de realizar a alocação de recursos permite explorar as múltiplas funcionalidades disponibilizadas nas MFMs e, no exemplo visto anteriormente ilustrado na Figura 2, aplicando-se a nova abordagem, o sistema de controle de realocação de recursos identificaria que a atividade $\mathrm{A} 2$ pode ser realizada na MFM, compartilhando-a para não interromper o processo " $A$ ", confome lustrado na Figura 3. 
Processo A

Processo B

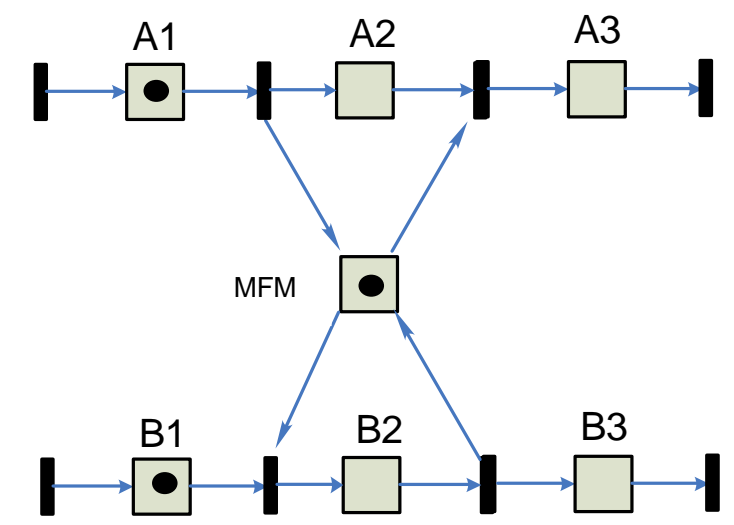

Figura 3 - Representa os processos "A" e "B" e o compartilhamento da MFM

A implementação dessa solução envolve a necessidade de conceber uma nova arquitetura para o sistema de controle realizar a alocação dinâmica de recursos que considere a flexibilidade funcional das MFMs.

\subsection{OBJETIVO}

Propor uma arquitetura que considera o conceito de flexibilidade funcional, para resolver o problema de deadlock (travamento) do processo (de produção) causado pela indisponibilidade imprevista de recursos. Essa arquitetura permite que o sistema de controle de realocação de recursos explore a flexibilidade funcional para realocação dinâmica de recursos a fim de regenerar o sistema produtivo (SP) de um possível estado de deadlock causado por quebra de máquina.

Neste trabalho são considerados os recursos que possuem múltiplas funcionalidades o que resulta em uma maior dificuldade em estabelecer um modelo para a especificação da solução de controle de realocação dinâmica de recurso no SP. Portanto, basicamente as metas são:

- Definir um procedimento que torne a alocação de atividades do processo que é determinística (estática) como alocação não determinística, isto é, um 
procedimento em que a alocação de atividades do processo não seja vinculada ao recurso.

- Definir um procedimento para que o sistema de controle de realocação dinâmica de recursos atue integrado com a programação desenvolvida pelo planejamento (scheduling), que é fundamental para manter o sincronismo de produção.

- Definir uma arquitetura que esteja em consonância com as normas vigentes e que tem sido adotada nas implementações existentes de sistemas de gerenciamento global de processos em SPs.

\subsection{ESTRUTURA DO TRABALHO}

O capítulo 1 é dedicado à introdução, na qual são apresentadas as motivações do trabalho, definição do problema e objetivo.

No capítulo 2, apresentam-se os conceitos relacionados aos sistemas produtivos (SPs), sistemas a eventos discretos (SED) e sistemas de variáveis contínuas (SVC). As definições e conceitos são abordados sobre flexibilidade do SP e, em seguida, apresenta-se a evolução das máquinas-ferramenta até chegar à Máquina Ferramenta Multifuncional (MFM). Apresenta-se também uma análise da complexidade para modelar o comportamento dinâmico do SP.

No capítulo 3, mostra-se a dinâmica do procedimento de alocação de recursos e também se abordam as principais arquiteturas de sistemas holônicos, são citadas as vantagens e, ao mesmo tempo, as limitações que essas arquiteturas possuem para o caso em questão.

O capítulo 4 refere-se ao método proposto para regenerar o SP. Apresenta-se a proposta de uma nova arquitetura de realocação dinâmica de recursos no SP e um 
método para implementação dos módulos da arquitetura de controle. Apresenta-se também a comunicação que ocorre entre os módulos de controle.

No capítulo 5, apresenta-se a aplicação do método proposto. São apresentados dois exemplos de aplicação, são desenvolvidos os grafos para designação e alocação de recursos e os resultados.

No capítulo 6, apresentam-se as conclusões finais, as contribuições do trabalho e os trabalhos futuros. Por fim, as referências bibliográficas, apêndice e anexos. 


\section{SISTEMAS PRODUTIVOS}

Neste capítulo apresentam-se os conceitos fundamentais de Sistemas Produtivos (SPs) e suas principais características com destaque para a flexibilidade dos recursos para sua alocação no chão de fábrica e as ações de controle que asseguram um comportamento dinâmico desejado diante de eventos não esperados.

\subsection{CONCEITOS FUNDAMENTAIS}

Entende-se que as empresas estão em constante competição, e os fatores que interferem na dinâmica de um SP envolvem o ciclo de vida útil dos produtos cada vez mais curto e, como consequência, o processo de comercialização também é dinâmico. Além disso, os clientes possuem diferentes necessidades que forçam as empresas a diversificarem seus produtos junto com ações para melhorar a eficiência e produtividade de suas atividades de produção (HE et al., 2014).

Diante desse cenário, exige-se cada vez mais do sistema de controle da produção, uma solução de alocação otimizada dos recursos, resposta rápida às mudanças imprevistas ou não esperadas, menor custo e melhoria do desempenho da produção (ZADEH et al., 2014).

Nesse contexto, é evidente que se deve aproveitar ao máximo os benefícios/ capacidades contidas nos recursos do chão de fábrica.

Uma atenção especial está na ocorrência de um evento não esperado, que é, por exemplo, o travamento (deadlock) devido à quebra de máquina ou qualquer outro problema de indisponibilidade de recurso, dentro de um horizonte de planejamento (scheduling), pode-se, realocar outros recursos, explorando o conceito de flexibilidade funcional, evitando-se, assim, um replanejamento (rescheduling) geral do SP. 
Neste trabalho, define-se sistema produtivo (SP) como sendo um sistema que transforma, por meio de processos, os insumos (entradas) em produtos (saídas) (GROOVER, 2011). São exemplos de SPs os sistemas industriais que possuem um conjunto de recursos como máquinas e equipamentos, com capacidade de realizar diferentes tarefas, de modo que a designação desses recursos ocorre em função dos processos a serem executados dinamicamente nesse ambiente, de tal forma que a evolução de estados do SP ocorre a partir de eventos que podem provocar situação de conflito, assincronismo e concorrência de processos que necessitam ser devidamente controlados (GROOVER, 2011; SANTOS FILHO et al., 2011).

O comportamento de parte dos elementos que constituem os SPs pode ser modelado por meio de leis invariantes da Física. Nesse caso, a evolução dinâmica dos estados de cada um desses elementos é descrita pela variação contínua de certos parâmetros em função do tempo, conforme ilustra a Figura 4. Esses elementos podem ser classificados como sistemas de variáveis contínuas (SVC) (MIYAGI, 1996).

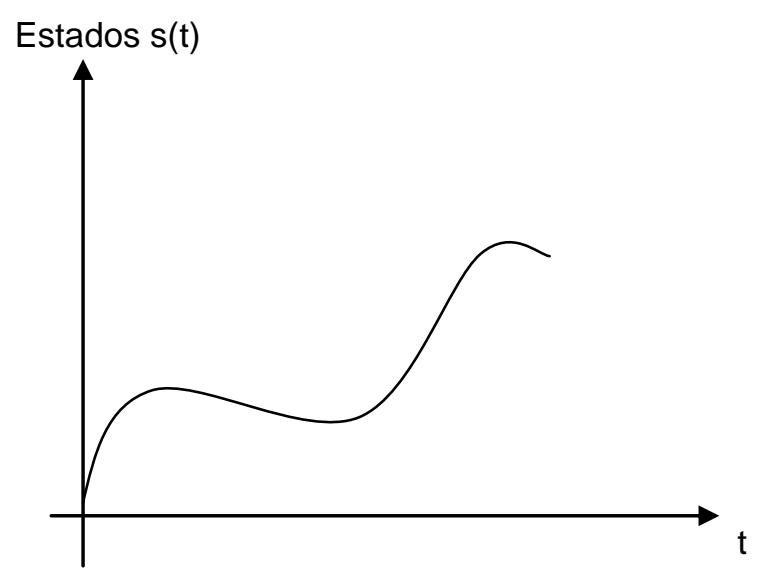

Figura 4 - Representa a evolução de uma variável física em função do tempo

Entretanto, apesar dos SPs serem constituídos por elementos que pertencem à classe de SVCs, o comportamento resultante, deles não se restringe à simples justaposição desses elementos. A realização dos processos produtivos envolve a interação entre os elementos de acordo com processos e regras de produção específicas e estabelecidas pelo homem. Nesse contexto, para a integração desses 
elementos, faz-se necessário controlar os eventos que regem essas interações. Os avanços tecnológicos resultaram em SPs considerados sistemas feitos pelo homem e para o homem (man-made system), e o comportamento dinâmico em questão não permite ser modelado apenas por meio das leis da Física como os SVCs. Dessa forma, foi introduzida uma nova visão de sistemas para incluir a classe de sistemas denominada de sistemas a eventos discretos (SED) (MIYAGI, 1996).

Os SPs abordados nesse trabalho fazem parte da classe de SEDs e são caracterizados por realizarem processos produtivos compostos por uma sequência de etapas, sendo cada uma dessas etapas interpretada como uma ação ou conjunto de ações que transformam o item que está sendo processado (Figura 5). O objetivo do SP é a execução desses processos para transformar os insumos de entradas em produtos na saída do sistema (CASSANDRAS; LAFORTUNE, 2007) de acordo com critérios de produtividade, qualidade, etc.

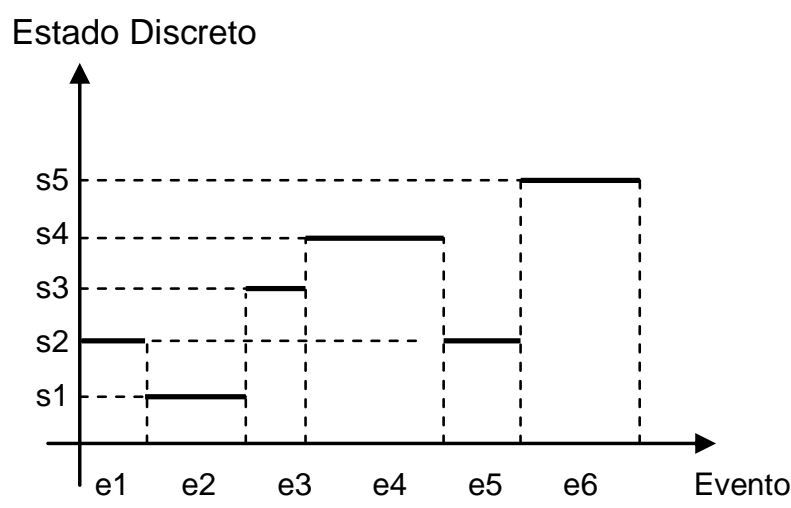

Figura 5 - Evolução de estados em sistemas a eventos discretos

A Figura 5 representa o comportamento de um SP visto como um sistema a eventos discretos (SED), em que, no eixo da abscissa, estão os eventos e, no eixo da ordenada, estão os respectivos estados discretos. Os eventos são ações que ocorrem durante um curto intervalo de tempo, provocando a transição de estado no sistema. 


\subsection{FLEXIBILIDADE DO SISTEMA PRODUTIVO}

Para atender a determinados objetivos do SP, é necessária tanto a flexibilidade física quanto a flexibilidade lógica (CHOI et al., 2013; NAKAMOTO et al., 2008).

A flexibilidade de um SP pode ser definida como sendo a sua habilidade de mudar ou reagir com pouca perda de tempo, esforço, custo e mantendo alto desempenho (MATSUSAKI; SANTOS FILHO, 2006).

Segundo Groover (2011), a flexibilidade de um SP pode ser classificada como:

- Flexibilidade de recurso: a máquina tem meios de ser configurada para realizar diferentes tarefas.

- Flexibilidade de produto: o SP possui a capacidade de produzir novos conjuntos de itens.

- Flexibilidade de rota: os itens podem ser confeccionados por meio de rotas alternativas.

- Flexibilidade de volume: o SP possui a capacidade de produzir diferentes volumes do produto de forma rentável.

- Flexibilidade de expansão: o SP tem meios de expandir sua capacidade produtiva.

O conceito de flexibilidade pode ainda ser interpretado como a capacidade de determinados sistemas de adaptarem-se a diferentes dinâmicas de seus processos. Isso envolve, por exemplo (SANTOS FILHO, 2011):

- A capacidade de processar diferentes itens que podem ser materiais ou informação.

- A capacidade de gerenciar fluxos alternativos para movimentação dos itens do sistema.

- A capacidade de alocação dinâmica dos recursos para a execução de diferentes processos. 


\subsection{FLEXIBILIDADE DE MÁQUINAS-FERRAMENTA MULTIFUNCIONAIS (MFMs)}

Para atender à crescente demanda por maior produtividade e flexibilidade, a evolução tecnológica dos sistemas mecatrônicos resultou nas máquinas-ferramenta multifuncionais (MFMs), que é uma máquina capaz de realizar múltiplas funções de usinagem em um único conjunto eletromecânico e tem sido introduzida em indústrias de transformação como as indústrias automobilística e aeroespacial ( $\mathrm{CHOl}$ et al. 2013).

A MFM além de visar à redução do tempo global de usinagem, também amplia a flexibilidade das máquinas para oferecer além da flexibilidade operacional, a flexibilidade funcional, como o torneamento, a fresagem, a furação, entre outras funcionalidades disponíveis usualmente em apenas uma única máquina (MORIWAKI, 2008).

Segundo Moriwaki (2008), a evolução do centro de torneamento é ilustrada na Figura 6, na qual se observa que, em 1980, o torno possuía apenas dois eixos controlados, e posteriormente passou a ter quatro eixos controlados. A incorporação da funcionalidade fresa ocorreu antes do desenvolvimento do controle automático do eixo $\mathrm{Y}$ e continuou a evolução de tal maneira que as máquinas passaram a ter 0 controle automático das ferramentas (CAF) e, por volta do ano 2000 , tem-se a máquina ferramenta multifuncional (MFM).

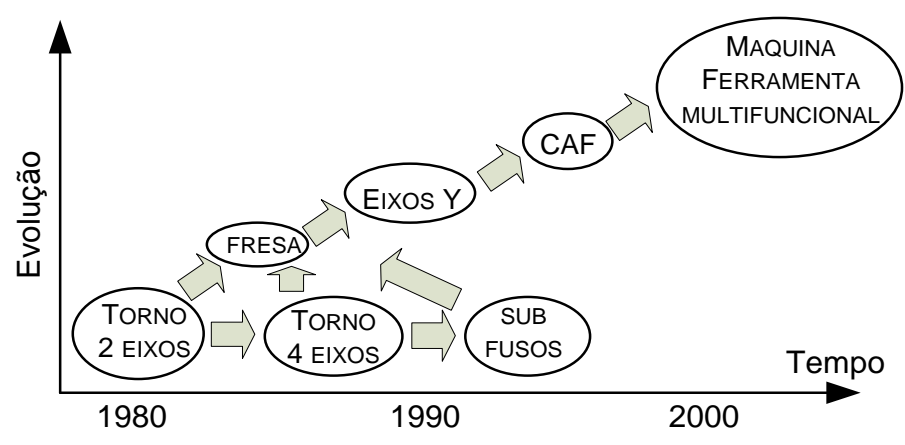

Figura 6 - Evolução do centro de torneamento (adaptado de CHOI et al., 2013; MORIWAKI, 2008) 
A Figura 7 ilustra uma MFM. Nesse caso, a flexibilidade da máquina está nos movimentos de seus eixos, sendo que o $1^{\circ}$ fuso permite rotação nos sentidos horário ou anti-horário, conforme identificado por $\mathrm{C} 1$ e o $2^{\mathrm{O}}$ fuso permite rotação no sentido horário ou anti-horário, conforme identificado por C2. A $1^{\underline{a}}$ torre seleciona a ferramenta e executa os movimentos nos eixos: $x 1, z 1, y . A 2^{\underline{a}}$ torre seleciona a ferramenta e executa os movimentos nos eixos: $x 2, \mathrm{z} 2$.

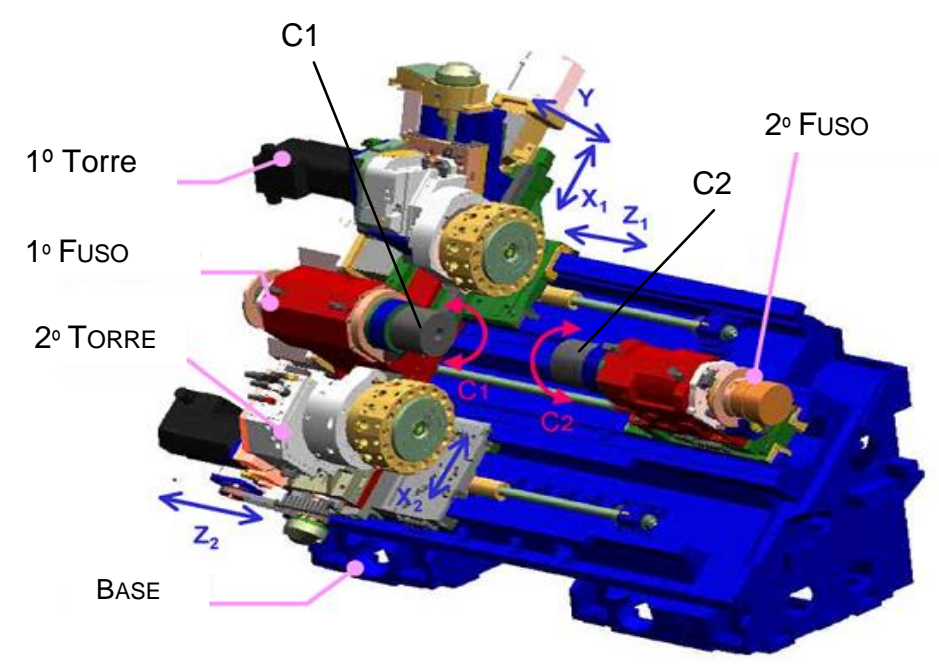

Figura 7 - Exemplo de Máquina Ferramenta Multifuncional (MFM)

(adaptado de MORIWAKI, 2008)

Segundo Choi et al. (2013), uma MFM, possui basicamente fusos controlados e torres para troca de ferramentas de modo a realizar várias operações de vários processos de usinagem e que podem ser operados simultaneamente.

Do ponto de vista tecnológico, segundo Moriwaki (2008), o controle simultâneo de vários eixos possibilita a usinagem de peças com geometria complexa e tanto a funcionalidade de tornear quanto a de fresar podem trabalhar na peça de modo que há dificuldades em afirmar qual das funcionalidades a MFM realiza melhor. Essa afirmação vem reforçar a ideia de que o recurso MFM pode substituir indistintamente uma fresa ou um torno, pois ambas as tarefas são realizadas de modo eficiente. A 
estrutura mecânica associada aos servomecanismos, sistemas de controle de posicionamento e velocidade têm contribuído para que a máquina disponha de múltiplas funcionalidades e alta precisão.

A Figura 8 ilustra a evolução das máquinas-ferramenta do ponto de vista das peças que as máquinas são capazes de usinar. De 1990 a 1995, as máquinas-ferramenta executavam funções de torneamento e fresagem somente em peças com perfil cilíndrico. No período de 1996 a 2000, passaram a executar funções de torneamento e fresagem de peças com perfil prismático e, próximo dos anos 2000, as máquinas MFMs passaram a trabalhar peças com geometria complexa.

ANO

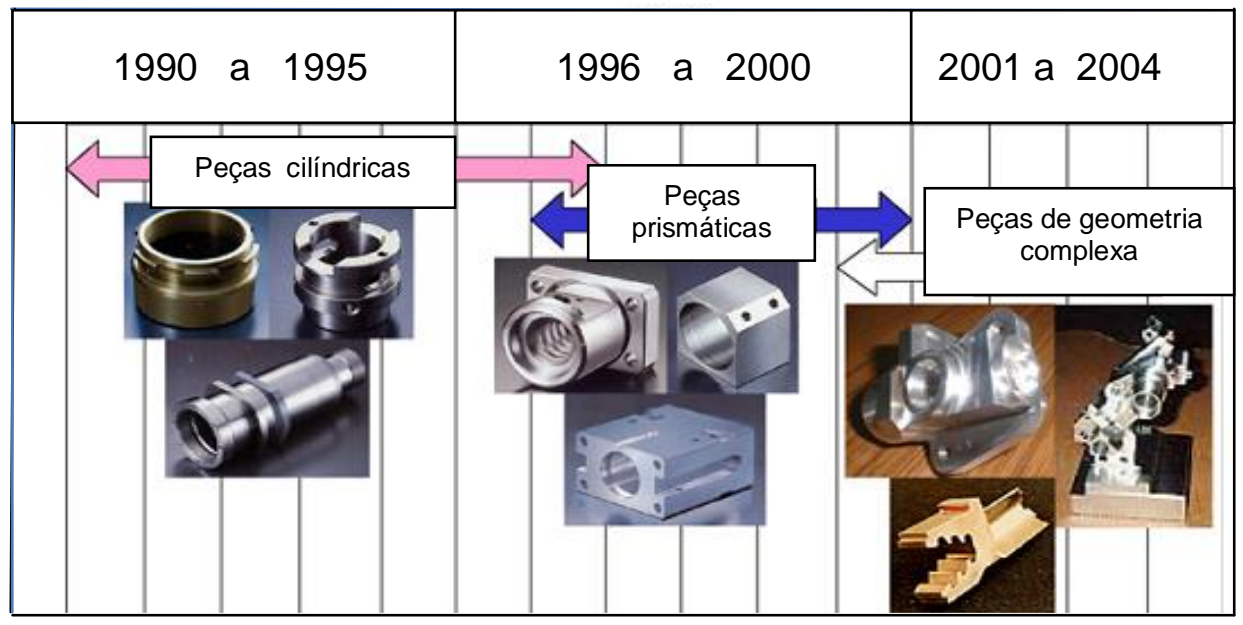

Figura 8 - Evolução das máquinas vista através das peças (adaptado de MORIWAKI, 2008)

\subsection{COMPLEXIDADE EM SISTEMAS PRODUTIVOS}

Existem várias definições diferentes sobre a complexidade de um sistema de manufatura e, segundo Calinescu et al. (2000), um SP que realiza a alocação de recursos no chão de fábrica, onde vários processos são executados simultaneamente para produção de vários produtos, de tal forma que os recursos são compartilhados entre os processos, deve tratar também do problema 
relacionado com a existência de várias rotas de produção. Considerando ainda a possibilidade de falha (quebra) de máquina ou qualquer outro problema de indisponibilidade de recursos, a complexidade para modelar o comportamento dinâmico desses sistemas é evidente e denominado sistema complexo (CALINESCU et al., 2000).

Nesse contexto, a complexidade nos SPs também é reconhecida como sendo uma situação em que não é possível modelar com relações matemáticas simples o comportamento dinâmico do sistema, isto é, considera-se um sistema complexo porque, mesmo conhecendo o comportamento individual de cada elemento do SP, quando estes atuam de forma integrada, de modo que vários processos atuam simultaneamente, não é trivial desenvolver um modelo que represente tal comportamento (LI et al., 2014).

A complexidade para modelar o comportamento dinâmico de sistemas produtivos com MFMs é caracterizado e derivado de três tipos de indeterminismo, sendo que os dois primeiros são descritos em Santos Filho (2000):

- Indeterminismo em relação ao tempo: não se consegue predeterminar quando é que certos eventos ocorrem devido à existência de paralelismo, conflitos e assincronismo dos processos.

- Indeterminismo em relação à sequência de ocorrência de eventos: não é possível predeterminar completamente qual evento precede outro porque no processo global existem múltiplos processos sendo executados simultaneamente e a sequência global de eventos pode ser sempre alterada.

- Indeterminismo em relação à sequência de uso de funcionalidades nos recursos que possui a flexibilidade funcional: não é possível determinar, no caso das MFMs, qual funcionalidade precede outra porque existe 0 indeterminismo da sequência de ocorrência de eventos. 
Dessa forma, a complexidade para especificar e implementar uma solução para alocação/realocação dinâmica de recursos no chão de fábrica deve considerar os três tipos de indeterminismo.

\subsection{SISTEMA DE APOIO À PRODUÇÃO}

Conforme anteriormente explicado, os SPs são formados por um conjunto de máquinas, equipamentos e procedimentos organizados para realizar as operações de produção em uma empresa. Segundo Groover (2011), é um sistema que pode ser dividido em dois níveis: um nível refere-se ao sistema de apoio à produção, e outro nível às instalações de produção conforme ilustrado na Figura 9 (GROOVER, 2011).

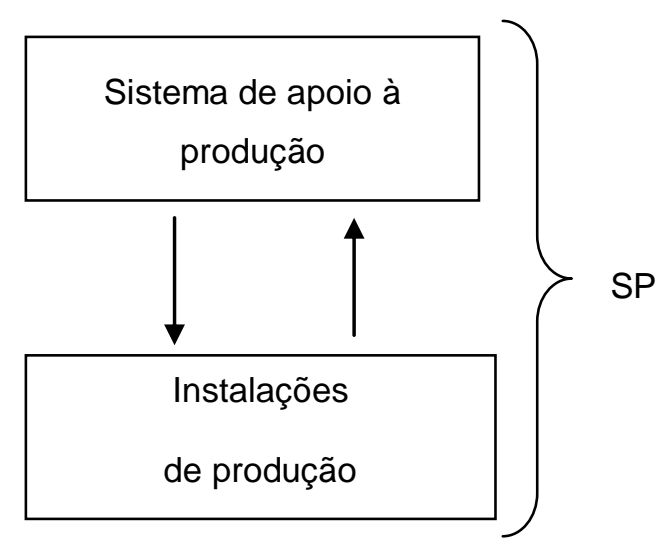

Figura 9 - Estrutura geral de um SP (adaptado de GROOVER, 2011)

As instalações de produção de uma empresa são projetadas para operar de forma eficiente. Para tanto, são planejadas considerando desde os registros de pedido dos produtos até o controle da produção. As operações são organizadas pelo sistema de apoio à produção, que envolve funções de negócio, projeto do produto, planejamento da produção e controle da produção, conforme ilustra figura 10: 
- Funções de negócios: nesta categoria estão as funções de vendas e marketing assim como a função de registro de pedidos e a de geração da ordem de produção de um determinado produto.

- Projeto do produto: o projeto de um novo produto é iniciado no departamento de vendas e marketing passando pela engenharia de projetos. Se necessário, são gerados protótipos que podem envolver funções de pesquisa e desenvolvimento.

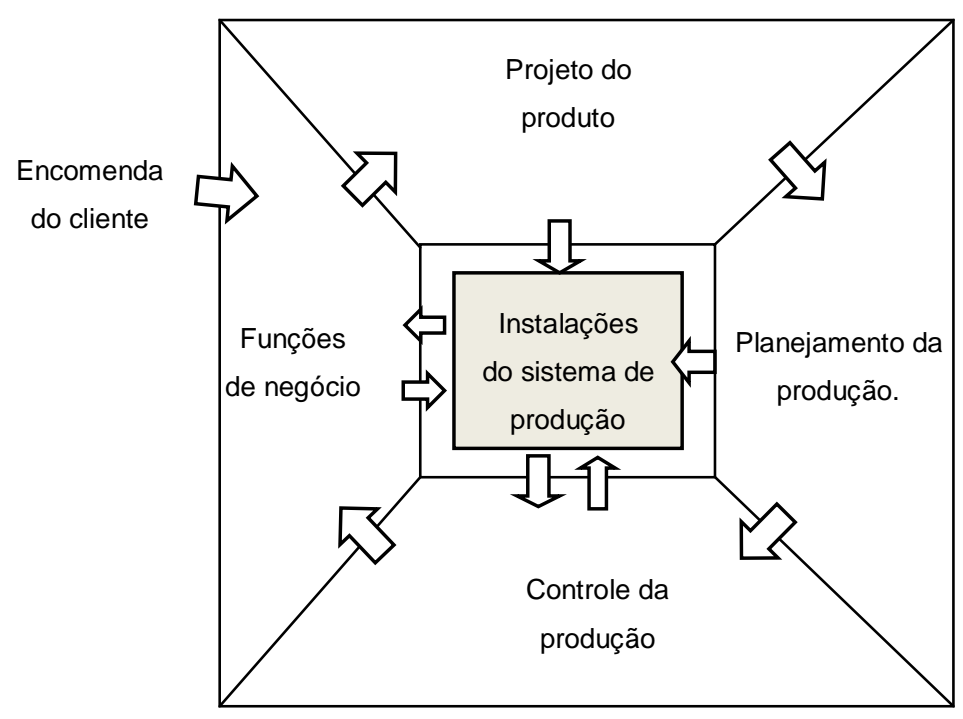

Figura 10 - Ciclo de processamento da informação de produção (adaptado de GROOVER, 2011)

- Planejamento da produção: as funções aqui são as bases para todas as atividades gerenciais, que estabelecem as linhas de ações e o momento em que ações específicas devem ser realizadas para atingir os objetivos organizacionais utilizando os recursos de produção (GODINHO FILHO et al., 2012). Toda a documentação e informações referentes ao projeto do produto seguem para a função do planejamento da produção e, nesta fase, desenvolvem-se o planejamento do processo, o plano mestre de produção, o planejamento das necessidades materiais, o planejamento da capacidade produtiva e a programação da produção. 
- Planejamento do processo: determinação da sequência de atividades e operações para produção de cada peça ou do lote de peças.

- Plano mestre de produção: uma lista de produtos a ser produzidos com as datas em que devem ser entregues e com as respectivas quantidades.

- Planejamento das necessidades de materiais: a matéria prima que deve ser adquirida considerando estoque necessário para atender aos recursos disponíveis.

- Planejamento da capacidade produtiva: planejamento otimizado dos recursos da empresa.

- Programação da produção (scheduling): programação da produção determinando o início e o término de cada ordem de produção para cumprir o plano mestre de produção. Para tanto, determina a ordem na qual as operações serão executadas, isto é, determina o sequenciamento das operações e também distribui as operações nos diversos recursos.

- Controle da Produção: esta fase preocupa-se com o controle das operações físicas realizadas na fábrica com vista à execução do plano de produção.

- Fluxo das informações: estabelecido a partir das entidades que realizam as funções do planejamento até as entidades que realizam as funções de programação e controle de produção.

\subsection{Síntese do capítulo}

Neste capitulo, foram apresentados os conceitos de sistemas produtivos (SPs), sistemas a eventos discretos (SED) e sistemas de variáveis contínuas (SVC). 
Abordou-se a definição de flexibilidade em SPs e apresentou-se a evolução das máquinas-ferramenta, incluindo as Máquinas-Ferramenta Multifuncionais (MFM). Apresentou-se também a questão da complexidade para modelar o comportamento dinâmico para alocação dinâmica de recursos em SPs considerando as MFMs que possuem flexibilidade funcional. E, por fim, apresentou-se o conceito de ciclo de processamento da informação de produção. 


\section{CONTROLE DE ALOCAÇÃO DE RECURSOS}

Controlar o SP significa impor um conjunto de ações com a finalidade de assegurar comportamento dinâmico do sistema que atenda a um determinado objetivo (SANTOS FILHO et al., 2011).

O comportamento dinâmico desejado visa a cumprir o plano de produção elaborado pelo setor de planejamento, que é produzir uma variedade de produtos, utilizando os recursos (máquinas) disponíveis e aplicando uma lógica de controle para execução das atividades dos processos.

Entretanto, problemas nos recursos, como a ocorrência de falhas nas máquinas, são eventos que não podem ser eliminados completamente em um SP real (YUE et al., 2013; RIASCOS, 2002) e, dependendo do problema, pode haver a indisponibilidade de uso de um recurso resultando até no travamento (deadlock) do SP.

\subsection{DINÂMICA DE ALOCAÇÃO DE RECURSOS}

Os SPs possuem vários processos que são executados simultaneamente e cada processo é formado por uma sequência de atividades que devem ser realizadas em máquinas-ferramenta no chão de fábrica e que, no final, resultam em um produto. Considerando que, na prática, por questão de custos e de outras restrições, os recursos são compartilhados entre os processos e os processos competem entre si pela alocação de recursos, uma das formas de organizar esse problema é estabelecendo regras de alocação de recurso para garantir que todas as atividades sejam devidamente realizadas (TRICAS et al., 2014):

- Regra 1 - Requisitar o recurso: significa verificar se o recurso está disponível para ser utilizado

- Regra 2 - Alocar o recurso: significa que o processo reserva o recurso para ser utilizado. 
- Regra 3 - Utiliza o recurso alocado: significa que a atividade está sendo executada pelo recurso.

- Regra 4 - Libera o recurso: significa que a atividade foi executada pelo recurso de modo que o processo que o alocou libera o recurso deixando disponível para uso da próxima atividade.

Dessa forma, o sistema de alocação de recursos é responsável pelo recurso escolhido para realizar cada uma das atividades que compõem os diversos processos.

\subsection{ARQUITETURA UTILIZANDO SISTEMAS HOLÔNICOS}

Analisando as arquiteturas aplicadas ao SPs, com alto grau de automação e flexibilidade, tem-se o que é chamado sistema de manufatura holônica (HMS), que explora o conceito de "hólon", introduzido na década de 60 por Koestler (1967), segundo o qual, a "parte" se comporta como o "todo" para modelar organizações complexas de culturas biológicas. Koestler observou que uma estrutura estável e autossuficiente pode se agrupar formando uma estrutura maior e esta também pode ser estável e autossuficiente assim como as células do corpo humano, que são estruturas estáveis e autossuficientes que se unem formando estruturas maiores para formar os tecidos que são estáveis e autossuficientes (VAN BRUSSEL et al., 1998; LEITÃO, 2009; VRBA et al., 2011).

Definições e conceitos adotados em um HMS

Hólon: é um componente autônomo e cooperativo do sistema de manufatura, como, por exemplo, um recurso de transformação, transporte ou armazenamento.

Autonomia : capacidade de criar e controlar a execução de seus próprios planos de produção. 
Cooperação: conjunto de entidades que desenvolvem e executam planos de produção mutuamente.

Holarquia: um sistema de hólons que cooperam para alcançar um objetivo. Considera todo o conjunto de atividades da manufatura como o recebimento de pedidos, projeto e produção. Pode definir regras básicas de cooperação dos hólons.

A abordagem de sistema holônico, utilizado na modelagem de sistemas de controle de manufatura, busca mesclar as melhores características do sistema hierárquico e do sistema heterárquico, resultando em maior robustez diante de distúrbios.

Existem várias propostas de arquiteturas holônicas e neste trabalho são analisadas algumas como a PROSA, HAPBA, a arquitetura CoBASA e a arquitetura semiheterárquica.

\subsubsection{PROSA}

A PROSA (Product Resource Order Staff Architecture), segundo Wyns et al. (1996), descreve três tipos básicos de hólons que são: hólon de pedido, hólon de produto e hólon de recurso.

A arquitetura forma uma holarquia que prevê hólons especializados que podem ser agregados aos hólons básicos, aumentando a capacidade de trabalho do sistema. São estruturados com base no conceito de orientação a objeto. Pode existir também o hólon especialista que visa a dar suporte à base de conhecimento (VAN BRUSSEL et al., 1998). 
A relação básica entre os blocos do HMS é vista na Figura 11.

\section{Sistema de Manufatura Holônica}

(HMS)

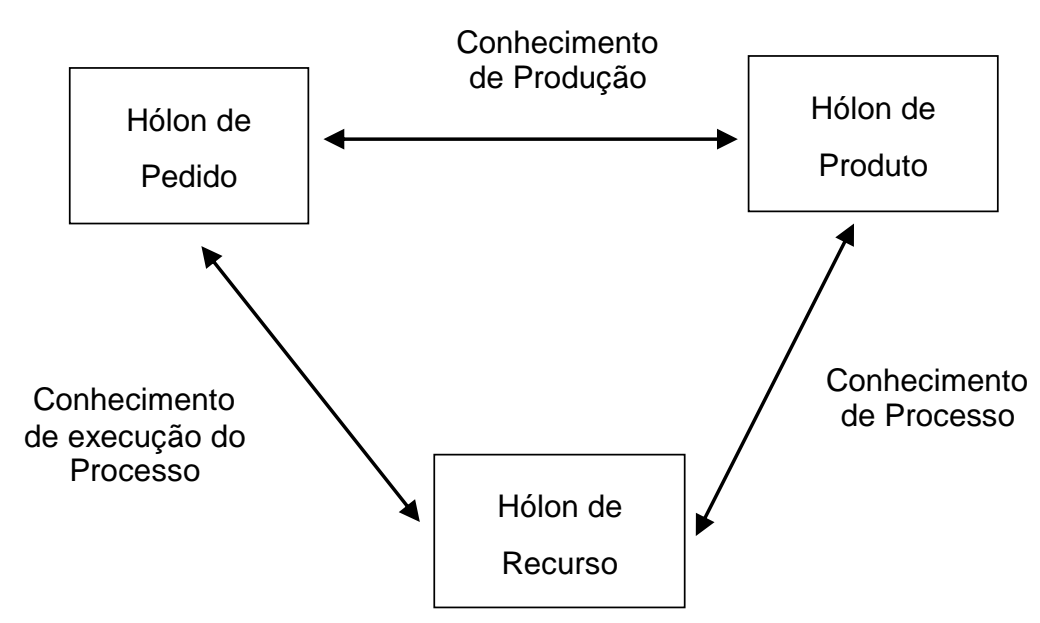

Figura 11 - Relação dos blocos do sistema de manufatura Holônico (VAN BRUSSEL et al., 1998)

Hólon de Pedido: representa uma tarefa dentro do sistema de manufatura, gerencia os produtos que estão sendo produzidos e ,no modelo de estado do produto, inclui as informações de logística pertinentes à ordem de produtos para os estoques relacionados ao processo. O hólon de pedido pode ser visto como um controlador que administra a fábrica.

Hólon de Produto: possui o conhecimento do produto e processos para garantir a produção correta do produto. O hólon de produto detém as informações atualizadas do ciclo de vida do produto, necessidades dos clientes, projeto do produto, planejamento do processo, procedimento de qualidade, entre outros. Este hólon representa a informação sobre o produto (material, processos, qualidade) e é um hólon que serve de informante para outros hólons.

Hólon de Recurso: representa a parte física, que são os recursos do chão de fábrica do sistema de manufatura, e também possui uma parte da informação dos 
processos que necessitam dos recursos. Este hólon aloca os recursos e detém o conhecimento de produção e organização.

Hólon Especialista : é um hólon que pode ser incluído no sistema (staff holon) para suprir um conhecimento que não está disponível em nenhum dos participantes do agrupamento. Possui um conhecimento especializado no cumprimento de determinadas tarefas específicas.

Conhecimento de processo: são informações referentes a como executar o processo por meio de determinados recursos, conhecendo a capacidade do recurso e dos processos que podem ser realizados.

Conhecimento de produção: são informações referentes a como produzir certo produto utilizando determinados recursos e aos possíveis roteiros de fabricação com determinados recursos.

Conhecimento de execução: são informações referentes ao progresso de execução dos processos em determinados recursos.

A PROSA possui a capacidade de integrar novos componentes e visa a facilitar a configuração do SP. Além disso, atende aos requisitos de controle tanto no aspecto hierárquico como o heterárquico. Os pontos importantes dessa arquitetura são:

- Comutação automática entre a estrutura hierárquica cujo foco está na utilização ótima dos recursos e a estrutura heterárquica cujo foco está na agilidade para alterações de ordem de produção.

- Permite inserir outros algoritmos de controle.

- Execução de novas funções concebidas, como por exemplo, as funções de abastecimento de peças de acordo com a demanda.

Essa arquitetura combina as vantagens do controle hierárquico e também do controle heterárquico. Durante a operação normal do SP, o controle da sequência de atividades é executado de modo hierárquico e quando ocorre um evento não 
esperado, o sistema de controle passa para o modo heterárquico. Isso baseado na autonomia e cooperação que são características específicas para um sistema holônico, e a utilização para a resolução dos problemas (VAN BRUSSEL et al., 1998).

\subsubsection{HAPBA}

HAPBA (Holonic Adaptive Plan-Based Architecture) utiliza os mesmos tipos de hólons da PROSA, mas com papéis diferentes para os hólons de pedidos, hólons de produtos e hólons especialistas (staff holons).

Os hólons de pedidos estão localizados no nível mais alto em uma holarquia e hólons de recursos são colocados em posições mais baixas, os hólons de produtos fazem o planejamento e monitoração das atividades para cumprir as ordens de fabricação, de acordo com os objetivos recebidos dos hólons de pedidos.

O conceito de HMS é explorado na concepção da parte de controle da fabricação, estruturando-o em blocos básicos caracterizados pela autonomia e cooperação. A tarefa de produção é tratada por meio da cooperação entre várias entidades e o sistema como um todo é visto como uma entidade única, o que torna mais fácil de integrar tais estruturas com os níveis superiores de uma empresa. (PASCAL; PANESCU, 2011).

\subsubsection{CoBASA}

A arquitetura CoBASA (Coalition Based Approach for Shopfloor Agility) é baseada em multiagentes no controle e supervisão do chão de fábrica do SP. Essa arquitetura utiliza as relações entre os membros da coalizão entre agentes de produção em busca de agilidade no chão de fábrica e baseia-se no conceito de módulos reutilizados para produção. A arquitetura CoBASA é implementada utilizando a plataforma JADE (LEITÃO; VRBA, 2011). 
A tecnologia de agentes tem sido abordada em sistemas de controle industriais para a automação de processos, logística e controle de tráfego (LEITÃO; VRBA, 2011).

Agente é uma entidade computacional com um comportamento autônomo que the permite decidir suas próprias ações. Os benefícios dos sistemas multiagentes estão presentes na computação distribuída e inteligência artificial, visando a assegurar maior autonomia, robustez, escalabilidade e reconfiguração (LEITÃO, 2009).

Quando ocorre um problema no SP, a arquitetura CoBASA atua da mesma forma como uma empresa age para participar de um consórcio, ou seja, o procedimento adotado é análogo ao problema de adaptação. Em outras palavras, as empresas entram na formação de uma coalizão para responder a uma oportunidade de negócio e, de forma análoga, quando se tem um problema de indisponibilidade de um recurso no chão de fábrica, um conjunto de recursos entra em acordo para encontrar outro recurso para realizar a execução da tarefa.

A coalisão permite a criação de diferentes estruturas de controle, mas nas literaturas abordadas, não fica claro como é realizada a coalisão.

\subsubsection{Arquitetura Semi-heterárquica}

Segundo Borangiu et al. (2014), a arquitetura semi-heterarquica é uma solução de gestão de mudanças devido à realocação de pedidos de produção em um ambiente perturbado, isto é, em que ocorrem eventos não esperados. A arquitetura de controle é distribuída, sendo que o controle está organizado em dois níveis: global e local.

No nível global, assume-se a responsabilidade pelo planejamento e coordenação das atividades no chão de fábrica e pela resolução de conflitos entre os objetivos dos elementos que compõem o SP.

No nível local há autonomia sobre o planejamento e controle das atividades internas locais (por exemplo, escolha dos recursos para uma operação de montagem). 
Existe uma entidade colocada em um nível superior de decisão: o Planejamento (scheduling) Global de Produção (GPS) - que envia o pedido de produtos, de forma programada e otimizada.

Hólons de pedidos possuem entidades localizadas nos níveis inferiores, que são os recursos, por exemplo, robô, máquinas, controladores. Todos os recursos cooperam para cumprir com os pedidos. As informações do GPS não são impostas aos recursos individuais, são tratadas como recomendações para as entidades de tomada de decisão.

$\mathrm{Na}$ ocorrência de problemas, há necessidade de recuperação, sendo que o planejamento e a programação de produção são revistos a partir de recursos disponíveis e com base em um mecanismo de cooperação, isto é, chaveando para o modo de funcionamento heterárquico.

O sistema holônico controla automaticamente a alternância entre esses dois modos de operação: hierarquica e a heterárquica (BORANGIU et al., 2014).

\subsection{LIMITAÇÕES DAS ARQUITETURAS HOLÔNICAS EM SPS}

Na prática, quando se trabalha no nível de chão de fábrica para controlar a alocação de recursos, são consideradas as normas IEC 61131 e IEC 61499, e o conceito de scan-time, para os controladores que estão presentes no sistema de controle do SP. Nesse contexto, há a necessidade de se utilizar o conceito de preempção para que as constantes de tempos envolvidas nos processos sejam consideradas em tempo real e para que seja possível gerar as interrupções necessárias durante cada janela de tempo pertinente ao ciclo do scan time.

Quando se utiliza outro paradigma, como sistemas holônicos, a abordagem é outra, ou seja, segundo Vrba et al. (2011), é necessário adequar-se à necessidade de gerar uma série de interrupções para mapear o fluxo de comunicação entre os processos executados pelos diferentes hólons. Isso é essencial para garantir o fato 
de haver sincronismo entre os hólons para cumprir a execução dos referidos processos em tempo real. Dessa forma, surge o desafio de estabelecer soluções que tornem viáveis ações para verificar e validar essas trocas de informações entre os hólons e que atendam aos requisitos para execução do controle dos processos em tempo real.

Segundo Vrba et al. (2011), existem dúvidas sobre a confiabilidade e a escalabilidade, isto é, em um SP real, quando ocorre a execução de milhares de agentes (hólons) em paralelo, há dúvidas em assegurar as condições de comunicação com a robustez que a indústria requer.

Segundo Marik e McFarlane (2005), não há garantias sobre o desempenho operacional, porque uma fábrica baseada em agentes não tem qualquer elemento de controle central, e um comportamento imprevisível e emergente é provável.

A maioria das arquiteturas holônicas citadas utilizam como referencial o desenvolvimento de um novo sistema computacional para a solução de realocação de recursos quando eventos não previstos, como a quebra de máquina, ocorrem no SP. Entretanto, não converge com relação ao que já existe estabelecido por normas internacionalmente aceitas (IEC 61131 e a IEC 61499) sobre a questão de métodos para a programação de algoritmos de controle em controladores programáveis que compõem o chão de fábrica em SPs.

A aplicacão da tecnologia de agentes em ambientes industriais requer uma mudança na visão de automação, uma vez que, hoje em dia, as aplicações industriais estão centradas numa estrutura baseada em Controladores Lógico Programáveis (PLCs). Nesse contexto, para sistemas de controle industriais baseados em PLCs, é conveniente priorizar-se a questão de execução dos programas de controle de acordo com a norma IEC 61131-3, garantindo a capacidade de resposta em tempo real (VRBA et al., 2011). 
Segundo Leitão e Vrba (2011), o desenvolvimento de soluções baseadas em agentes em ambiente industrial não é uma tarefa fácil, e as poucas aplicações industriais relatadas ainda se encontram em ambientes acadêmicos e não em plantas reais (LEITÃO et al., 2011).

Portanto, enquanto vários trabalhos partem de requisitos de software para implementar uma realocação dinâmica de recursos; no presente estudo, parte-se de requisitos de uma arquitetura física de controle de sistema de produção segundo as normas IEC61131 e IEC61499 para implementar uma solução que envolve recursos de uma nova natureza, ou seja, que possuem flexibilidade funcional, não prevista nas correspondentes normas.

O paradigma fundamental é de que existe um conjunto de processos préprogramados para serem executados e, para isso, é necessário sincronizar cada etapa de cada processo no uso dos recursos necessários. 


\section{REGENERAÇÃO DE SISTEMAS PRODUTIVOS}

Neste capítulo, é introduzida a proposta de uma arquitetura para realocação de recursos que se baseia nos seguintes princípios:

- Controle de funcionalidades associadas aos processos de fabricação de cada produto.

- Formalismos para designação dos recursos disponíveis, de acordo com as funcionalidades requisitadas.

- Sincronização do controle de designação de recursos de acordo com a demanda de funcionalidades necessárias para execução dos processos de produção.

Neste trabalho, considera-se o horizonte de tempo associado ao planejamento da produção despachado para o chão de fábrica, isto é, considera-se uma "janela de tempo" em que todos os processos dentro desse intervalo possuem suas sequências de utilização de recursos associados aos respectivos processos. Essa informação é utilizada para gerar as sequências de funcionalidades correspondentes. Portanto, no lugar dos recursos, considera-se as funcionalidades previamente especificadas de acordo com os modelos dos processos.

Dessa forma, ao utilizar a sequência de funcionalidades, permite-se que o sistema de controle atue de forma flexível, considerando a alocação de diferentes recursos e rotas alternativas do processo produtivo.

A proposta do presente trabalho envolve um sistema de controle capaz de tratar eventos não esperados, como a ocorrência de quebra de máquina no SP, que pode levar o sistema ao estado de deadlock. Como solução, explora-se a disponibilidade de recursos com flexibilidade funcional e para controlar o uso desses recursos, utiliza-se o conceito de sequência de funcionalidades. Portanto, quando ocorre uma falha no processo, causado por problemas nos recursos, o sistema de alocação de 
recurso utiliza o conceito de flexibilidade funcional para realocar os recursos e, consequentemente, retirar o sistema do estado de deadlock.

A vantagem em utilizar a sequência de funcionalidades para realizar a realocação é que o recurso não fica mais atrelado em uma determinada atividade do processo, deixando de ser uma alocação estática. Dessa forma, alocar o recurso a partir da sequência de funcionalidades fornece um novo nível de flexibilidade para a designação dos recursos.

Nesse contexto, a dinâmica do sistema para alocar o recurso funciona da seguinte forma: enquanto não ocorrer nenhum evento inesperado, como a quebra de um recurso, o sistema de alocação designa os recursos prescritos na programação original (scheduling).

No momento em que ocorre um evento indesejável, como a quebra de máquina, o sistema entra no estado prévio de deadlock. Nesse instante, o sistema de controle processa o algoritmo baseado em regras heurísticas para realizar a busca de recursos adequados. Obtida a resposta, que pode não ser única, seleciona-se um dos recursos com base em algum critério e aplica-o para retirar o sistema do estado de deadlock.

\subsection{ARQUITETURA PROPOSTA PARA A REGENERAÇÂO DE SPs.}

A arquitetura proposta para o sistema de alocação de recursos e regeneração do SP está ilustrada na Figura 12. Ela possui três módulos que são: i) Módulo de Controle de Processos (CP); ii) Módulo para Designar a Funcionalidade (DF); iii) Módulo para Designar o Recurso (DR). O Objeto de Controle são os recursos disponíveis no chão de fábrica. 


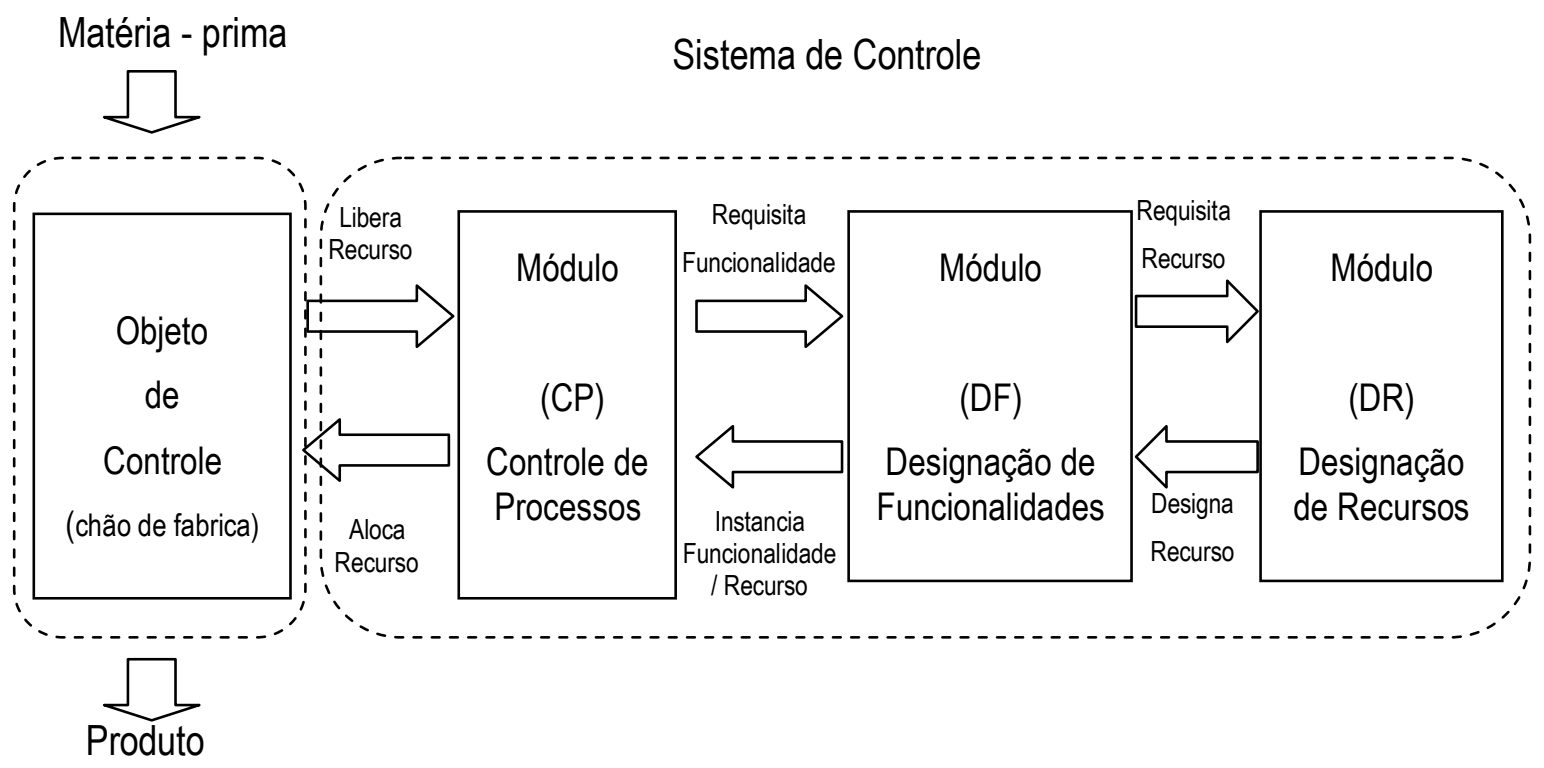

Figura 12 - Arquitetura do sistema de controle de alocação de recurso

(i) Módulo para o Controle de Processos (CP)

Este módulo é responsável pelo sequenciamento das atividades dos processos.

Nesse módulo executa-se a função de controle de alocação de recurso que é baseado na sequência de funcionalidades de cada processo produtivo descrito por meio do E-MFG (Enhanced Mark Flow Graph). O grafo destas sequências faz a interface entre os recursos físicos no chão da fábrica e os processos com as funcionalidades a serem executadas. A execução do grafo em conformidade com as regras do E-MFG estabelece a sequência dos processos de produção no SP, por meio da alocação e liberação de recursos.

(ii) Módulo Designação de Funcionalidades (DF)

Este módulo é responsável pela estruturação de todas as funcionalidades envolvidas nos processos do SP.

(iii) Módulo Designação de Recursos (DR) 
Este módulo é responsável pela escolha do recurso, isto é, executa um algoritmo de decisão para selecionar o recurso mais adequado para substituir um recurso indisponível. O aspecto relevante que deve ser considerado para a escolha do algoritmo é quanto à sua complexidade computacional e tempo de resposta porque o algoritmo deve obter uma resposta em tempo real.

O sistema de controle de alocação de recursos segue a programação (scheduling), estabelecida no nível de planejamento de produção; mas, no caso de uma ocorrência imprevista, tal como um recurso indisponível, o módulo de Controle de Processos (CP) solicita um novo recurso para o módulo de Designação de Funcionalidades (DF), onde a funcionalidade do recurso procurado é identificada. Essa informação é passada para o módulo Designação de Recursos (DR) que executa um algoritmo para selecionar o recurso apropriado e retorna essa informação para o Controle de Processos (CP), que aloca os recursos no chão de fábrica. Uma vez que a utilização do recurso estiver concluída, o recurso fica no estado disponível para uma próxima atribuição. 


\subsection{MÉTODO PARA IMPLEMENTAR OS MÓDULOS}

Para implementar os principais módulos da arquitetura do sistema de alocação e realocação de recursos é necessário desenvolver os seguintes grafos: Grafo de Sequência de Funcionalidades (GSF), Grafo para o Controle do Processo (GCP) e Grafo para Designação de Funcionalidades (GDF), conforme apresenta-se a seguir. A sistemática para a síntese dos grafos de controle da alocação/realocação de recursos está ilustrada na Figura 13.

As funções de controle da alocação dos recursos são especificadas por meio de grafos e, para gerá-los, inicia-se com a sequência de recursos fornecida pelo planejamento da produção (scheduling). Utilizando essa sequência de recursos, associam-se os recursos em suas respectivas funcionalidades e, dessa forma, obtém-se o Grafo de Sequência de Funcionalidades (GSF). A partir do GSF, derivam-se os grafos: Grafo para Designação de Funcionalidades (GDF) e ० Grafo para o Controle de Processos (GCP).

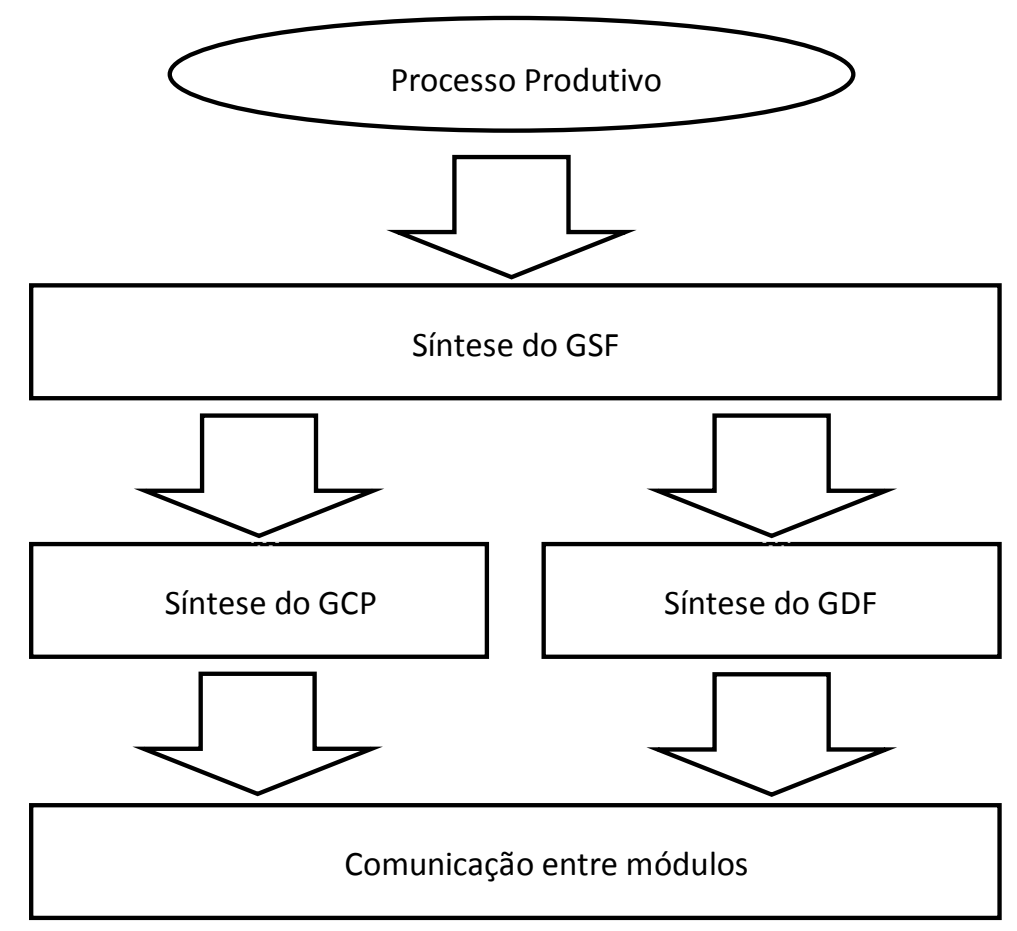

Figura 13 - Processo para a síntese dos grafos do sistema de controle da alocação de recursos 


\subsubsection{Síntese do Grafo Sequência de Funcionalidades (GSF)}

O grafo de sequência de funcionalidade (GSF) é obtido diretamente da sequência de recursos (scheduling) e é gerado pelo planejamento de produção.

$\mathrm{Na}$ Figura 14, apresenta-se, como exemplo, um processo com a sequência de recursos necessários. Essa sequência tem a finalidade de produzir um determinado produto.

Essa sequência é descrita por meio do E-MFG (Enhanced Mark Flow Graph) em que:

- "IN" representa a entrada da matéria prima.

- "Ai" é a transição que representa a ação do evento (sendo $i=1, . ., N$ ).

- O $\underline{\text { box }}$ "Ri" representa a utilização do recurso Ri (sendo $\mathrm{i}=1$.., $\mathrm{N}-1$ ) se a marca (token) estiver nesse box, significa que a peça foi alocada para o recurso "Ri".

A peça (modelada pelo token) vai sendo processada pelos recursos, iniciando em "IN" e finalizando o processo em "OUT" que representa o término do processo.

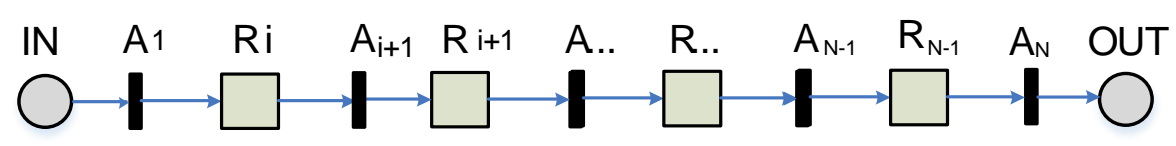

Figura 14 - Exemplo de um processo produtivo descrito por uma sequência de recursos.

O Grafo da Sequência de Funcionalidades (GSF) é derivado do grafo de sequência de recurso, no qual se associa cada recurso pela sua respectiva funcionalidade, conforme mostrado na Figura 15, em que F1 é a funcionalidade do recurso R1, F2 é a funcionalidade do recurso R2 e assim sucessivamente. 


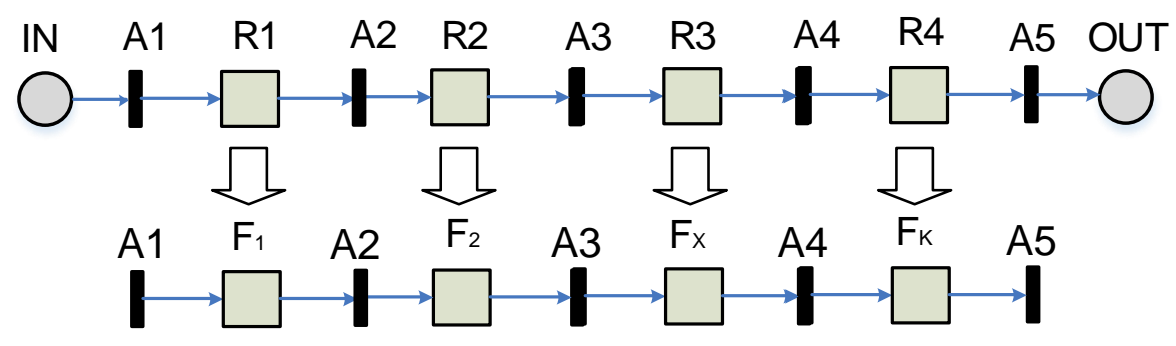

Figura 15 - Exemplo de síntese do grafo GSF.

* Todos os elementos estruturais do E-MFG estão sublinhados neste texto.

4.2.2. Síntese do Grafo para a Designação de Funcionalidade (GDF)

A síntese do GDF é realizada em dois passos, sendo o passo 1 o refinamento do GSF, e o passo 2 a fusão dos boxes controladores de mesma semântica.

- Passo 1: Considere a funcionalidade descrita em GSF entre as transições " $A_{i}$ "e transição " $A_{i+1}$,", conforme mostrado na Figura 16. O refinamento é feito por meio da inserção de um box de entrada (buffer de entrada), um box controlador (representando a funcionalidade) e de um box de saída (buffer de saída).

- Passo 2: Após o refinamento de todas as funcionalidades do GSF, realizase a fusão dos boxes controladores de mesma semântica (mesma funcionalidade). A Figura 17 ilustra o caso da fusão de boxes controladores relacionados com a funcionalidade $\mathrm{F} 1$. 


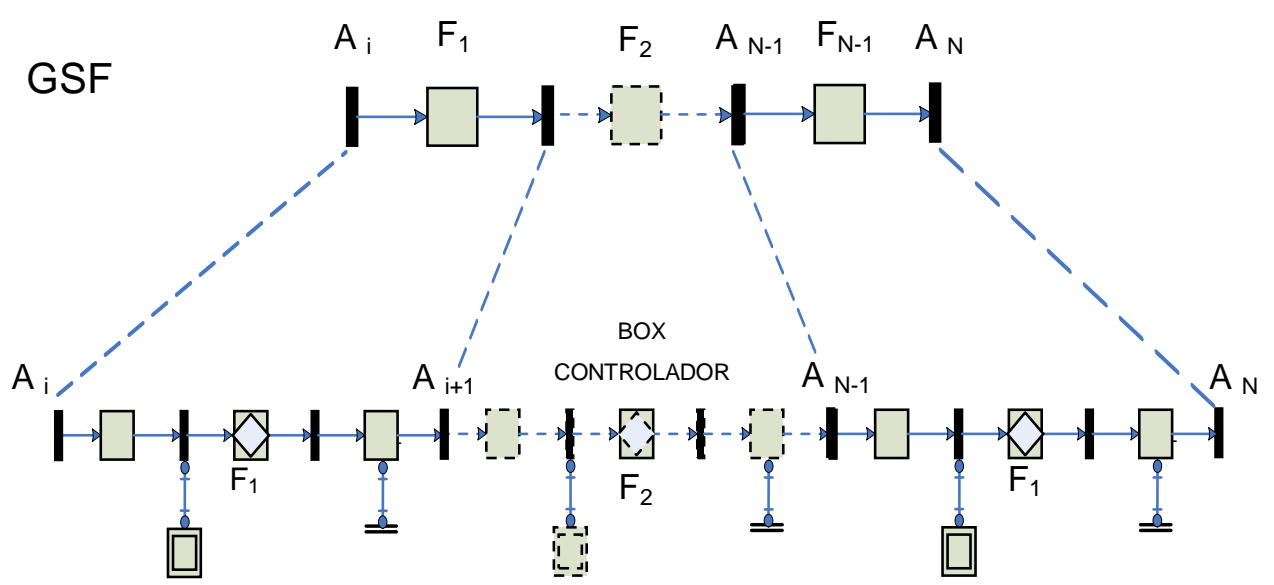

Figura 16 - Exemplo do refinamento - passo 1 para construir o GDF

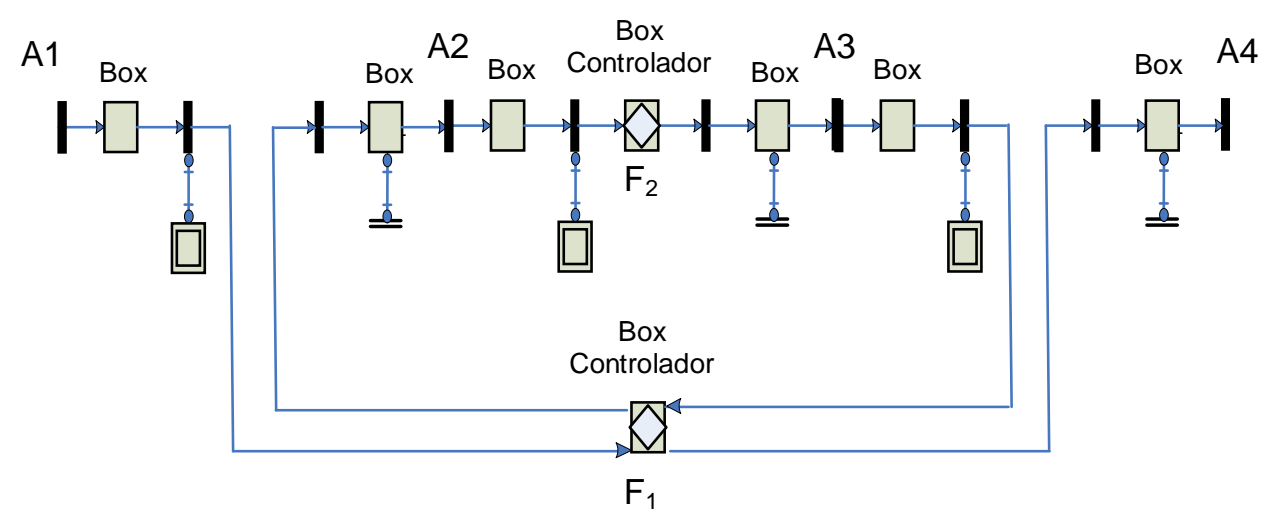

Figura 17 - Exemplo de fusão dos boxes controladores - passo 2 para construir o GDF

\subsubsection{Síntese do Grafo para o Controle do Processo (GCP)}

Para a síntese do grafo para o controle do processo (GCP), considere o grafo GSF e cada funcionalidade identificada entre as transições $A_{i}$ e $A_{i+1}$, conforme Figura 18. Realiza-se um refinamento substituindo o box "Fi" por um conjunto de duas interfaces de transmissão e recepção: um que requisita recurso e um que aloca recurso. 
Dessa forma, obtém-se o GCP derivado do GSF.

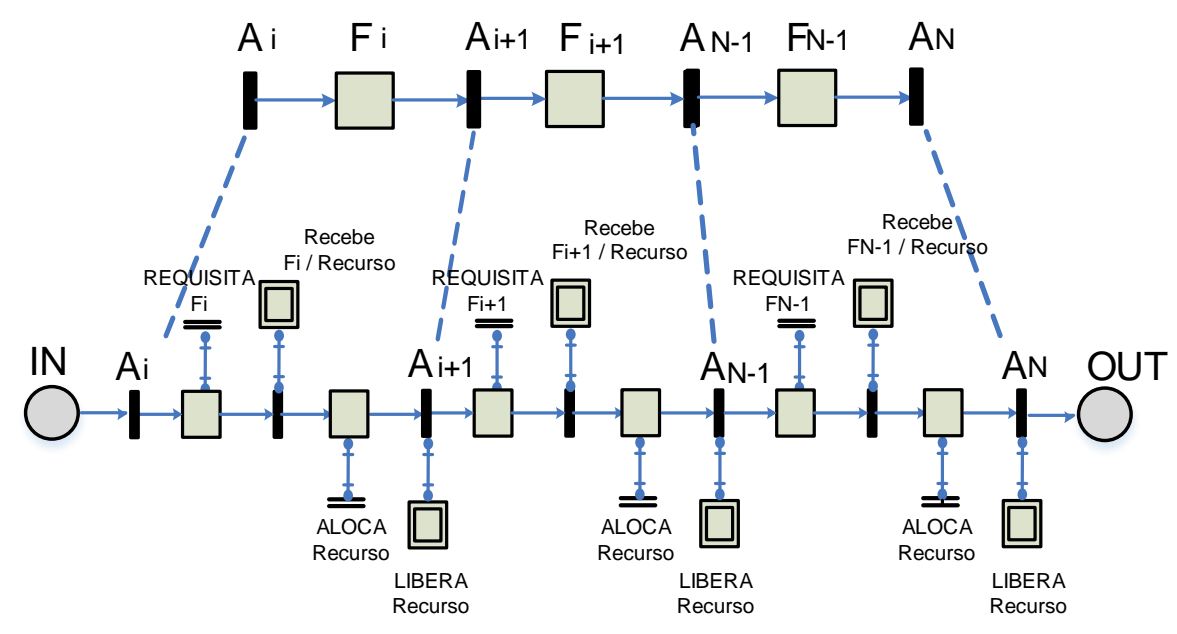

Figura 18 - Exemplo de grafo de controle do GCP derivado do GSF

\subsubsection{Síntese do algoritmo para designar o recurso (DR)}

O módulo que designa o recurso (DR) é um algoritmo para a tomada de decisão, isto é, escolhe o recurso mais adequado para o momento. Por exemplo, quando ocorre um evento inesperado, como a indisponibilidade de um recurso, o algoritmo realiza a busca de outro recurso a ser alocado de acordo com a funcionalidade do recurso a ser realocado e manter o processo produtivo. Considera-se também a complexidade computacional e o tempo de resposta do algoritmo por esse atuar em tempo real. Entre os algoritmos aqui analisados, estão o Algoritmo Genético (AG), Algoritmo Colônia de Formigas, entre outros algoritmos de baixa complexidade computacional (ASATO et al., 2012; KATO et al., 2009; DORIGO, 1997).

\subsection{COMUNICAÇÃO ENTRE OS MÓDULOS}

O módulo CP possui informações referentes ao processo e os módulos DF e DR possuem informações referentes aos recursos. Dessa forma, a troca de informações entre os módulos é estabelecida por meio dos arcos de envio / recepção. 
O CP tem a função de atuar como uma interface entre os recursos que estão no chão de fábrica e o sistema de alocação de recursos. Esses módulos interagem da seguinte forma: o GCP acompanha a evolução dos estados do SP e, quando uma atividade do processo produtivo deve ser realizada, envia-se uma requisição de recurso, por meio do arco de envio de mensagem que é recebido pelo arco de recepção de mensagem no grafo designação de funcionalidade (GDF).

O grafo designação de funcionalidades (GDF), por sua vez, aciona o algoritmo para designação de recursos que está no DR para selecionar o recurso mais adequado e essa informação é enviada para o grafo controle de processos (GCP).

O grafo controle de processo (GCP) aloca o recurso no chão de fábrica, isto é, envia para o chão de fábrica a informação do recurso a ser efetivamente utilizado e após receber a confirmação do chão de fábrica que a tarefa foi completada, envia mensagem por meio do arco de envio, liberando o recurso e, assim, disponibilizando-o para a próxima alocação de recurso (Figura 19).

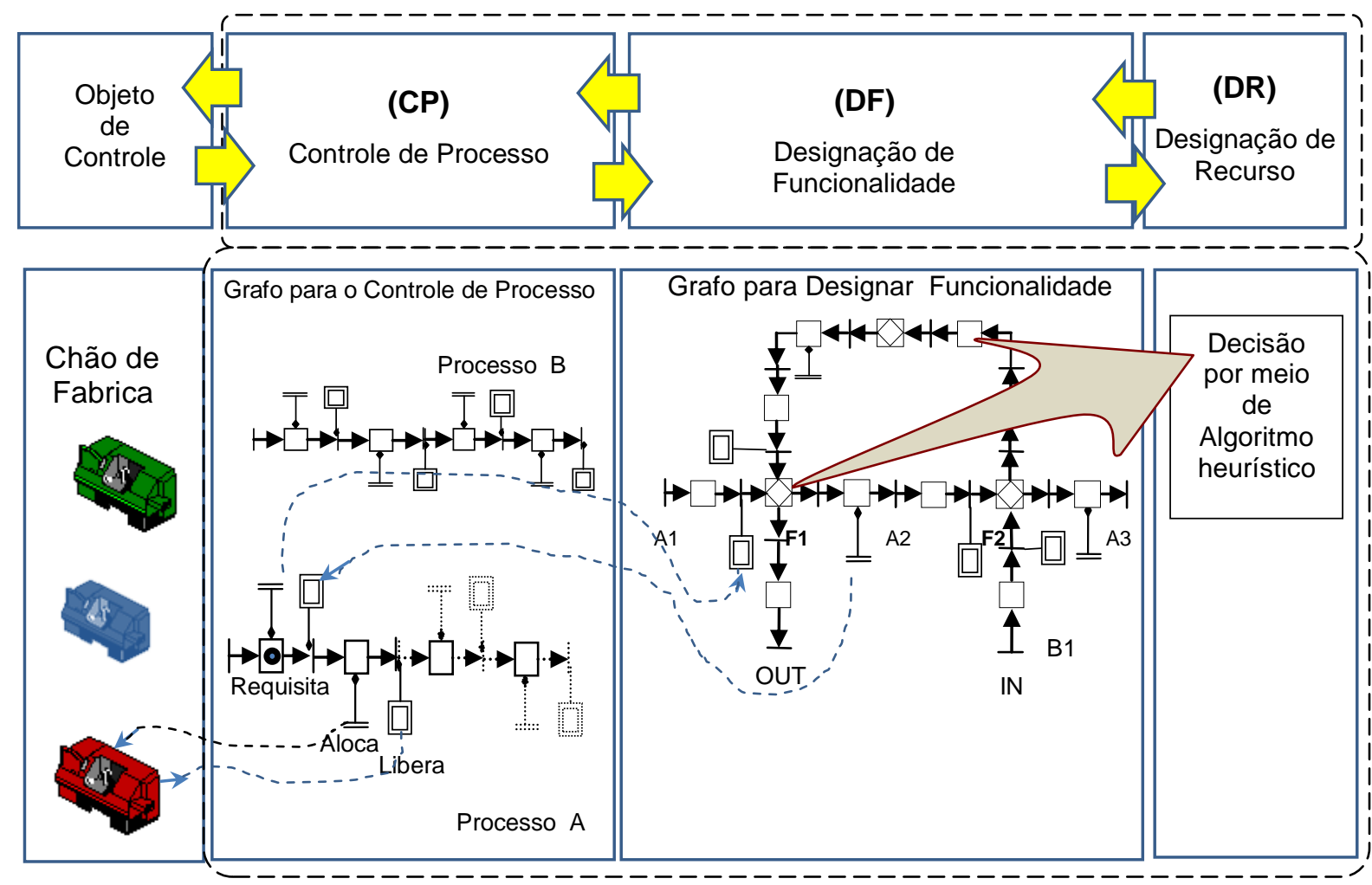

Figura 19 - Comunicação entre os módulos 


\subsection{OBSERVAÇÕES COMPLEMENTARES}

O módulo para o Controle do Processo (CP) da manufatura é responsável pela execução da sequência de atividades de cada processo e também realiza a interface entre os recursos que estão no chão de fábrica e o sistema de alocação de recursos. A solução de controle é baseada no princípio do "model following", de modo que a execução do modelo em E-MFG especifica as ações de controle a serem executadas.

Como os modelos são em E-MFG, a comunicação é descrita por meio de elementos externos e que corresponde a uma rede de Petri estendida, Assim, o modelo pode ser transcrito para a forma de programas de controle de acordo com as linguagens previstas pela norma IEC 61131-3 (IEC, 2003) para controladores programáveis industriais. É importante destacar que essa transcrição pode ser realizada com base no isomorfismo (MELLO et al., 2011).

O módulo de Designação de Funcionalidade (DF) é responsável por organizar as sequências de funcionalidades dos processos, isto é, fazer a integração das funcionalidades necessárias para os processos e sua representação por meio de grafos E-MFG permite que a arquitetura adotada esteja de acordo com a norma IEC 61131-3, de modo que é possível adequar-se à implementação de sistemas de controle distribuídos.

O módulo Designação de Recursos (DR) é responsável pela escolha do recurso, incluindo recursos com flexibilidade funcional (máquinas-ferramenta multifuncionais), para ser alocado no chão de fábrica. Esse módulo assegura flexibilidade de escolha para a heurística que for mais aderente para cada situação do SP, ou seja, a necessidade de executar múltiplos processos simultâneos, a possibilidade de existir um forte compartilhamento de recursos, entre outros aspectos.

Uma vez que cada situação possui características específicas de seus processos, o presente capítulo apresenta um método para a implementação das funções a serem executadas nos módulos da arquitetura proposta, de modo que os programas de controle possam ser obtidos de forma isomórfica aos grafos trabalhados em cada um 
dos módulos do sistema de alocação de recursos. Portanto, uma vez que os modelos gráficos sejam validados por isomorfismo, obtém-se os algoritmos de controle a serem implementados nos Controladores Programáveis (MELLO et al., 2011). 


\section{EXEMPLO DE APLICAÇÃO}

\subsection{PRIMEIRO EXEMPLO DE APLICAÇÃO}

Neste exemplo, o SP executa três processos usando seis recursos que estão disponíveis no chão de fábrica, sendo que quatro máquinas são recursos convencionais (com uma funcionalidade) e duas são MFMs.

llustra-se o caso de indisponibilidade de um recurso e como o sistema de alocação de recursos realiza a busca de outro recurso retirando o SP do estado de deadlock. O sistema deve manter, na medida do possível, a alocação de recursos da programação original (scheduling), exceto o recurso inoperante.

Os recursos são identificados por: $R 1, R 2, R 3, R 4, R 5, R 6$. Sendo que os recursos R1,R2,R3,R4 são máquinas convencionais e R5, R6 são MFMs.

Nesse SP, são produzidos três produtos $A, B, C$, com os respectivos processos $P(A), P(B), P(C)$.

As letras F1, F2, F3 referem-se às três funcionalidades.

Os processos utilizam as seguintes sequências de recursos:

- Processo $A \quad P(A):(R 2$ usando $F 1) \rightarrow(R 4$ usando $F 2) \rightarrow(R 6$ usando $F 3)$

- Processo $B \quad P(B):(R 6$ usando $F 3) \rightarrow(R 2$ usando $F 1) \rightarrow(R 4$ usando $F 2)$

- Processo $C \quad P(C):($ R5 usando $F 2) \rightarrow(R 5$ usando $F 3) \rightarrow(R 1$ usando $F 1)$

Cada recurso possui a(s) funcionalidade(s) de acordo com a Tabela 5.1 
Tabela 5.1 - Descrição da funcionalidade de cada recurso.

\begin{tabular}{|c|c|}
\hline Recurso & Funcionalidade \\
\hline R1 & F1 \\
\hline R2 & F1 \\
\hline R3 & F2 \\
\hline R4 & F2 \\
\hline R5 & F3 e F2 \\
\hline R6 & F3 e F2 \\
\hline
\end{tabular}

O SP visa a transformar a matéria prima em produto ao final de cada processo, utilizando os recursos de acordo com a programação da produção, entretanto pode ocorrer que o recurso previsto pela programação fique impossibilitado de uso devido à quebra de máquina, levando o sistema ao estado de deadlock .

No caso de indisponibilidade de algum recurso, o sistema realiza a busca de outro recurso (mantendo os recursos previamente programados) por meio do algoritmo colônia de formigas, escolhendo o recurso de menor custo entre os disponíveis para realocá-lo e regenerar o sistema do estado de deadlock.

Hipóteses:

- O custo de transporte de peça de um recurso para o outro é considerado conforme indicado na Tabela 5.3

- O custo de execução das atividades nos recursos é considerado todos iguais a 10 unidades de custo (uc).

A Tabela 5.2 apresenta, na primeira coluna, os recursos e, na segunda coluna, o custo referente ao carregamento inicial da peça no recurso e, na terceira coluna, o custo do despacho final da peça. 
Tabela 5.2 - Custo inicial atribuído carregando inicial e despacho de peça do recurso.

\begin{tabular}{|c|c|c|}
\hline Recurso & $\begin{array}{c}\text { Custo do } \\
\text { carregamento inicial }\end{array}$ & $\begin{array}{c}\text { Custo do Despacho } \\
\text { final }\end{array}$ \\
\hline R1 & $1 \mathrm{uc}$ & $1 \mathrm{uc}$ \\
\hline R2 & $1 \mathrm{uc}$ & $1 \mathrm{uc}$ \\
\hline R3 & $1 \mathrm{uc}$ & $1 \mathrm{uc}$ \\
\hline R4 & $1 \mathrm{uc}$ & $1 \mathrm{uc}$ \\
\hline R5 & $1 \mathrm{uc}$ & $1 \mathrm{uc}$ \\
\hline R6 & $1 \mathrm{uc}$ & $1 \mathrm{uc}$ \\
\hline
\end{tabular}

A Tabela 5.3 apresenta o custo de uma peça para ser transportada de um recurso para outro. A peça inicia em um recurso de origem, localizado na coluna 1 e atinge um recurso destino, localizado na linha1.

$\mathrm{Na}$ intersecção dessa linha com a coluna, encontra-se o custo do transporte de peça de um recurso para outro em uc.

Tabela 5.3 - Custo para transporte de uma peça de um recurso para outro.

\begin{tabular}{|c|c|c|c|c|c|c|}
\hline De Para & R1 & R2 & R3 & R4 & R5 & R6 \\
\hline R1 & 1 & 2 & 2 & 3 & 4 & 5 \\
\hline R2 & 4 & 1 & 3 & 2 & 5 & 6 \\
\hline R3 & 4 & 3 & 1 & 2 & 2 & 3 \\
\hline R4 & 3 & 2 & 3 & 1 & 6 & 2 \\
\hline R5 & 4 & 5 & 3 & 3 & 1 & 2 \\
\hline R6 & 5 & 4 & 3 & 2 & 3 & 1 \\
\hline
\end{tabular}

Programação fornecida pelo setor de planejamento.

Processo A (sequência de recursos): R2 (F1) $\rightarrow \mathrm{R} 4(\mathrm{~F} 2) \rightarrow \mathrm{R} 6(\mathrm{~F} 3)$

Processo $B$ (sequência de recursos): $\mathrm{R} 6(\mathrm{~F} 3) \rightarrow \mathrm{R} 2(\mathrm{~F} 1) \rightarrow \mathrm{R} 4(\mathrm{~F} 2)$ 
Processo C (sequência de recursos): $\mathrm{R} 5(\mathrm{~F} 2) \rightarrow \mathrm{R} 5(\mathrm{~F} 3) \rightarrow \mathrm{R} 1(\mathrm{~F} 1)$

Para obter os grafos utilizados pelo sistema de alocação de recursos, primeiramente se realiza a síntese do grafo de sequência de funcionalidades (GSF) e, após, a síntese do grafo para designar funcionalidade (GDF) e o grafo de controle do processo (GCP).

\section{Etapa A) Síntese do grafo de sequência de funcionalidade (GSF)}

Com base no planejamento da produção, gera-se o grafo da Figura 20.

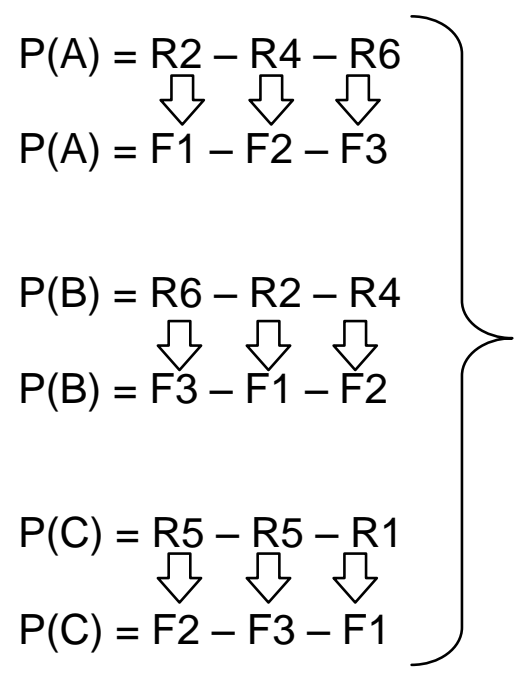
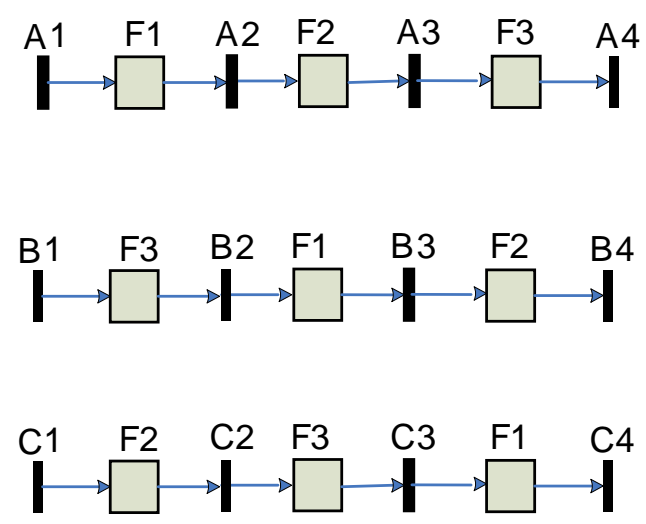

Figura 20 - Geração do grafo de sequência de funcionalidade (GSF) 
Etapa B) Síntese do grafo para designar funcionalidade (GDF), a partir do GSF, se tem os grafos da Figura 21, 22, 23.

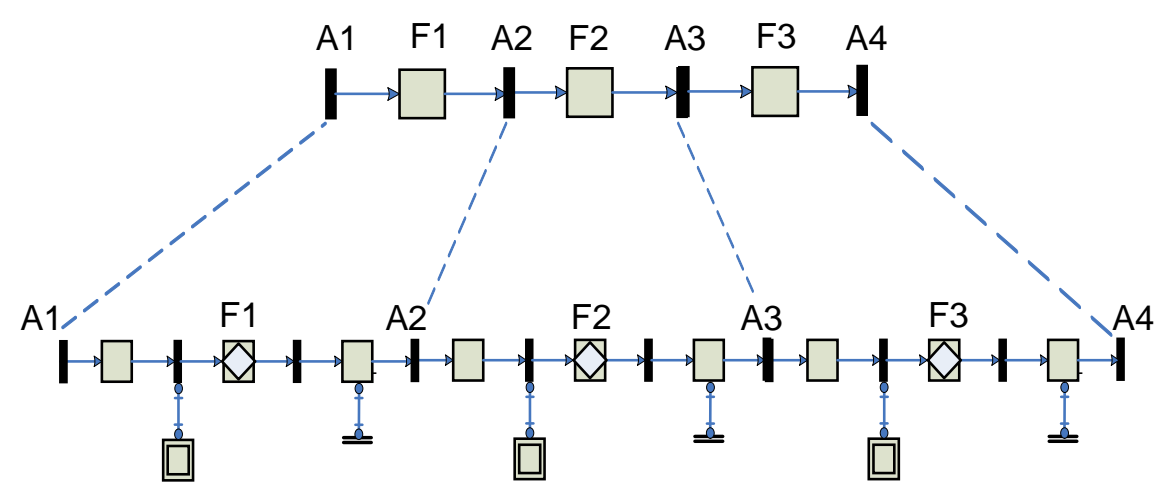

Figura 21 - Passo 1 - Geração do grafo para designar funcionalidade (GDF) do produto $A$

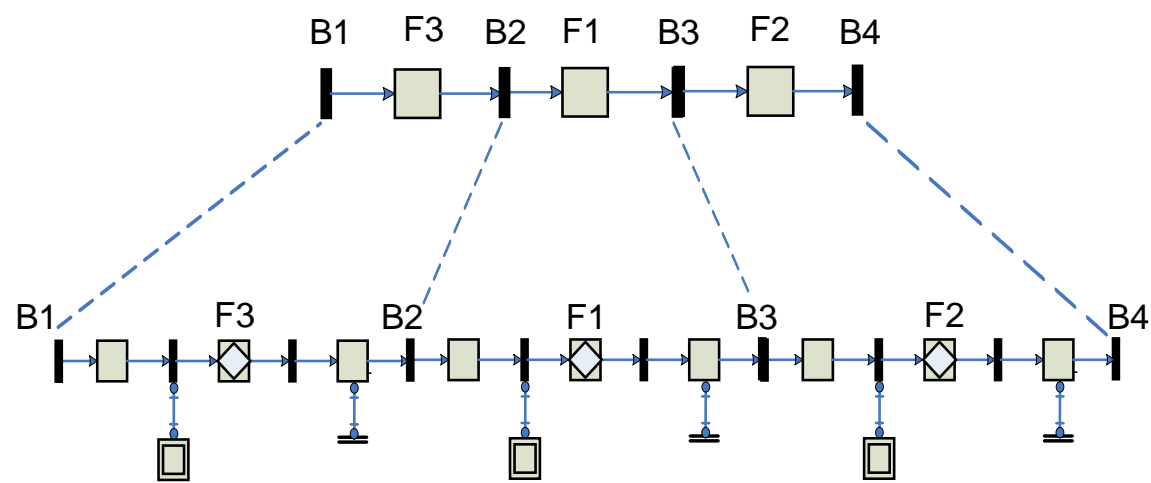

Figura 22 - Passo 1 - Geração do grafo para designar funcionalidade (GDF) do produto $B$

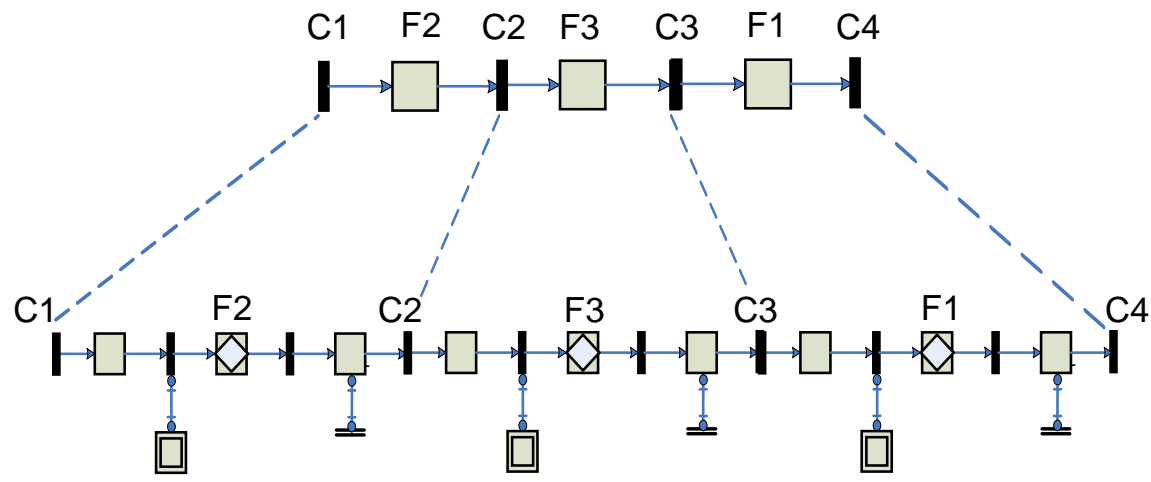

Figura 23 - Passo 1 - Geração do grafo para designar funcionalidade (GDF) do produto $\mathrm{C}$ 
Executando o passo 2, se tem a fusão dos boxes de mesmas funcionalidades (Figura 24).

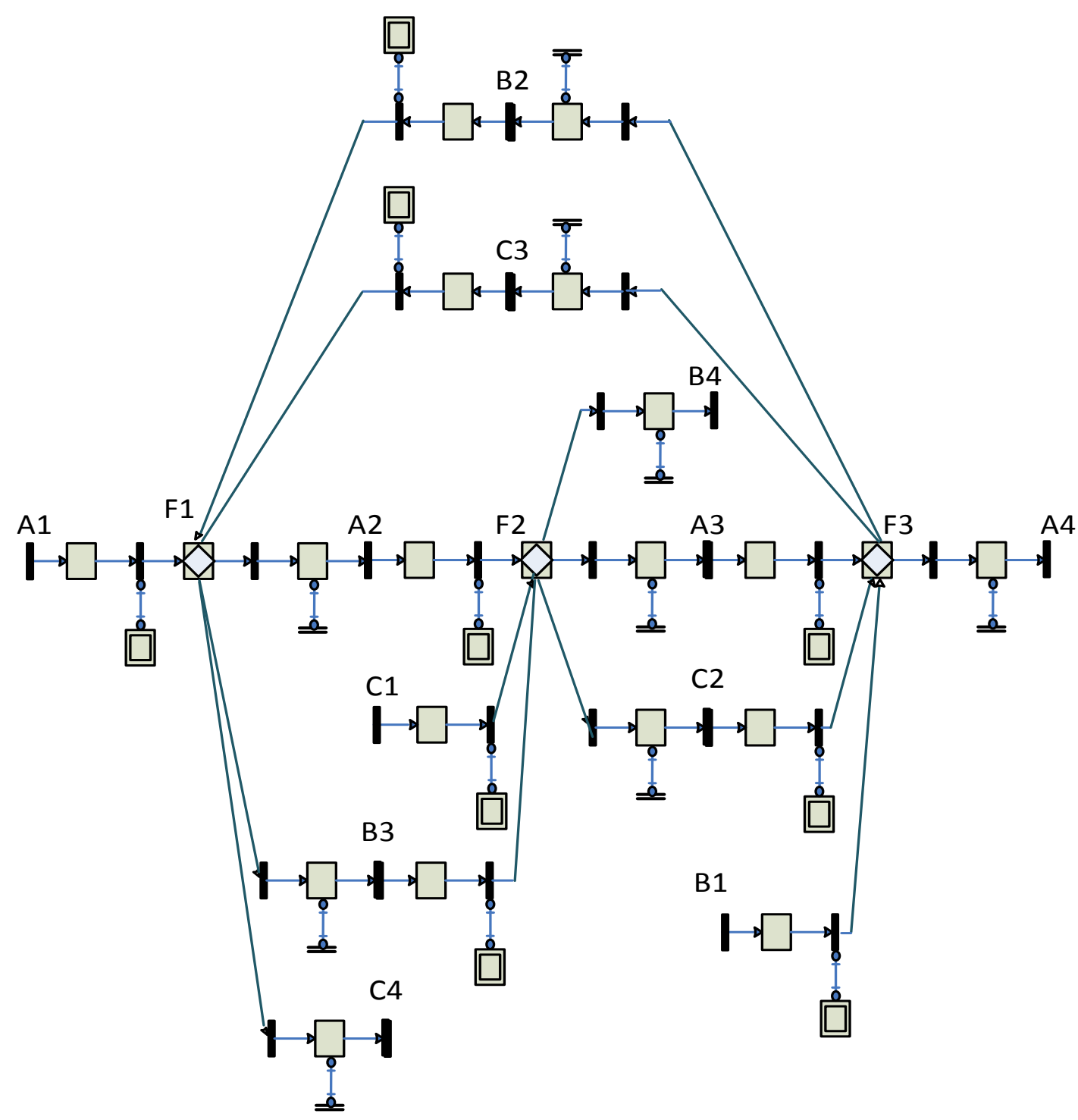

Figura 24 - Passo 2- Grafo para Designar Funcionalidade (GDF)

Etapa C) Síntese do grafo de controle do processo (GCP): a partir do GSF, obtém-se os grafos das Figuras 25, 26, 27. 


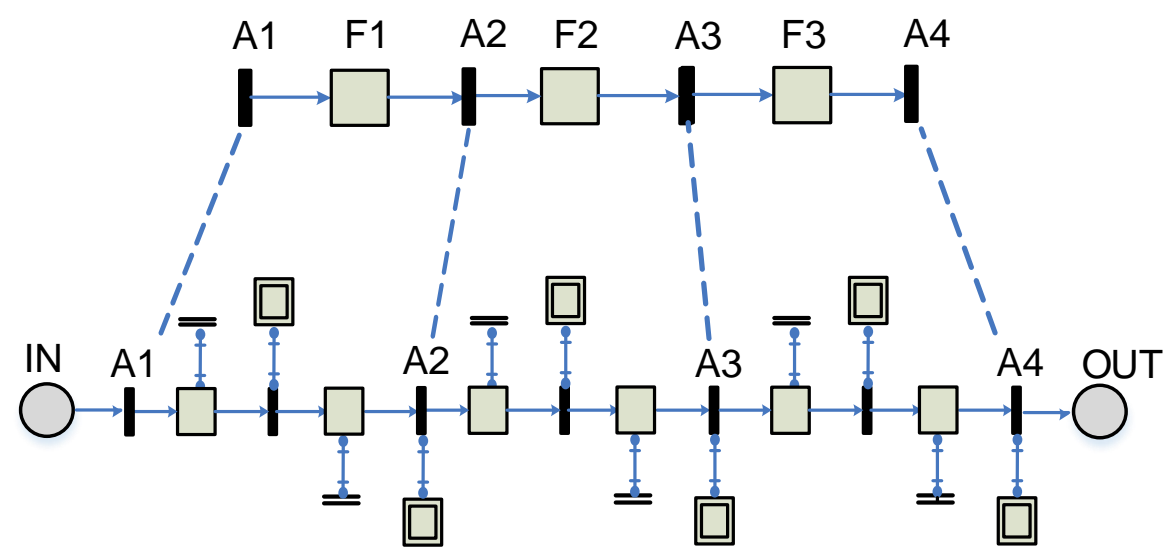

Figura 25 - Grafo de Controle do Processo "A" (GCP)

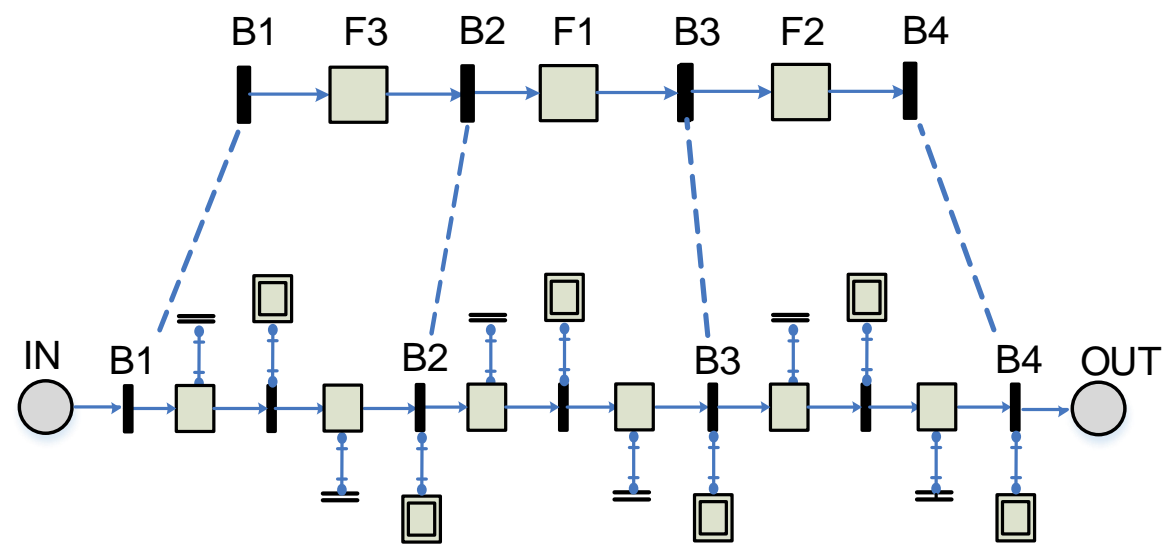

Figura 26 - Grafo de Controle do Processo "B" (GCP) 


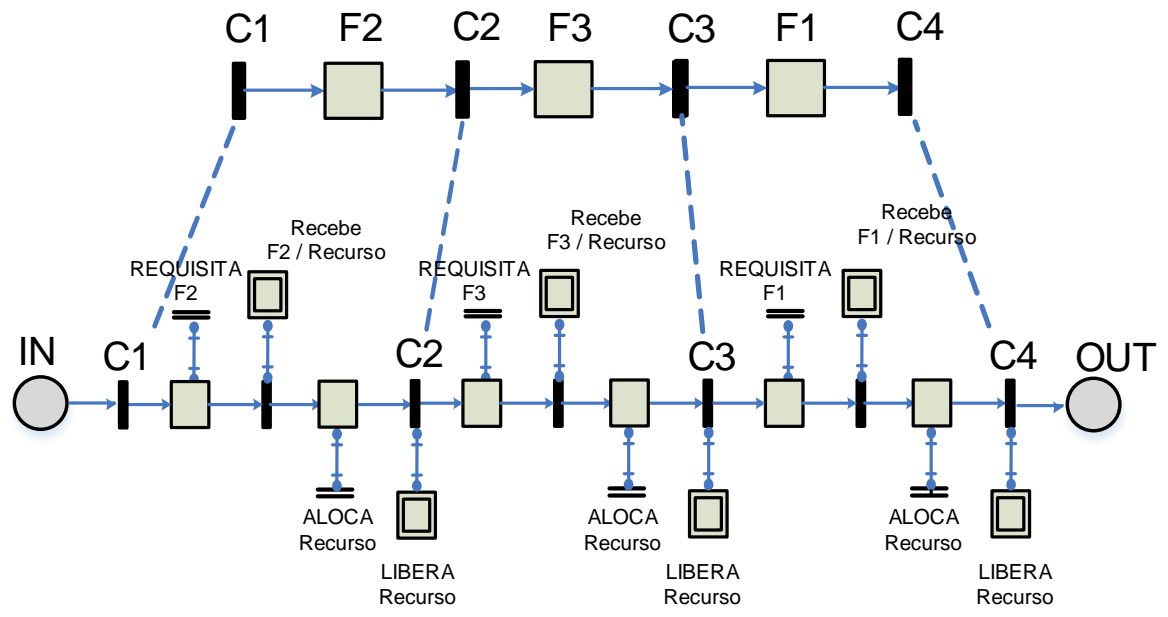

Figura 27 - Grafo de Controle do Processo "C" (GCP)

Neste exemplo, utilizou-se o algoritmo colônia de formiga para a designação de recursos, conforme o fluxograma da Figura 28.

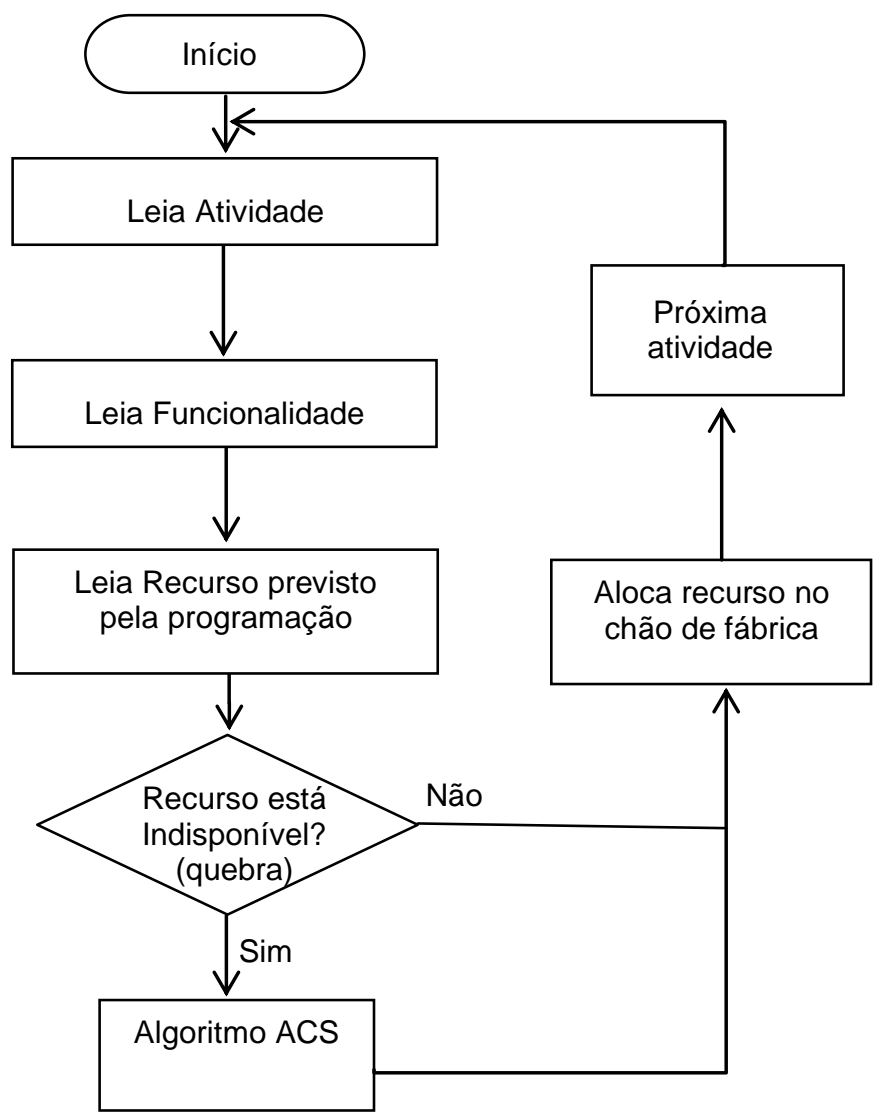

Figura 28 - Fluxograma do algoritmo. 
Para uma análise comparativa dos resultados, foi simulado o caso quando não existe nenhum problema de indisponibilidade de recursos.

De acordo com o fluxograma, enquanto não houver recurso impossibilitado para uso no chão de fábrica, os recursos alocados seguem conforme foi programado pelo planejamento da produção, mostrado na Tabela 5.4

Tabela 5.4 - Resultado da simulação sem a ocorrência de indisponibilidade de recurso:

\begin{tabular}{|c|c|c|c|c|c|c|c|}
\hline Processo & $\begin{array}{c}\text { Primeira } \\
\text { funcionalidade } \\
\text { da sequência }\end{array}$ & $\begin{array}{c}\text { Recur } \\
\text { so }\end{array}$ & $\begin{array}{c}\text { Segunda } \\
\text { funcionalidade } \\
\text { da sequência }\end{array}$ & $\begin{array}{c}\text { Recur } \\
\text { so }\end{array}$ & $\begin{array}{c}\text { Terceira } \\
\text { funcionalidade } \\
\text { da sequência }\end{array}$ & $\begin{array}{c}\text { Recur } \\
\text { so }\end{array}$ & $\begin{array}{c}\text { Resultado } \\
\text { (custo) }\end{array}$ \\
\hline A & F1 & R2 & F2 & R4 & F3 & R6 & 36 u.C. \\
\hline B & F3 & R6 & F1 & R2 & F2 & R4 & 38 u.C. \\
\hline C & F2 & R5 & F3 & R5 & F1 & R1 & 37 u.c. \\
\hline & & & & & & total & 111 u.C. \\
\hline
\end{tabular}

Mantém a programação de acordo com o planejamento.

No momento em que ocorre algum problema de indisponibilidade (quebra) de recurso o algoritmo colônia de formigas é acionado.

Aplicou-se a equação probabilidade de Dorigo, (1997):

$P=[T(r, s)]^{\alpha}[\rho(r, s)]^{\beta} / \sum[T(r, s)]^{\alpha}[\rho(r, s)]^{\beta}$

Os parâmetros considerados foram:

- $T$ : 0,9 intensidade do feromônio presente no caminho $(r, s)$.

- $r$ : representa o recurso de origem.

- $s$ : representa o recurso destino.

- $\alpha$ : 1 parâmetro que regula a intensidade de feromônio $T$.

- $\rho=1 / d_{r i}$ : visibilidade de um recurso i com relação ao recurso $r$. 
- $\mathrm{d}_{\mathrm{ri}}$ : custo de um recurso $\mathrm{r}$ para o recurso i.

- $\beta$ : 2 parâmetro que regula a influencia $\rho$.

- u.c.: significa unidade de custo.

Os resultados estão apresentados nas Tabelas 5.5 a 5.10 .

Tabela 5.5 - Resultado da simulação referente à indisponibilidade do recurso R1

\begin{tabular}{|c|c|c|c|c|c|c|c|}
\hline Processo & $\begin{array}{c}\text { Primeira } \\
\text { funcionalidade } \\
\text { da sequência }\end{array}$ & $\begin{array}{c}\text { Recur } \\
\text { so }\end{array}$ & $\begin{array}{c}\text { Segunda } \\
\text { funcionalidade } \\
\text { da sequência }\end{array}$ & $\begin{array}{c}\text { Recur } \\
\text { so }\end{array}$ & $\begin{array}{c}\text { Terceira } \\
\text { funcionalidade } \\
\text { da sequência }\end{array}$ & $\begin{array}{c}\text { Recur } \\
\text { so }\end{array}$ & $\begin{array}{c}\text { Resultado } \\
\text { (custo) }\end{array}$ \\
\hline A & F1 & R2 & F2 & R4 & F3 & R6 & 36 u.C. \\
\hline B & F3 & R6 & F1 & R2 & F2 & R4 & 38 u.c. \\
\hline C & F2 & R5 & F3 & R5 & F1 & R2 & 38 u.C. \\
\hline & & & & & & total & 112 u.c. \\
\hline
\end{tabular}

De acordo com a Tabela 5.5 o recurso R1 que ficou indisponível possui funcionalidade $\mathrm{F} 1 \mathrm{e}$ a sequência dos processos resulta em:

Processo A (sequência de recursos): $\mathrm{R} 2(\mathrm{~F} 1) \rightarrow \mathrm{R} 4(\mathrm{~F} 2) \rightarrow \mathrm{R} 6(\mathrm{~F} 3)$
Processo B (sequência de recursos): $\mathrm{R} 6(\mathrm{~F} 3) \rightarrow \mathrm{R} 2(\mathrm{~F} 1) \rightarrow \mathrm{R} 4(\mathrm{~F} 2)$
Processo C (sequência de recursos): $\mathrm{R} 5(\mathrm{~F} 2) \rightarrow \mathrm{R} 5(\mathrm{~F} 3) \rightarrow \mathrm{R} 2(\mathrm{~F} 1)$

Neste caso, só o recurso R2 possui a funcionalidade F1 e está disponível; portanto, realoca-se o recurso $\mathrm{R} 2$.

Tabela 5.6 - Resultado da simulação referente à indisponibilidade do recurso R2.

\begin{tabular}{|c|c|c|c|c|c|c|c|}
\hline Processo & $\begin{array}{c}\text { Primeira } \\
\text { funcionalidade } \\
\text { da sequência }\end{array}$ & $\begin{array}{c}\text { Recur } \\
\text { so }\end{array}$ & $\begin{array}{c}\text { Segunda } \\
\text { funcionalidade } \\
\text { da sequência }\end{array}$ & $\begin{array}{c}\text { Recurceira } \\
\text { so }\end{array}$ & $\begin{array}{c}\text { funcionalidade } \\
\text { da sequência }\end{array}$ & $\begin{array}{c}\text { Recur } \\
\text { so }\end{array}$ & $\begin{array}{c}\text { Resultado } \\
\text { (custo) }\end{array}$ \\
\hline A & F1 & R1 & F2 & R4 & F3 & R6 & 37 u.C. \\
\hline B & F3 & R6 & F1 & R1 & F2 & R4 & 40 u.c. \\
\hline C & F2 & R5 & F3 & R5 & F1 & R1 & 37 u.c. \\
\hline & & & & & & total & 114 u.c. \\
\hline
\end{tabular}

De acordo com a Tabela 5.6 o recurso R2 que ficou indisponível possui funcionalidade $\mathrm{F} 1 \mathrm{e}$ a sequência dos processos resulta em: 
Processo A (sequência de recursos) : $\mathrm{R} 1(\mathrm{~F} 1) \rightarrow \mathrm{R} 4(\mathrm{~F} 2) \rightarrow \mathrm{R} 6(\mathrm{~F} 3)$

Processo $B$ (sequência de recursos): $\mathrm{R} 6(\mathrm{~F} 3) \rightarrow \mathrm{R} 1(\mathrm{~F} 1) \rightarrow \mathrm{R} 4(\mathrm{~F} 2)$

Processo C (sequência de recursos): R5 (F2) $\rightarrow R 5(F 3) \rightarrow R 1(F 1)$

Neste caso, só o recurso R1 possui a funcionalidade F1 e está disponível; portanto, aloca-se o recurso $\mathrm{R} 1$.

Tabela 5.7 - Resultado da simulação referente à indisponibilidade do recurso R3

\begin{tabular}{|c|c|c|c|c|c|c|c|}
\hline Processo & $\begin{array}{c}\text { Primeira } \\
\text { funcionalidade } \\
\text { da sequência }\end{array}$ & $\begin{array}{c}\text { Recur } \\
\text { so }\end{array}$ & $\begin{array}{c}\text { Segunda } \\
\text { funcionalidade } \\
\text { da sequência }\end{array}$ & $\begin{array}{c}\text { Recur } \\
\text { so }\end{array}$ & $\begin{array}{c}\text { Terceira } \\
\text { funcionalidade } \\
\text { da sequência }\end{array}$ & $\begin{array}{c}\text { Recur } \\
\text { so }\end{array}$ & $\begin{array}{c}\text { Resultado } \\
\text { (custo) }\end{array}$ \\
\hline A & F1 & R2 & F2 & R4 & F3 & R6 & 36 u.C. \\
\hline B & F3 & R6 & F1 & R2 & F2 & R4 & 38 u.c. \\
\hline C & F2 & R5 & F3 & R5 & F1 & R1 & 37 u.c. \\
\hline & & & & & & total & 111 u.c. \\
\hline
\end{tabular}

De acordo com a Tabela 5.7 o recurso R3 que ficou indisponível, possui funcionalidade F2 e a sequência dos processos resulta em:

$$
\begin{aligned}
& \text { Processo A (sequência de recursos): } \mathrm{R} 2(\mathrm{~F} 1) \rightarrow \mathrm{R} 4(\mathrm{~F} 2) \rightarrow \mathrm{R} 6(\mathrm{~F} 3) \\
& \text { Processo B (sequência de recursos): } \mathrm{R} 6(\mathrm{~F} 3) \rightarrow \mathrm{R} 2(\mathrm{~F} 1) \rightarrow \mathrm{R} 4(\mathrm{~F} 2) \\
& \text { Processo C (sequência de recursos): } \mathrm{R} 5(\mathrm{~F} 2) \rightarrow \mathrm{R} 5(\mathrm{~F} 3) \rightarrow \mathrm{R} 1(\mathrm{~F} 1)
\end{aligned}
$$

Neste caso, foi mantida a sequência programada pelo planejamento.

Tabela 5.8 - Resultado da simulação referente à indisponibilidade do recurso R4.

\begin{tabular}{|c|c|c|c|c|c|c|c|}
\hline Processo & $\begin{array}{c}\text { Primeira } \\
\text { funcionalidade } \\
\text { da sequência }\end{array}$ & $\begin{array}{c}\text { Recur } \\
\text { so }\end{array}$ & $\begin{array}{c}\text { Segunda } \\
\text { funcionalidade } \\
\text { da sequência }\end{array}$ & $\begin{array}{c}\text { Recur } \\
\text { so }\end{array}$ & $\begin{array}{c}\text { Terceira } \\
\text { funcionalidade } \\
\text { da sequência }\end{array}$ & $\begin{array}{c}\text { Recur } \\
\text { so }\end{array}$ & $\begin{array}{c}\text { Resultado } \\
\text { (custo) }\end{array}$ \\
\hline A & F1 & R2 & F2 & R3 & F3 & R6 & 38 u.C. \\
\hline B & F3 & R6 & F1 & R2 & F2 & R3 & 39 u.C. \\
\hline C & F2 & R5 & F3 & R5 & F1 & R1 & 37 u.C. \\
\hline & & & & & & total & 114 u.c. \\
\hline
\end{tabular}

De acordo com a Tabela 5.8, o recurso $\mathrm{R} 4$ que ficou indisponível possui a funcionalidade $\mathrm{F} 2$ e a sequência dos processos resulta em: 
Processo A (sequência de recursos) : R2 (F1) $\rightarrow \mathrm{R} 3(\mathrm{~F} 2) \rightarrow \mathrm{R} 6(\mathrm{~F} 3)$

Processo $B$ (sequência de recursos): $\mathrm{R} 6(\mathrm{~F} 3) \rightarrow \mathrm{R} 2(\mathrm{~F} 1) \rightarrow \mathrm{R} 3(\mathrm{~F} 2)$

Processo C (sequência de recursos): R5 (F2) $\rightarrow R 5(F 3) \rightarrow R 1(F 1)$

Tabela 5.9 - Resultado da simulação referente à indisponibilidade do recurso R5.

\begin{tabular}{|c|c|c|c|c|c|c|c|}
\hline Processo & $\begin{array}{c}\text { Primeira } \\
\text { funcionalidade } \\
\text { da sequência }\end{array}$ & $\begin{array}{c}\text { Recur } \\
\text { so }\end{array}$ & $\begin{array}{c}\text { Segunda } \\
\text { funcionalidade } \\
\text { da sequência }\end{array}$ & $\begin{array}{c}\text { Recur } \\
\text { so }\end{array}$ & $\begin{array}{c}\text { Terceira } \\
\text { funcionalidade } \\
\text { da sequência }\end{array}$ & $\begin{array}{c}\text { Recur } \\
\text { so }\end{array}$ & $\begin{array}{c}\text { Resultado } \\
\text { (custo) }\end{array}$ \\
\hline A & F1 & R2 & F2 & R4 & F3 & R6 & 36 u.C. \\
\hline B & F3 & R6 & F1 & R2 & F2 & R4 & 38 u.c. \\
\hline C & F2 & R4 & F3 & R6 & F1 & R1 & 37 u.c. \\
\hline & & & & & & total & 111 u.c. \\
\hline
\end{tabular}

De acordo com a Tabela 5.9, o recurso R5 que ficou indisponível possui a funcionalidade $\mathrm{F} 3$ e a sequência dos processos resulta em:

Processo A (sequência de recursos): $R 2(F 1) \rightarrow R 4(F 2) \rightarrow R 6(F 3)$

Processo $B$ (sequência de recursos): $R 6(F 3) \rightarrow R 2(F 1) \rightarrow R 4(F 2)$

Processo C (sequência de recursos): $\mathrm{R} 4(\mathrm{~F} 2) \rightarrow \mathrm{R} 6(\mathrm{~F} 3) \rightarrow \mathrm{R} 1(\mathrm{~F} 1)$

Tabela 5.10 - Resultado da simulação referente à indisponibilidade do recurso R6.

\begin{tabular}{|c|c|c|c|c|c|c|c|}
\hline Processo & $\begin{array}{c}\text { Primeira } \\
\text { funcionalidade } \\
\text { da sequência }\end{array}$ & $\begin{array}{c}\text { Recur } \\
\text { so }\end{array}$ & $\begin{array}{c}\text { Segunda } \\
\text { funcionalidade } \\
\text { da sequência }\end{array}$ & $\begin{array}{c}\text { Recur } \\
\text { so }\end{array}$ & $\begin{array}{c}\text { Terceira } \\
\text { funcionalidade } \\
\text { da sequência }\end{array}$ & $\begin{array}{c}\text { Recur } \\
\text { so }\end{array}$ & $\begin{array}{c}\text { Resultado } \\
\text { (custo) }\end{array}$ \\
\hline A & F1 & R2 & F2 & R4 & F3 & R5 & 40 u.c. \\
\hline B & F3 & R5 & F1 & R2 & F2 & R4 & 39 u.c. \\
\hline C & F2 & R3 & F3 & R5 & F1 & R1 & 38 u.c. \\
\hline & & & & & & total & 117 u.c. \\
\hline
\end{tabular}

De acordo com a Tabela 5.10, o recurso R6 que ficou indisponível possui a funcionalidade $\mathrm{F} 3 \mathrm{e}$ a sequência dos processos resulta em:

Processo A (sequência de recursos): R2 (F1) $\rightarrow \mathrm{R} 4(\mathrm{~F} 2) \rightarrow \mathrm{R} 5(\mathrm{~F} 3)$

Processo B (sequência de recursos): $\mathrm{R} 5(\mathrm{~F} 3) \rightarrow \mathrm{R} 2(\mathrm{~F} 1) \rightarrow \mathrm{R} 4(\mathrm{~F} 2)$

Processo C (sequência de recursos): R3 (F2) $\rightarrow \mathrm{R} 5(\mathrm{~F} 3) \rightarrow \mathrm{R} 1(\mathrm{~F} 1)$ 
Este exemplo mostra que, para o caso de um SP em que existam múltiplos processos sendo executados simultaneamente e um conjunto de recursos (incluindo as MFMs) e diante da indisponibilidade de um determinado recurso, embora exista uma maior complexidade para alocar os recursos, o sistema de alocação de recursos proposto permitiu realizar a realocação para atender à realização de processos e ainda atende a um critério de menor custo. Mesmo no caso de múltiplos processos, a abordagem adotada mantém a facilidade de traduzir de forma isomórfica os grafos dos módulos da arquitetura adotada para os correspondentes algoritmos a serem programados nos controladores programáveis.

\subsection{SEGUNDO EXEMPLO DE APLICAÇÃO}

Este exemplo de aplicação considera o SP apresentado em Nakamoto (2008).

O sistema produtivo transforma a matéria-prima em produto utilizando os recursos de acordo com a programação da produção entretanto, pode ocorrer que um dos recursos previsto pela programação fique impossibilitado de uso. Nesse caso, o sistema de alocação de recursos deve realizar a busca de outro recurso levando em consideração a sequência de funcionalidades para regenerar o SP.

Neste exemplo de aplicação, são consideradas sete máquinas-ferramenta que estão no chão de fábrica do SP. As máquinas-ferramenta utilizadas são denominadas de: $R 1, R 2, R 3, R 4, R 5, R 6, R 7$. Sabendo que os recursos $R 1, R 2, R 3$ e R4 são máquinas convencionais (uma funcionalidade) e os recursos R5, R6 e R7 são MFMs.

As letras F1, F2 e F3 referem-se às funcionalidades (por exemplo, F1 refere-se a tornear, F2 refere-se a fresar, F3 refere-se a furar). 
Tabela 5.11 - Descrição da funcionalidade de cada recurso.

\begin{tabular}{|c|c|}
\hline Recurso & Funcionalidade \\
\hline R1 & F1 \\
\hline R2 & F2 \\
\hline R3 & F1 \\
\hline R4 & F2 \\
\hline R5 & F3 e F2 \\
\hline R6 & F3 e F2 \\
\hline R7 & F1,F2,F3 \\
\hline
\end{tabular}

A Tabela 5.11 mostra que os recursos R5 e R6 possuem duas funcionalidades e o recurso $\mathrm{R} 7$ possui três funcionalidades.

No chão de fábrica, são executados seis tipos de processos $P=\left\{P_{A}, P_{B}, P_{C}, P_{D}, P_{E}\right.$, $P_{G}$ \} concomitantemente, compartilhando o mesmo conjunto de recursos entre os processos.

O sequenciamento preestabelecido de utilização de recursos/funcionalidades e as respectivas atividades dos processos são apresentados a seguir:

$$
\begin{aligned}
& \mathrm{P}(\mathrm{A}): \mathrm{R} 1(\mathrm{~F} 1) \rightarrow \mathrm{R} 2(\mathrm{~F} 2) \rightarrow \mathrm{R} 3(\mathrm{~F} 1) \rightarrow \mathrm{R} 4(\mathrm{~F} 2) \\
& \mathrm{P}(\mathrm{B}): \mathrm{R} 7(\mathrm{~F} 1) \rightarrow \mathrm{R} 4(\mathrm{~F} 2) \\
& \mathrm{P}(\mathrm{C}): \mathrm{R} 4(\mathrm{~F} 2) \rightarrow \mathrm{R} 7(\mathrm{~F} 3) \\
& \mathrm{P}(\mathrm{D}): \mathrm{R} 6(\mathrm{~F} 3) \rightarrow \mathrm{R} 5(\mathrm{~F} 2) \\
& \mathrm{P}(\mathrm{E}): \mathrm{R} 5(\mathrm{~F} 2) \rightarrow \mathrm{R} 1(\mathrm{~F} 1) \\
& \mathrm{P}(\mathrm{G}): \mathrm{R} 3(\mathrm{~F} 1) \rightarrow \mathrm{R} 2(\mathrm{~F} 2) \rightarrow \mathrm{R} 6(\mathrm{~F} 3)
\end{aligned}
$$

A execução das atividades dos processos é disparada de acordo com uma lista gerada a partir do scheduling de atividades fornecidas pelo planejamento da produção. 
O layout da planta é apresentado na Figura 29.

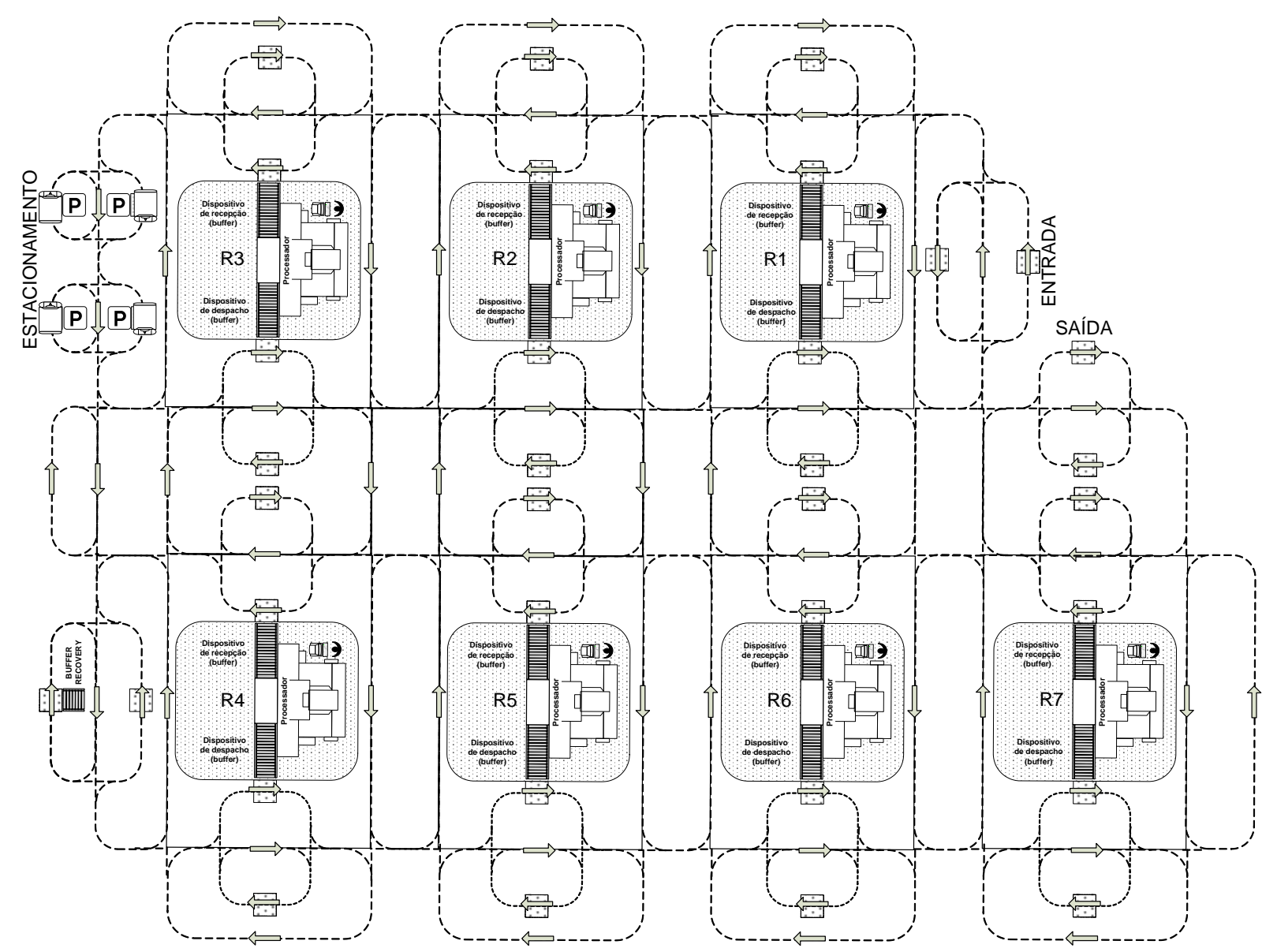

Figura 29 Layout da planta (NAKAMOTO, 2008).

No layout da planta, estão representados os recursos $R 1, R 2, R 3, R 4, R 5, R 6, R 7$ e os sentidos de movimentação dos pallets com as peças/produtos.

Para desenvolver a síntese dos grafos utilizados pelo sistema de alocação de recursos primeiramente, realiza-se a síntese do grafo de sequência de funcionalidades (GSF) e, após, a síntese do grafo para designar funcionalidade (GDF) e o grafo de controle do processo (GCP).

Etapa A) Síntese do grafo de sequência de funcionalidade (GSF)

Com base no planejamento da produção, geram-se os grafos das Figuras $30,31,32$, $33,34,35$. 
Síntese do grafo de sequência de funcionalidade (GSF) do processo "A"

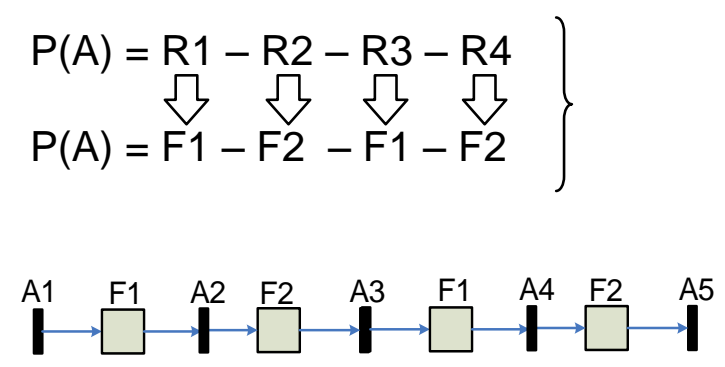

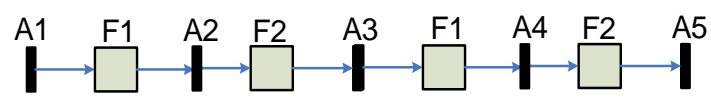

Figura 30 - Geração do grafo de sequência de funcionalidade (GSF) do processo "A"

Síntese do grafo de sequência de funcionalidade (GSF) do processo "B"

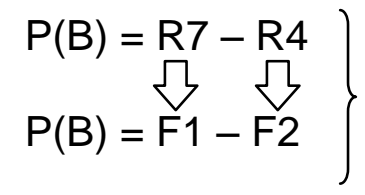

$$
\begin{aligned}
& \stackrel{\mathrm{B} 1}{\mathrm{~F} 1} \stackrel{\mathrm{B} 2}{\mathrm{~B} 3}
\end{aligned}
$$

Figura 31 - Geração do grafo de sequência de funcionalidade (GSF) do processo "B"

Síntese do grafo de sequência de funcionalidade (GSF) do processo "C"

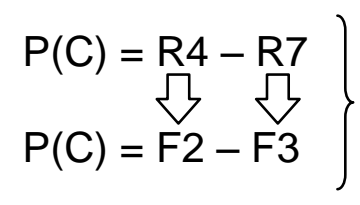

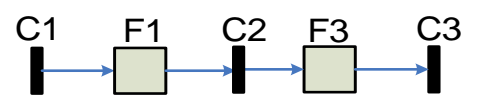

Figura 32 - Geração do grafo de sequência de funcionalidade (GSF) do processo "C" Síntese do grafo de sequência de funcionalidade (GSF) do processo "D"

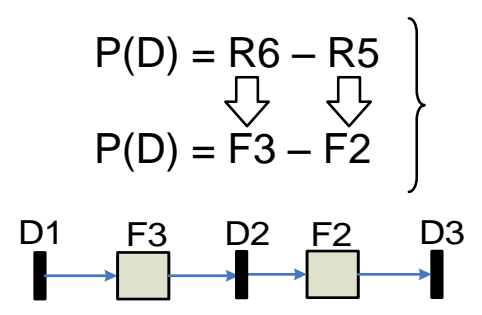

Figura 33 - Geração do grafo de sequência de funcionalidade (GSF) do processo "D" 
Síntese do grafo de sequência de funcionalidade (GSF) do processo "E"

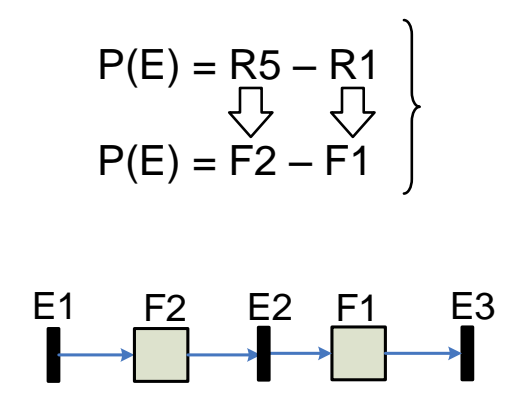

Figura 34 - Geração do grafo de sequência de funcionalidade (GSF) do processo "E"

Síntese do grafo de sequência de funcionalidade (GSF) do processo "G"

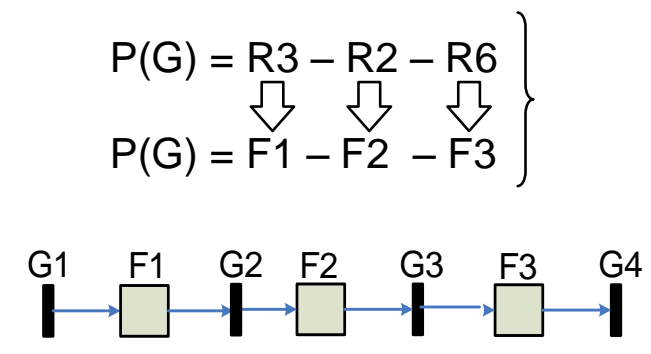

Figura 35 - Geração do grafo de sequência de funcionalidade (GSF) do processo "G"

Etapa B) Síntese do grafo para designar funcionalidade (GDF), a partir do GSF, elaboram-se os grafos das Figuras 36, 37, 38, 39, 40, 41.

Síntese do grafo para designar a funcionalidade (GDF) do processo "A"

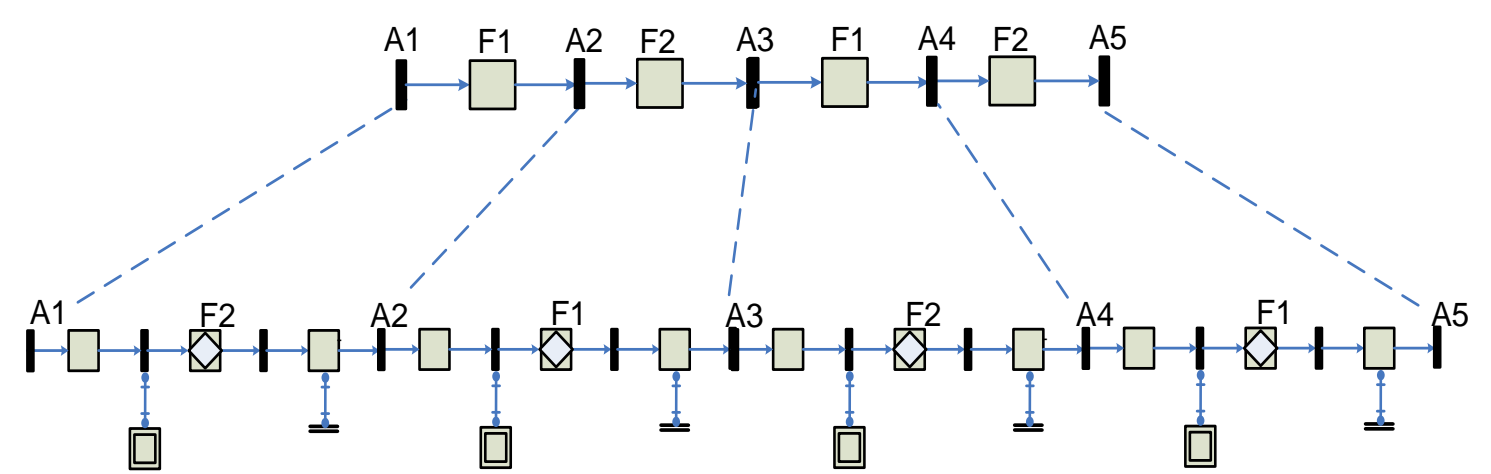

Figura 36 - Passo 1 - Geração do grafo para designação de funcionalidade (GDF) 
Síntese do grafo para designar a funcionalidade (GDF) do processo "B"

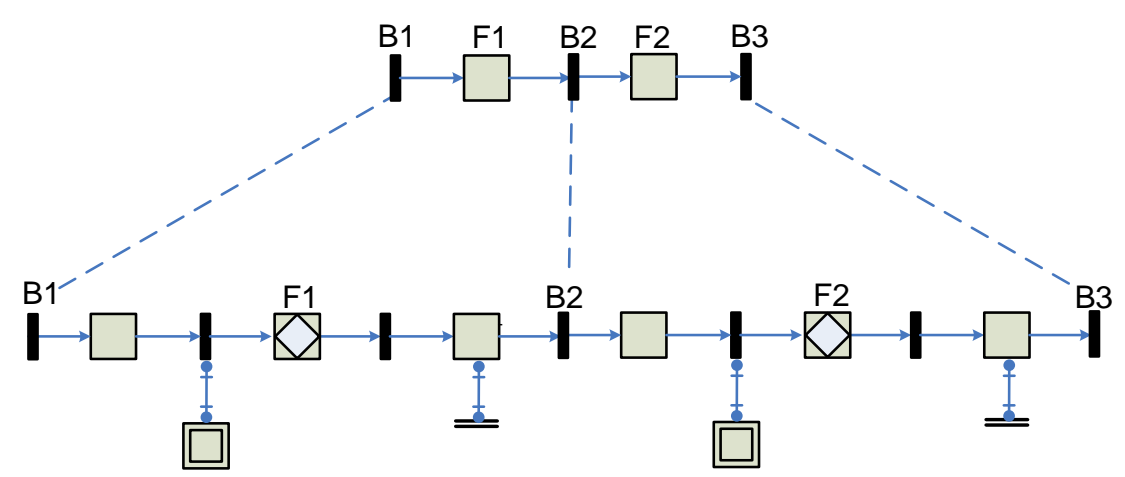

Figura 37 - Passo 1 - Geração do grafo para designação de funcionalidade (GDF)

Síntese do grafo para designar a funcionalidade (GDF) do processo "C"

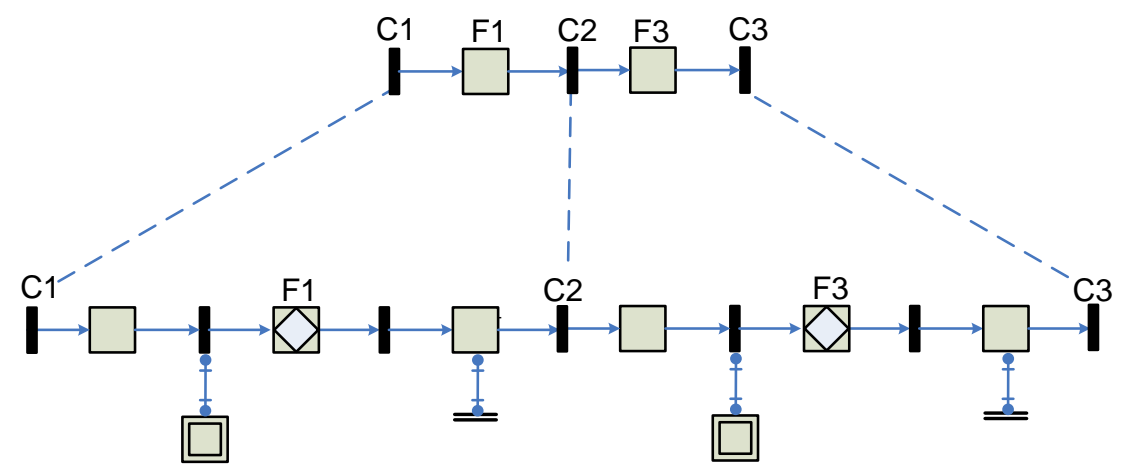

Figura 38 - Passo 1 - Geração do grafo para designação de funcionalidade (GDF)

Síntese do grafo para designar a funcionalidade (GDF) do processo "D"

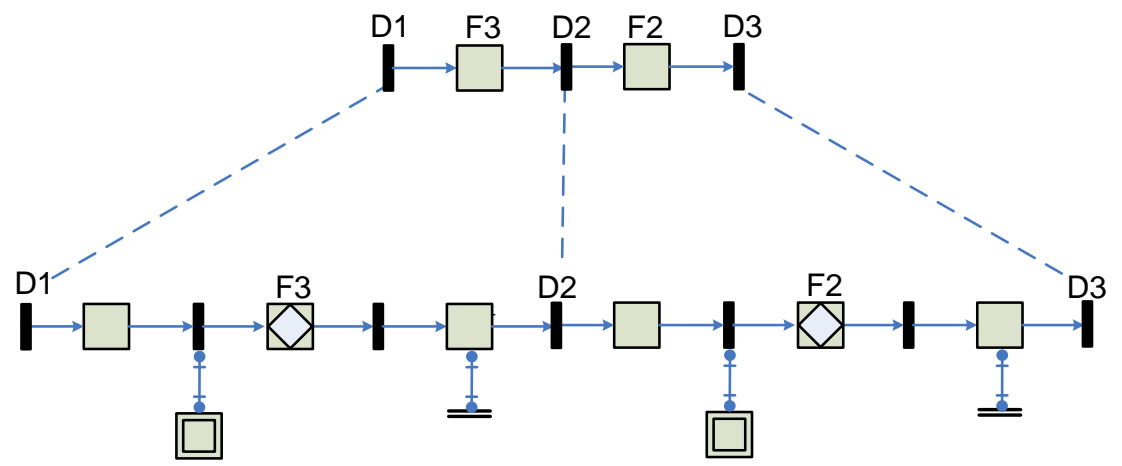

Figura 39 - Passo 1 - Geração do grafo para designação de funcionalidade (GDF) 
Síntese do grafo para designar a funcionalidade (GDF) do processo "E"

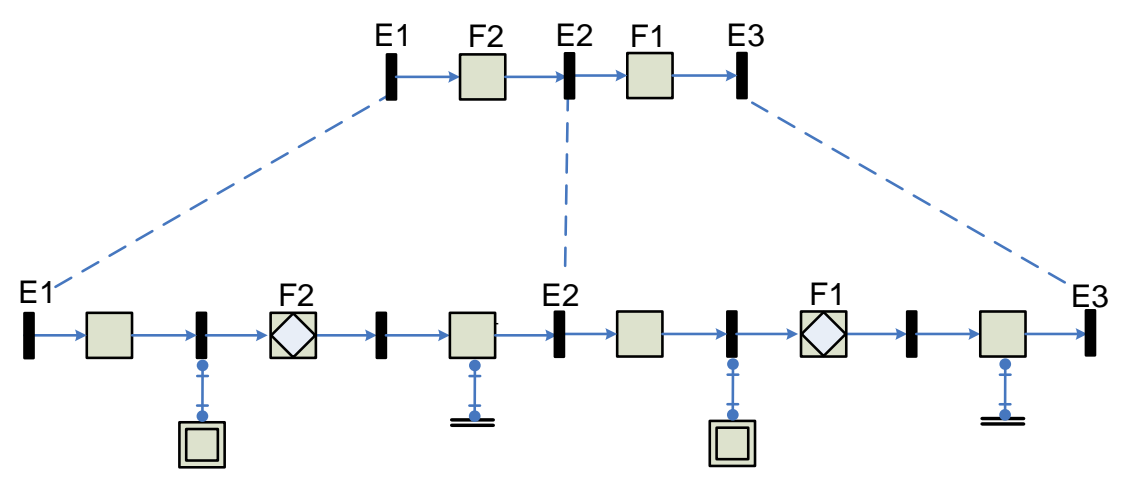

Figura 40 - Passo 1 - Geração do grafo para designação de funcionalidade (GDF)

Síntese do grafo para designar a funcionalidade (GDF) do processo "G"

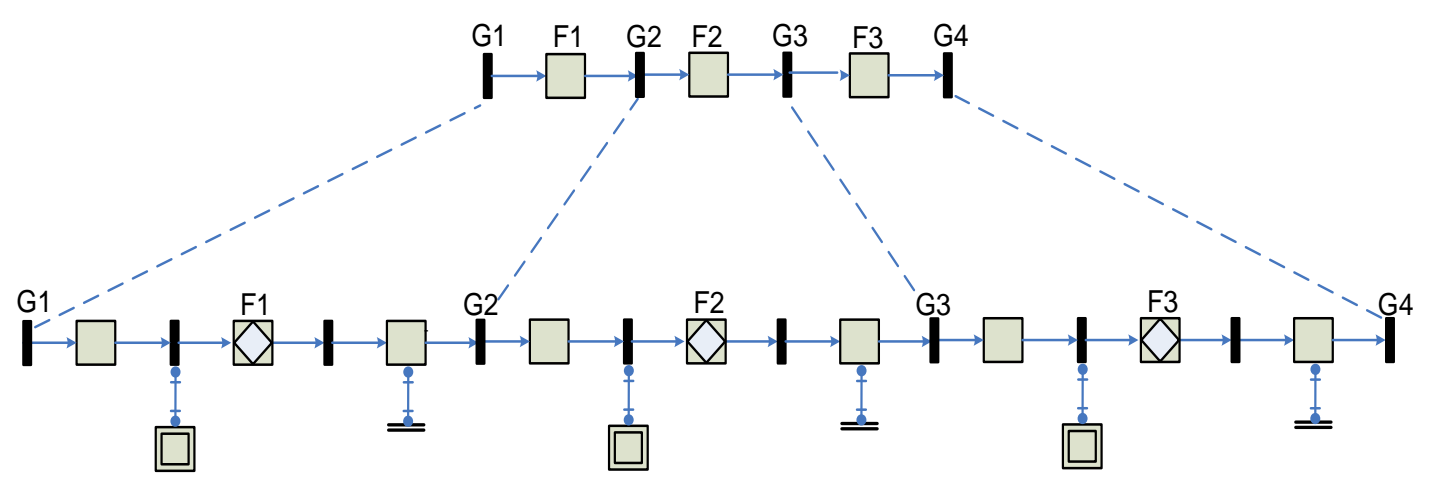

Figura 41 - Passo 1 - Geração do grafo para designação de funcionalidade (GDF)

Executando o passo 2, que é a integração dos GDF que foram gerados individualmente em cada processo (conforme desenvolvido no item acima).

Realiza-se a fusão dos boxes controladores de mesmas funcionalidades, gerando-se o grafo de designação de funcionalidade global (GDF), apresentado na figura 42

Elaboração do Grafo de Designação de Funcionalidades (Passo 2) 


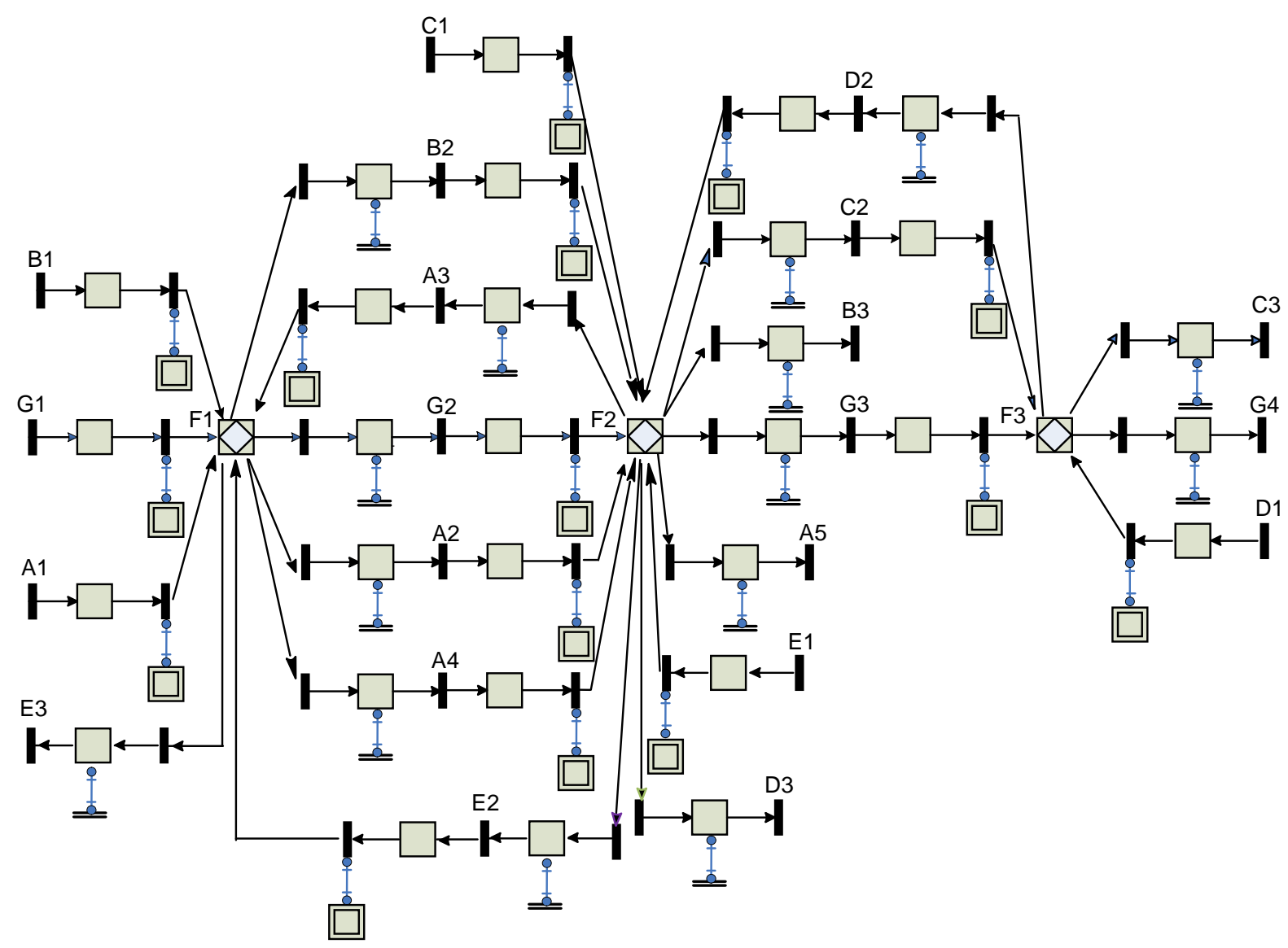

Figura 42 - Passo 2- Grafo para Designar Funcionalidade (GDF)

Etapa C) Síntese do grafo de controle do processo (GCP), a partir do GSF, geram-se os grafos GCP presentes nas Figuras 43, 44, 45, 46, 47, 48.

Síntese do Grafo de Controle do Processo "A" (GCP)

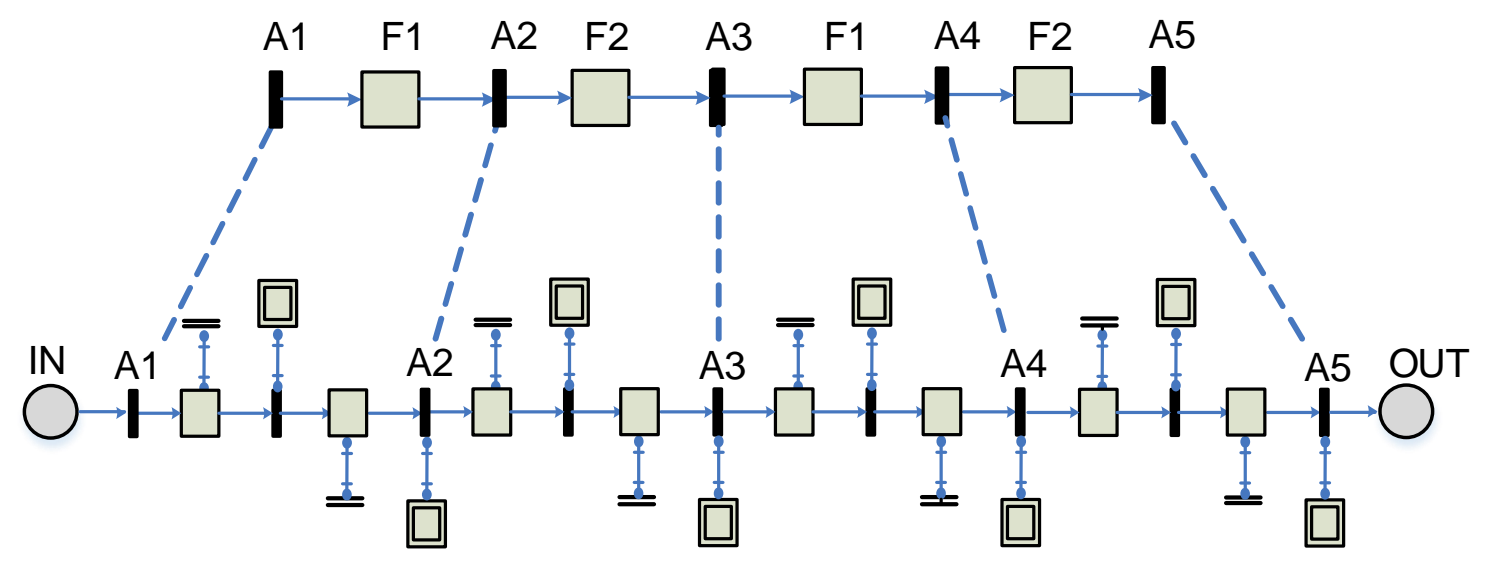

Figura 43 - Grafo de Controle do Processo "A" (GCP) 
Síntese do Grafo de Controle do Processo "B" (GCP)

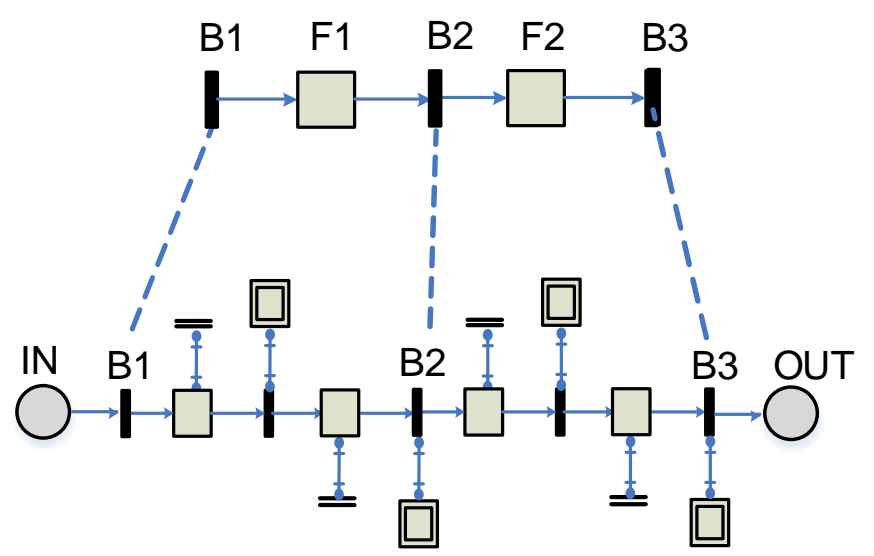

Figura 44 - Grafo de Controle do Processo "B" (GCP)

Síntese do Grafo de Controle do Processo "C" (GCP)

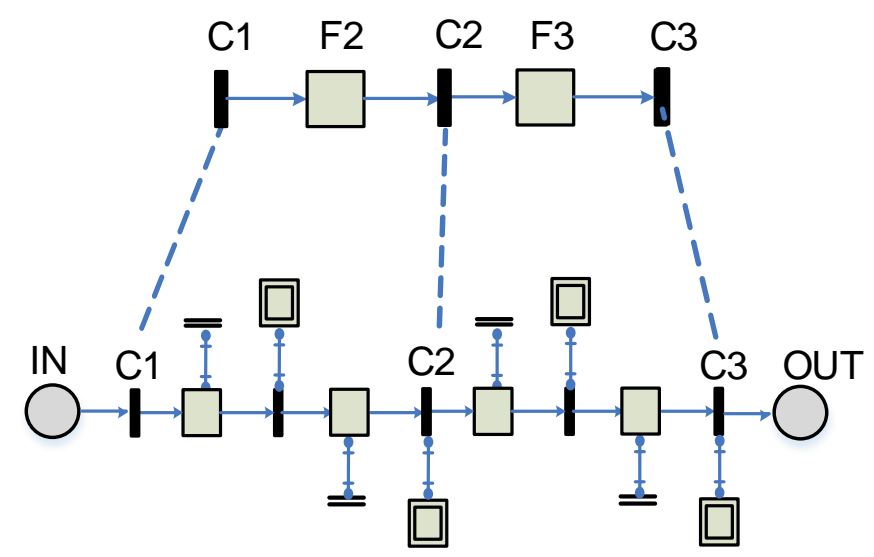

Figura 45 - Grafo de Controle do Processo "C" (GCP)

Síntese do Grafo de Controle do Processo "D" (GCP)

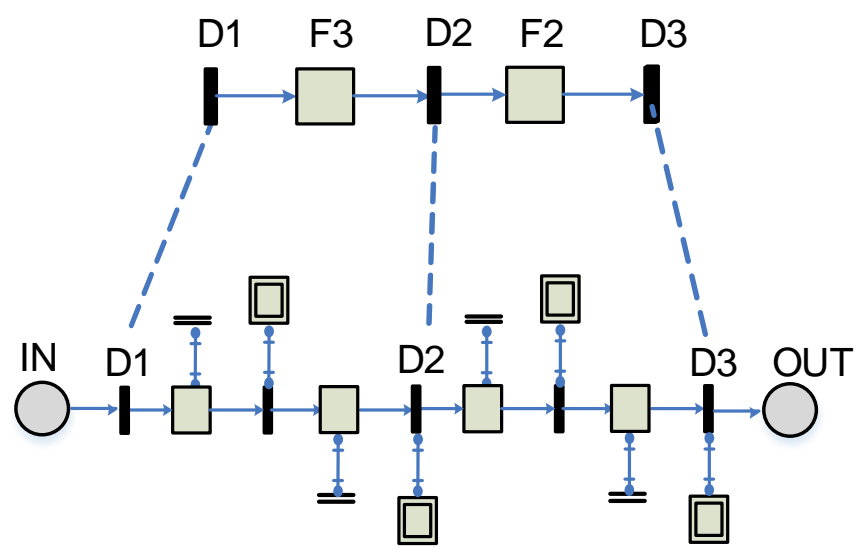


Figura 46 - Grafo de Controle do Processo “D” (GCP)

Síntese do Grafo de Controle do Processo "E” (GCP)

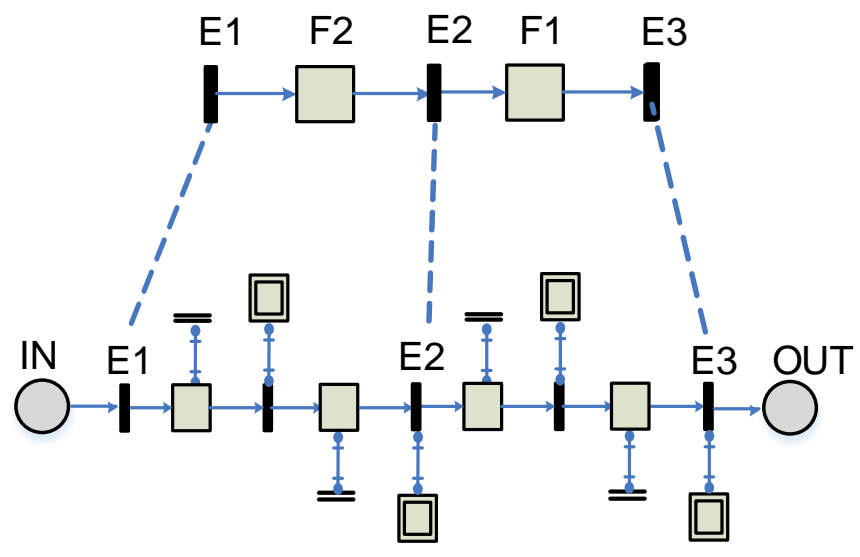

Figura 47 - Grafo de Controle do Processo "E" (GCP)

Síntese do Grafo de Controle do Processo "G" (GCP)

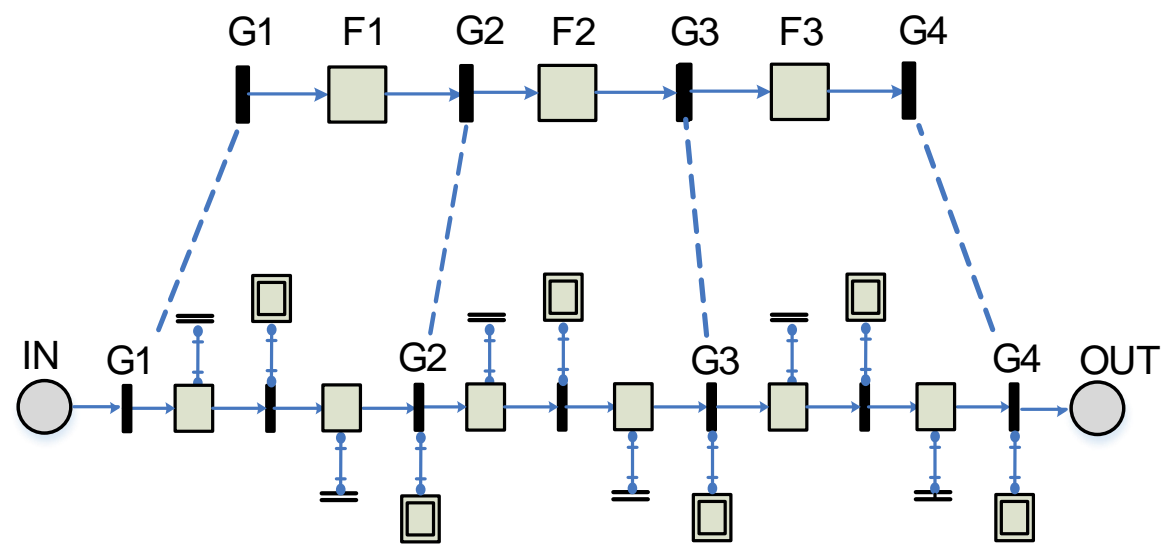

Figura 48 - Grafo de Controle do Processo "G" (GCP)

Os GCPs dos processos envolvidos e a comunicação com o GDF e os respectivos recursos estão ilustrados na Figura 49. 


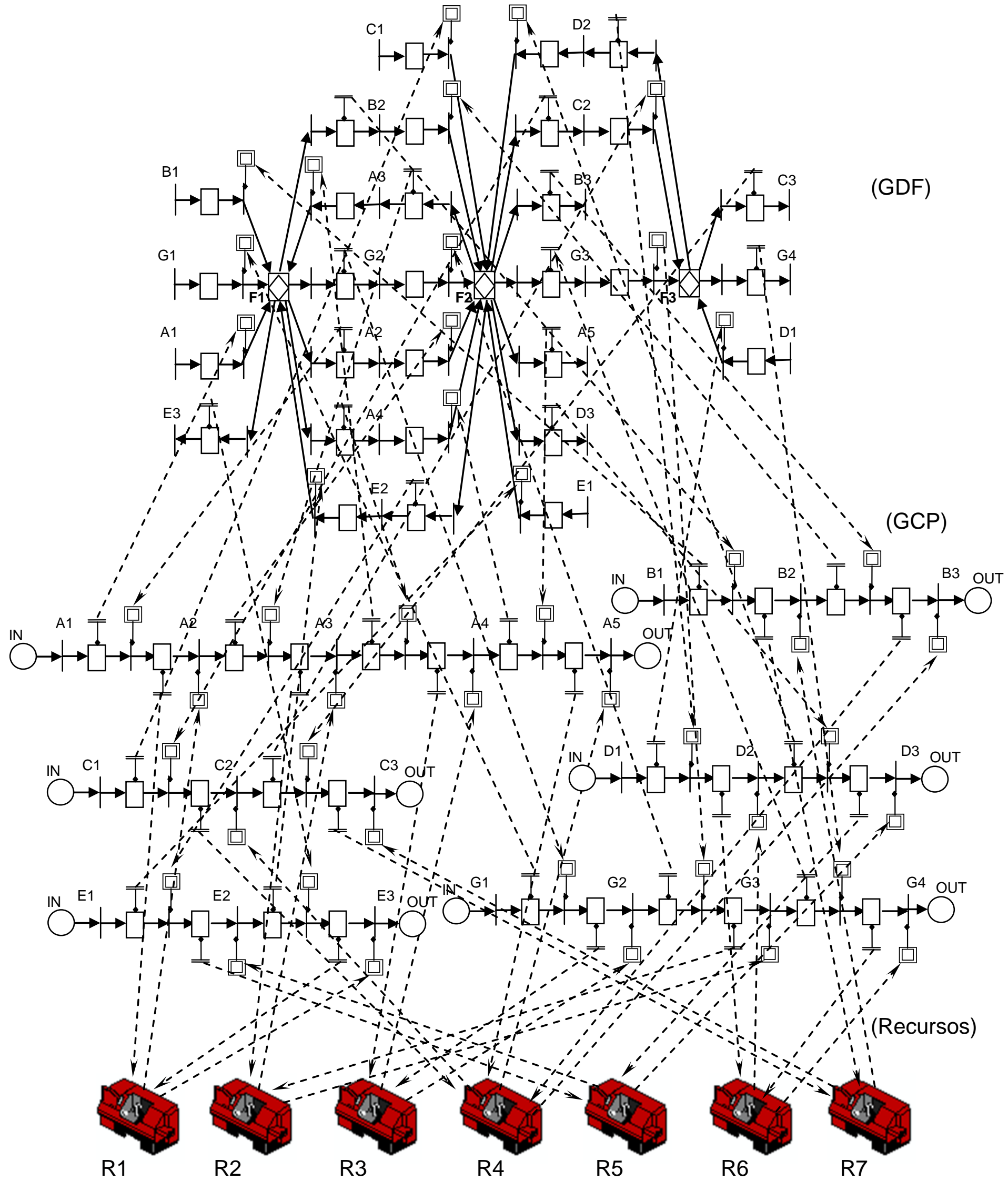

Figura 49 - Ilustra a comunicação dos GCPs com o GDF e os recursos do SP 

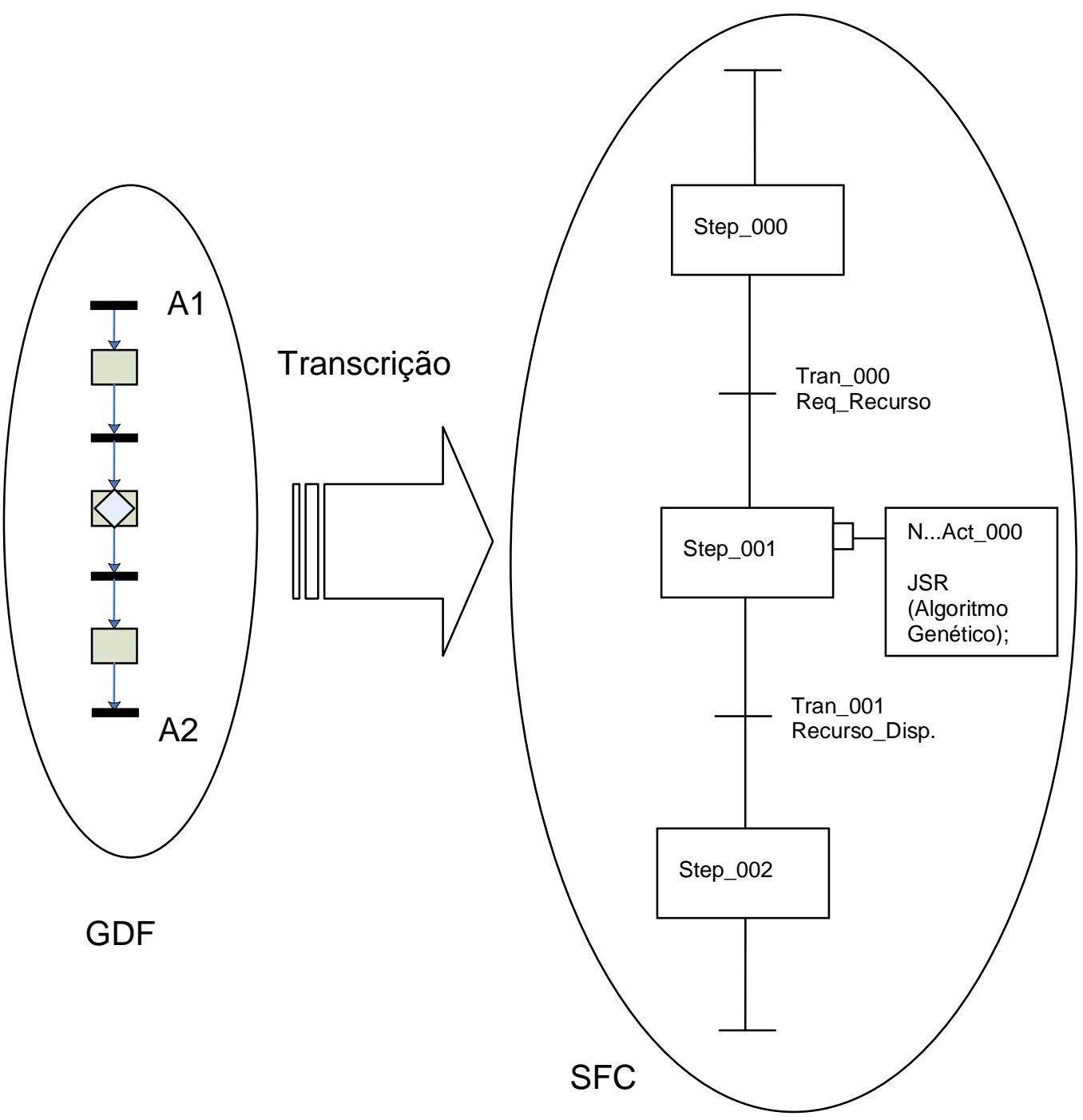

Figura 50 - Exemplo de transcrição de um trecho do GDF do processo "A" para a linguagem SFC.

O trecho do grafo de designação de funcionalidade (GDF), ilustrado na Figura 50, exemplifica como se realiza a transcrição para a linguagem SFC (Sequential Function Chart).

Os grafos de controle de processo e/ou de designação de funcionalidades podem ser transcritos para uma linguagem aderente à norma IEC 61131-3 e nesse caso, utilizou-se a linguagem SFC. Neste exemplo, foi utilizado o algoritmo genético, mas podem ser utilizados outros algoritmos que podem ser transcritos para outra linguagem aderente à norma IEC como o texto estruturado (ST). 
5.3 Análise dos resultados

Os exemplos ilustram os seguintes aspectos:

- Conhecendo os recursos no chão de fábrica e a sequência de funcionalidades programada, diante de uma perturbação no sistema que impossibilita o SP de prosseguir com a programação da produção inicialmente estabelecida, o sistema de alocação de recursos proposto utiliza a flexibilidade funcional para regenerar o SP, realocando, de forma dinâmica, outros recursos de acordo com critérios que garantem, por exemplo, o menor custo de produção.

- Existindo um cenário que possui múltiplos processos e diante da ocorrência de eventos indesejáveis que comprometam a disponibilidade do recurso previamente programado, também se pode utilizar o conceito de flexibilidade funcional para regenerar o SP realocando recursos incluindo as MFMs para manter a produção.

- A possibilidade de uso de um método de transcrição isomórfica dos grafos obtidos a partir do método proposto para gerar os programas de controle para os controladores programáveis.

- Testes com alguns algoritmos relativamente populares para a tomada de decisões (como o algoritmo genético e colônia de formigas) confirmam a viabilidade de obter resposta em tempo real e uma solução para a alocação /realocação dinâmica de recursos. 


\section{CONCLUSÕES FINAIS}

Neste trabalho, apresentou-se uma proposta de arquitetura para alocação dinâmica de recursos que explora o potencial de flexibilidade funcional dos recursos disponíveis para resolver os problemas decorrentes de indisponibilidade não prevista dos recursos. Foi necessário rever o paradigma de alocação de recursos para a alocação de funcionalidades.

Nessa arquitetura, existem três módulos básicos: módulo para o controle de processos (CP), módulo para designação de funcionalidades (DF) e módulo para designação de recursos (DR).

O módulo de controle de processos (CP) faz a interface entre os recursos que estão no chão de fábrica e o sistema de controle para alocar os recursos; mas, diferentemente das soluções convencionais, nessa interface, processa-se a sequência de funcionalidade de cada processo de produção.

O módulo para a designação de funcionalidades (DF) faz a integração de todos os processos produtivos, sendo que esses processos estão descritos de acordo com modelos (grafos) derivados das sequências de funcionalidades. Para fazer a integração dos processos, realiza-se a fusão de funcionalidades de mesma semântica; dessa forma, obtém-se uma única descrição/modelo com todos os processos e respectivas funcionalidades.

Por último, tem-se o módulo que realiza a designação de recurso (DR), que executa um algoritmo para identificar o recurso mais adequado para cada caso/situação.

Neste trabalho, o diferencial em relação aos outros métodos de alocação de recursos está em explorar o conceito de flexibilidade funcional na arquitetura desenvolvida, em que se destaca o seguinte:

- O sistema de controle de alocação de recursos passa a ter mais um grau de flexibilidade, isto é, permite que as múltiplas funcionalidades contidas na MFM possam ser utilizadas de forma eficiente e não mais ficar encapsuladas conforme métodos convencionais de alocação de recursos. 
- A arquitetura desenvolvida contempla as normas internacionais IEC 61131-3 e IEC61499 para manter o padrão de uso dos CLPs.

\subsection{CONTRIBUIÇÕES DO TRABALHO}

A arquitetura proposta de sistema de controle de alocação de recursos com flexibilidade funcional apresenta as seguintes contribuições:

- A solução para alocação/realocação dinâmica de recursos adotada permite inserir regras adicionais para realizar a designação de recursos por meio da simples edição dos procedimentos representados no modelo E-MFG pelos boxes controladores.

- Adotando-se o conceito de flexibilidade funcional, a sequência de processos não fica mais atrelada ao uso de um determinado recurso, isto é, o trabalho desenvolvido comprova que, de acordo com as funcionalidades disponíveis, pode-se definir o recurso mais adequado para cada situação. Dessa forma, ampliam-se a flexibilidade operacional do SP com os recursos com múltiplas funcionalidades (MFMs).

- A estrutura do sistema de alocação/realocação de recursos é modular para que cada parte possa contemplar objetivos distintos, isto é, um módulo atende às requisições de recurso; outro módulo, a designação de funcionalidades; e o terceiro módulo, a designação de recurso, de modo que aprimoramentos específicos podem ser facilmente implementados.

- A nova arquitetura torna possível explorar as potencialidades das máquinasferramenta multifuncionais (MFMs) de uma forma mais efetiva, isto é, disponibilizando todas as suas funcionalidades principalmente no caso de ocorrência de situações imprevistas. 


\subsection{TRABALHOS FUTUROS}

Pretende-se aplicar a proposta de regeneração de sistemas produtivos em uma indústria de transformação, mapeando as funcionalidades dos recursos, modelando os processos, elaborando os grafos de controle de processos (GCP), os grafos de designação de funcionalidades (GDF) e elaborando um algoritmo para designar o recurso mais apropriado para o estudo de caso e, quando ocorrerem eventos inesperados, como a indisponibilidade (quebra de máquina) de um determinado recurso no SP, à solução será a realocação dinâmica de recursos considerando o conceito de flexibilidade funcional. 


\section{REFERÊNCIAS BIBLIOGRÁFICAS}

AMERICAN NATIONAL STANDARD. ANSI/ISA-S95.00.03-2005, Enterprise-control system integration Part 3: Activity Models of Manufacturing Operations Management, 2005.

ASATO, O. L.; SA, L. S. C.; PESSOA, M. A. O.; JUNQUEIRA, F; SANTOS FILHO, D.J.; MIYAGI,P.E. Dynamic Control of Resource Allocation Considering Multifunctional Machine Tools. In: IMS 11th IFAC Workshop on Intelligent Manufacturing Systems, São Paulo, 2013. v.11. p. 360-365.

ASATO, O L.; DOBRIANSKYJ, G.M; JUNQUEIRA, F.; SANTOS FILHO, D.J.; MIYAGI, P. E. Process Control System Considering the Machines Functional Flexibilities. IFIP Advances in Information and Communication Technology, 2012. v. 372, p. 133-142, ISBN 978-3-642-28254-6

BARATA, J.; CAMARINHA-MATOS L.M. Coalitions of manufacturing components for shop floor agility - The CoBaSA architecture Int. Journal of Networking and Virtual Organizations, 2003. vol. 2, № 1, p. 50-77, ISSN 1470-9503

BORANGIU, T.; RAILEANU, S.; ROSU, A.; PARLEA, M.; ANTON, S.; ANTON F.D. Semi-Heterarchical Distributed Control of a Holonic Manufacturing Cell; CEAI, 2009. vol.11. p.14-21.

BORANGIU, T.; RAILEANU,S.; TRENTESAUX, D.; BERGER,T.; IACOB,I. Distributed manufacturing control with extended CNP interaction of intelligent products; J. Intell Manuf. 2014. v.25. p.1065-1075.

CALINESCU, A.; EFSTATHIOU,J.; SIVADASAN,S.; SCHIRN, J.; HUACCHO,L. complexity in manufacturing: an information theoretic approach. Proceedings of the International Conference on Complex Systems and Complexity in Industry Manufacturing, v.19, 2000.

CASSANDRAS,C.G.; LAFORTUNE,S. Introduction to Event Discrete System, second edition, New York, Spring Verlag, 2007

CAVALHEIRO, A.C.M. Projeto de sistemas de controle modulares e distribuídos, 157p. 2004, Dissertação (Mestrado) - Escola Politécnica, Universidade de São Paulo, São Paulo, 2004.

CHOI,Y.H.; KIM, S.T.; SEO, T.Y.; KIM, K.H. Analysis of Dynamic Cross Response between Spindles in a Dual Spindle Type Multi-Functional Turning Machine; Journal of Power and Energy Engineering, 2013. v.1. p. 20-24 
COFFMAN E. G. , Jr., ELPHICK M. J., SHOSHANI, A. System Deadlocks, Computing Surveys, 1971. vol. 3, n. 2, p. 67-78.

DOBREV, M.; GOCHEVA, D.; BATCHKOVA, I. An ontological approach for planning and scheduling in primary steel production. In: Intelligent Systems. IS '08. $4^{\text {th }}$ International IEEE Conference, 2008. v. 1, n. 4670433, p. 614-619.

DORIGO,M; GAMBARDELLA, L.M.; Ant colony system: a cooperative learning approach to the traveling salesmen problem. IEEE Transaction o Evolutionary Computation, 1997. v.1, n.1, p. 53-66.

DORIGO,M.; MANIEZZO,V.; COLORNI,A.; Positive feedback as a search strategy, Technical report 91-016, Dipartimento di Elettronica, Politecnico di Milano, Milan, 1991.

GIU, A.; SEATZU, C. Petri nets for the control of discret event systems, SpringerVerlag Berlin Heidelberg, DOI 10.1007/s10270-014-0425-1, 2014.

GODINHO FILHO M.; BARCO C.F.; TAVARES NETO R.F./ Using Genetic Algorithms to solve scheduling problems on flexible manufacturing systems (FMS): a literature survey, classification and analysis/ Flexible Services and Manufacturing Journal. 2012. p. 1-24.

GLEGHORN, R. Enterprise Application Integration: A Manager's Perspective. Em: IEEE - Computer Society - IT Professional, 2005. vol.7. p.17-23.

GRADISAR, D.; Music, G. Production-process Modelling Based on Productionmanagement Data: A Petri-net Approach. Int. J. Comput. Integr. Manuf., 20 (8), 2007. p. $794-810$.

GROOVER, M. P. Automation, production systems, and computer-integrated manufacturing. 2011, Prentice-Hall.

GUO, H., TAO, F., ZHANG, L., LAILI, Y.J., LIU, D.K. Research on measurement method of resource service composition flexibility in service-oriented manufacturing system. International Journal of Computer Integrated Manufacturing, 2012. 25 (2), p.113-135.

HASEGAWA, K.; Modeling Control and Deadlock Avoidance of Flexible Manufacturing Systems, In: Conference Plenaries of XI CBA Sao Paulo, SBA, 1996. p. 37-51.

HE, Y.; SUN, H.; LAI,K.K.; CHEN,Y.; Organizational empowerment and service strategy in manufacturing, Serv Bus, Springer-Verlag Berlin Heidelberg, 2014.

HU H.; ZHOU M.; LI Z.; TANG T. Deadlock-Free Control of Automated Manufacturing Systems With Flexible Routes and Assembly Operations Using Petri Nets, IEEE Transactions on Industrial Informatics, 2013. v. 9. 
HUANG, Y.S.; PAN Y.; SY P., Transition-Based Deadlock Detection and Recovery Policy for FMSs, Using Graph Technique, ACM Transactions on Embedded Computing Systems, 2013. v. 12.

IEC, International Electro technical Commission, Programmable Controllers (IEC 61131: Part 3) Programming Languages, 2003.

IEC, International Electro technical Commission, Function Blocks (IEC 61499: Part 2) Software tool requirements. Geneva, 2005.

ISA, Enterprise-Control System Integration, Part 3: Models of Manufacturing Operations Management, Copyright (C) 2004 by ISA - The Instrumentation, Systems, and Automation Society. Printed in the United States of America. 2004.

JIA, J.; YANG,Y.; YANG,T.; ZHANG, F.; YU,G.; Research on Dynamic Programming of the Series Manufacturing System Reliability Allocation, Journal of Convergence Information Technology (JCIT), 2012. V.7. n.7.

JENSEN, K. Coloured Petri Nets: Basic Concepts, Analysis Methods and Practical Use, Berlin, 1992.

KATO, E.R.R.; MORANDIN, Jr. O.; FONSECA, M.A.S.; Ant Colony Optimization Algorithm for Reactive, Production Scheduling Problem in the Job Shop System, Proceedings of the 2009 IEEE International Conference on Systems, Man, and Cybernetics, San Antonio, TX, USA - 2009. p. 2199-2204.

KOESTLER, A. The Ghost in the Machine, London. Arkana Books.1967.

LEITÃO, P.; Agent-based Distributed Manufacturing Control: A State of art Survey. Engineering Applications of Artificial Intelligence. 2009. v.22. p. 979-991.

LEITÃO, P.; VRBA, P.; Recent Developments and Future Trends of Industrial Agents, Holons MAS. Springer-Verlag Berlin Heidelberg. 2011. p. 15-28, 2011.

LI, C.; WU, W.; FENG, Y.; RONG, G.; Scheduling FMS problems with heuristic search function and transition-timed Petri nets; Journal Intelligent Manuf, Springer Science Business Media New York, 2014.

LIU, G.Y.; BARKAOUI,K.; Necessary and sufficient liveness condition of GS3PR Petri nets, International Journal of Systems Science, 2013. Taylor \& Francis.

LUI G.Y.; LI Z.W.; BARKAOUI K.; AL-AHMARI A.M.; Robustness of deadlock control for a class of Petri nets with unreliable resources, Information Sciences. 2013. p.259279, DOI: 10.1016/j.ins.2013.01.003

MARIK,V.; McFARLANE, D., Industrial adoption of agent-based Technologies IEEE Intelligent Systems, 2005, V.20, N.1, pp. 27-35. 
MATSUSAKI,C.T.M.; SANTOS FILHO,D.J.; Modeling of distributed collaborative control systems of production systems. ABCM Symp.Series in Mechatronics, 2006. v.2, p.345-352.

MELLO, A. T. F. ; BARBOSA, M. C. ; SANTOS FILHO, D. J. ; JUNQUEIRA, F. ; MIYAGI, P. E. . A Transcription Tool from Petri Net to CLP Programming Languages. In: COBEM'2011 21st International Congress of Mechanical Engineering, Proceedings of COBEM'2011. Rio de Janeiro, RJ: ABCM, 2011.

MIYAGI, P. E. Controle Programável - Fundamentos do Controle de Sistemas a Eventos Discretos. Ed. Edgard Blucher Ltda. São Paulo, Brasil, 1996.

MORANDIN, Jr. O.; KATO, E.R.R.; DERIZ, A.C.; SANCHES, D.S.; TSUNAKI, R. H.; . An Adaptive Genetic Algorithm Based Approach for Production Reactive Scheduling of Manufacturing Systems. In: ICIT 2009 - IEEE International Conference on Industrial Technology, 2009, Victoria. Proceedings of the 12th IEEE International Conference on Industrial Technology, 2009. v.1.

MORIWAKI, T.: Multi-functional machine tool. CIRP Annals Manufacturing Technology, 2008. pp.736-749.

NAKAMOTO, F. Y. ; MIYAGI, P. E. ; SANTOS FILHO, D. J. Resources Allocation Control in Flexible Manufacturing Systems Using the Deadlock Avoidance Method. ABCM Simposium Series in Mechatronics. Rio de Janeiro, RJ: ABCM, 2008, v.3, p. 454-460.

NAKAMOTO, F.Y.; Projetos de Sistemas Modulares de Controle para Sistemas Produtivos, 158p. 2008, Tese (Doutorado) - Escola Politécnica, Universidade de São Paulo, São Paulo, 2008.

PANESCU D.; PASCAL, C. Modelling a Holonic Agent based Solution by Petri Nets; ComSIS. 2012. v.9, n.3, Special Issue.

PASCAL, C.; PANESCU, D.; HAPBA A BDI agent based solution for Holonic Manufacturing Execution Systems; 2013. Studies in Computational Intelligence v. 472 , p. $57-70$.

PHILIPS, J.; SAINT GERMAIN, B.; VAN BELLE,J.; VALCKENAERS, P.; Traffic radar: A holonic traffic coordination system using PROSA++ and D-MAS Lecture Notes in Computer Science ;2013. 8062 LNAI, p. 163-174

PETERSON, J. L.; Petri Net theory and the modeling of systems. Englewood cliffs, Prentice-Hall, 1981.

QIU, R.G. The Challenges of Manufacturing in the Globally Integrated Economy. Int. J. Comput. Integr. Manuf., 2009. v.22 (4), p. 281-282. 
RAJ, J.A., RAVINDRAN, D., SARAVANAN, N., PRABAHARAN, T. Simultaneous Scheduling of Machines and Tools in Multimachine Flexible Manufacturing Systems Using Artificial Immune System Algorithm. Int. J. Comput. Integr. Manuf. 2014. v.27. p. 401-414.

REISIG, W. Petri net: An Introduction, Springer-Verlag, Berlin Heidelberg. 1985.

REVELIOTIS, S.A. Real-Time Management of Resource Allocation Systems - A Discrete Event Systems Approach. Atlanta: Springer Science, 2005.

RIASCOS, L.A.M.; Metodologia para detecção e tratamento de falhas em sistemas de manufatura através de rede de Petri, 164 p. Tese (Doutorado) - Escola Politécnica, Universidade de São Paulo, São Paulo, 2002.

SANTOS FILHO, D.J., Aspectos do projeto de sistemas produtivos. Tese de Livre Docência. Escola Politécnica da USP. São Paulo, SP. 2000,

SANTOS FILHO, D. J. ; NAKAMOTO, F. Y. ; JUNQUEIRA, F. ; MIYAGI, P. E. .Task Control of Intelligent Transportation Vehicles in Manufacturing Systems. In: Max Suell Dutra; Omar Lengerke. (Org. ). Mechatronics Series 1: Intelligent Transportation Vehicles. Dubai: Bentham Science Publishers, 2011, v.1, p. 146-169

SHIN, M., MUN, J., and JUNG, M., 2009. Self-evolution Framework of Manufacturing Systems Based on Fractal Organization. Comput. Ind. Eng., 56 (3), 1029-1039.

SUGIMURA, N.; UENO, S.; MISHIMA. N.; HACHIGA, S.; Design and evaluation of a new-type multifunctional machine tool. Transactions of the Japan Society of Mechanical Engineers, Part C, 1996. v.62, n. 595, p. 1133-1138.

TRICAS, F.; COLOM, J.M.; MERELO, J.J.; Computing Minimal Siphons in Petri Net Models of Resource Allocation Systems: An Evolutionary Approach, 308 PNSE'14 Petri Nets and Software Engineering, 2014. p.307-322.

VAN BRUSSEL, H., WYNS,J., VALCKENAER, P., BONGAERTS, L.,Reference architecture for holonic manufacturing systems: PROSA, Computers in industry, 1998, V.37, pp. 255-274.

VILLANI, E.; MIYAGI, P.E.; VALLETTE, R. Advances in Industrial Control: Modeling and analysis of hybrid supervisory systems. Springer-Verlag London. 2007.

VRBA, P. Review of industrial applications of multi-agent technologies; Studies in Computational Intelligence; 2013. v.472. p.327-338.

VRBA, P., MARIK,V, HALL, K.H. STARON,R.J. MATURANA, F.P., KADERA P., Rockwell Automation's Holonic and Multiagent Control Systems Compendium, IEEE Transations on systems, man, and cybernetics - part C: Applications and reviews, 2011, V.41, N1. pp.14-30. 
WYNS,J.; VAN BRUSSEL,H.; VALCKENAERS,P.; BONGAERTS, L. Workstation architecture in holonic manufacturing systems. Proceedings of the 28th CIRP International Seminar on Manufacturing Systems. 1996. p.220-231.

YUE, H; XING, K.; HU, Z.; Robust supervisory control policy for avoiding deadlock in automated manufacturing systems with unreliable resources; International Journal of Production Research, 2014. v.52. n.6, p.1573-1591.

YUSO, U.K.; KHALID,M.N.A; KHADER, A.T.; Artificial immune system for flexible manufacturing system machine loading problem, ICIC Express Letters. 2014. v.8, Issue 3, p.709-716.

ZADEH, A.H.; AFSHARI, H.; KHORSHID-DOUST, R.R.; Integration of process planning and production planning and control in cellular manufacturing, Production Planning Control, 2014, v.25, n.10, p. 840-857. 


\section{ANEXO A}

REDE DE PETRI

FERRAMENTA DE MODELAGEM

(Enhanced Mark Flow Graph) E-MFG

Neste anexo, apresenta-se a técnica de modelagem de sistemas, Enhanced Mark Flow Graph (E-MFG) derivada da rede de Petri. 


\section{FUNDAMENTOS DO MFG}

O MFG (HASEGAWA et al. 1984, MIYAGI, 1996) é uma rede interpretada derivada de redes de Petri (PETERSON,1981; REISIG, 1985) desenvolvida para a modelagem e controle de sistemas. O MFG é composto basicamente pelos seguintes elementos estruturais (vide Figura $A 1$ ):

a) as transições que indicam a ocorrência de eventos;

b) os boxes que representam as pré e pós-condições;

c) os arcos orientados que estabelecem uma relação causal entre os eventos e as condições;

d) as portas que habilitam ou inibem a ocorrência dos eventos e;

e) as marcas que indicam a manutenção de uma condição.

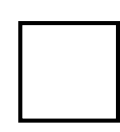

Box

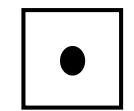

Marca e box

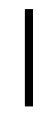

Transição

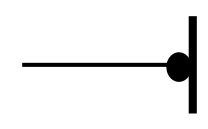

Porta e transição habilitadora

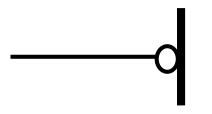

Porta e transição inibidora

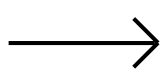

Arco

Figura A1 - Elementos básicos do MFG

No processo de modelagem de um SP, os boxes representam as condições, operações ou tarefas associadas aos dispositivos e as transições representam o início e término de um processo. O comportamento dinâmico do sistema é indicado pela evolução das marcas no grafo, de acordo com uma regra predefinida de disparo das transições e que correspondem ao fluxo de itens (materiais ou informações) no sistema real. 
Para representar a interface do modelo do sistema com o sistema real existem dois elementos estruturais: os arcos de sinal de saída e as portas habilitadoras / inibidoras. No caso das portas, ainda há uma classificação em portas externas ou internas, dependendo da natureza do sinal de origem.

\section{ENHANCED MARK FLOW GRAPH (E-MFG)}

O E-MFG é uma técnica de modelagem que permite a manipulação de marcas individuais com atributos, sendo capaz de modelar e controlar alterações de fluxo (rotas alternativas) das marcas e seleção de tarefas (condições) associadas aos boxes. A estrutura básica do grafo MFG e de seus principais elementos é mantida. A concepção de marcas com atributos fundamenta-se na teoria de 'Tagged MFG' (YOSHIDA 1988). Nesse sentido, procurou-se manter as regras básicas de manipulação dos atributos.

Apresentam-se, a seguir, os elementos estruturais fundamentais do E-MFG e a dinâmica de disparo das transições e atualização da marcação (SANTOS FILHO 2000; SANTOS FILHO; MIYAGI, 1996).

No E-MFG as marcas são acompanhadas por um vetor de atributos que thes garantem individualidade. A esses atributos, podem-se associar diversas informações referentes ao produto, ao processo e ao controle.

$\mathrm{O}$ atributo zero significa a ausência desse atributo.

A Figura A2 representa um exemplo de estrutura de uma marca individual.

A marca possui os atributos a1,a2, a3,a4

Onde: $\mathrm{a} 1$ = processo, $\mathrm{a} 2$ = custo, $\mathrm{a} 3=$ lote, $\mathrm{a} 4$ = máquina

$$
=(\mathrm{a} 1, \mathrm{a} 2, \mathrm{a} 3, \mathrm{a} 4)
$$

Figura A2 - Exemplo de estrutura de uma marca individual 
Manipulação dos atributos das marcas

O problema de manipulação dos atributos associados às marcas pode ser interpretado de duas maneiras. Ou podem ser modificados através de alterações condicionadas, ou através de filtragens seletivas.

A alteração condicionada significa que os estados dos atributos podem ser alterados dependendo do estado presente desses próprios atributos da marca, realizando-se dessa forma a função de atualização do estado do sistema. Essa tarefa é executada por outro box funcional denominado box controlador. Este box é assim denominado porque exerce a função de controlar o estado dos atributos de uma marca, no sentido de atualizar o estado global do sistema a partir da manutenção do estado local representado por cada uma dessas marcas. Regras de produção do tipo 'if...then...' são aplicadas para a verificação e atualização dos atributos previamente especificados.

Outra forma de alterar os atributos de uma marca corresponde à filtragem seletiva. Nesse caso, são estabelecidos os campos correspondentes aos atributos que devem ou não acompanhar a marca, após o disparo de uma transição. Essa especificação é realizada através de inscrições nos arcos orientados. É importante observar que as inscrições não representam restrições para a habilitação da transição que possui esse arco orientado do lado de entrada. Ao invés disso, representa restrições de quais campos de atributo devem ou não ser transmitidos. $A$ Figura A4 representa a atuação do procedimento filtragem seletiva. A inscrição variável a1 sobre $o$ arco de entrada da transição $t 1$ determina que apenas $o$ atributo correspondente ao primeiro elemento do vetor de atributos que acompanha a marca individual deve ser mantido, enquanto os demais não são transmitidos.

Dinâmica das regras de disparo 
A dinâmica de disparo de uma transição é estabelecida por regras de decisão segundo uma determinada hierarquia - a exemplo do que ocorre em $\phi$-nets (FUJI ELETRIC 1989), que estabelece três níveis hierárquicos de decisão.

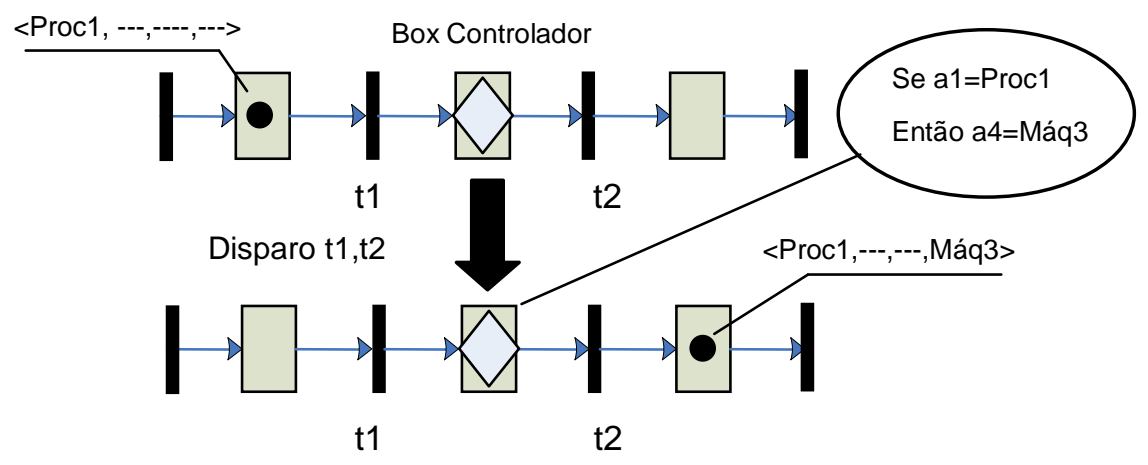

Figura A3 - Representação de um box controlador alterando o estado de uma marca individual

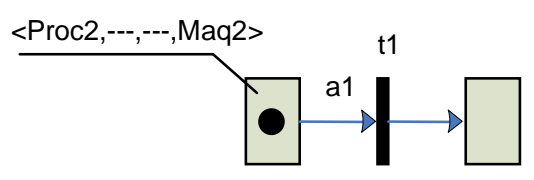

Disparo t1

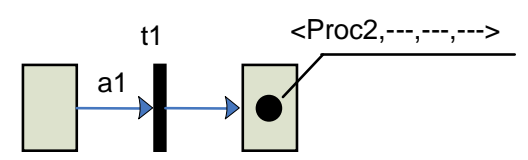

Figura A4 - Representação de um procedimento de filtragem seletiva

O primeiro nível corresponde às regras de restrições adicionais de disparo que são regras do tipo 'se-então' de sistemas de produção, necessárias para a representação de estratégias de controle específicas. A especificação dessas regras é realizada através de inscrições nas transições. Se não houver inscrições em uma transição, não há regras adicionais que limitem o seu disparo. Uma transição que satisfaz as regras de restrições adicionais é denominada transição em prontidão. 
O segundo nível corresponde às regras de habilitação de disparo. Uma transição é denominada transição habilitada se for uma transição em prontidão que satisfaz as seguintes condições:

a) Não existe box no lado de saída com marcas;

b) Não existe box no lado de entrada sem marcas ou com marcas com restrições;

c) Não existe porta habilitadora (interna ou externa) que esteja no estado de desabilitação;

d) Não existe porta inibidora (interna ou externa) que esteja no estado de inibição.

O terceiro e último nível corresponde às regras de realização de disparo propriamente ditas. Essas regras correspondem à verificação das regras de arbitragem em situações que envolvem conflito e a verificação das regras de filtragem seletiva dos atributos, de acordo com as inscrições nos arcos orientados. Uma transição habilitada que atende às regras de realização de disparo denominase transição deparável.

Uma transição deparável dispara imediatamente, fazendo que as marcas fluam pelo grafo e descrevendo o comportamento dinâmico do sistema, a exemplo do que já se realizava no MFG. A Figura A5 ilustra um grafo E-MFG antes da ocorrência do disparo da transição t1, e os respectivos atributos nas marcas.

$\mathrm{t} 1$

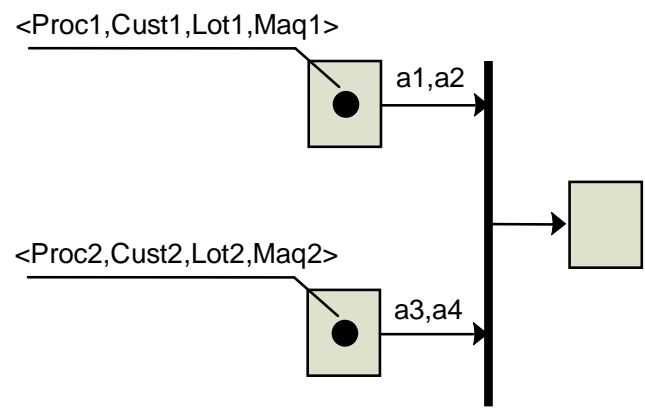

Figura A5 - Ilustra as marcas com os respectivos atributos 
Disparo t1

t1

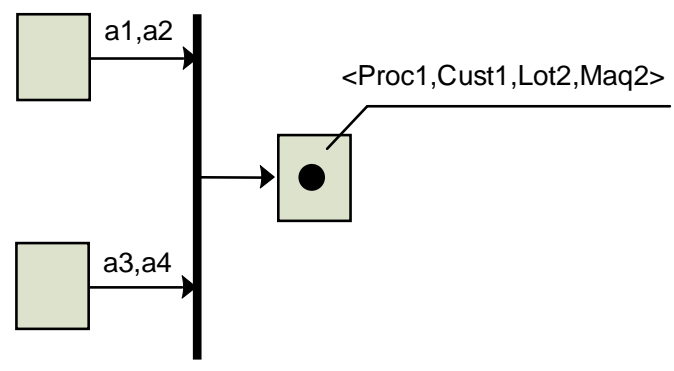

Figura A6 - Alteração dos atributos das marcas decorrentes do disparo

A Figura A6, ilustra a marca após o disparo da transição t1 com os respectivos atributos.

Interface de recepção e transmissão E-MFG com comunicadores

Em sistemas distribuídos, as técnicas de modelagem são fundamentais para análise e caracterização da interação entre as partes. MATSUSAKI (2006) introduziu assim elementos adequados de comunicação ao E-MFG para modelar as mensagens em um ambiente distribuído. O E-MFG com comunicadores mantém as marcas individualizadas dos elementos estruturais originais, adicionam-se os elementos de interface de transmissão e interface de recepção (NAKAMOTO, 2008).

A interface de transmissão envia mensagens assíncronas quando o box a ela conectada estiver marcado. A interface de transmissão de mensagem corresponde ao método "call" de outro objeto baseado no paradigma de orientação a objeto. Essa modela a emissão de mensagem para outros sistemas e é formada pela transição de envio de sinal e pelo arco de envio de sinal, ilustrado na Figura A7.

As interfaces de transmissão e de recepção de mensagens realizam o tráfego das informações. 
A captura e o processamento de mensagens vindos de outras partes é formada pelo box de recepção e pelo arco de recepção, ilustrado na Figura A8.

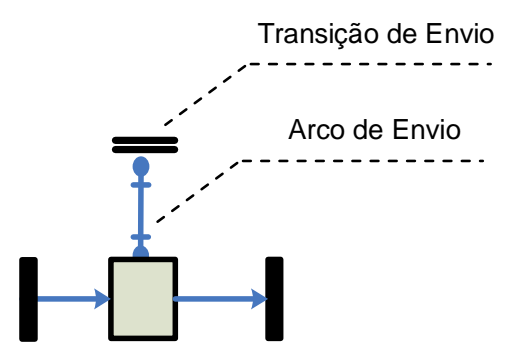

Figura A7 - Interface de transmissão

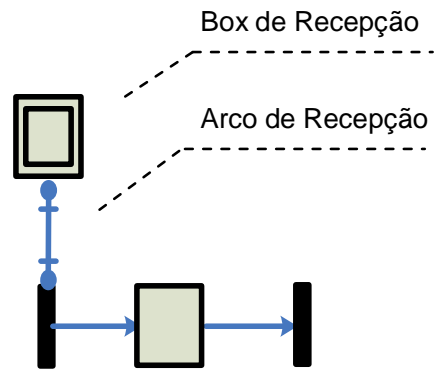

Figura A8 - interface de recepção 


\section{ANEXO B}

\section{ALGORITMO COLÔNIA DE FORMIGA}

Neste anexo apresenta-se o algoritmo utilizado para designação de recurso. 


\section{ALGORITMO COLÔNIA DE FORMIGA}

No sistema produtivo quando ocorre um evento imprevisto em um determinado recurso, como por exemplo, a quebra de máquina, o sistema de alocação dinâmica de recurso trabalha em busca de encontrar outro recurso, e a complexidade computacional do algoritmo utilizado deve ser considerada para que o sucesso da alocação de recurso seja capaz de executar em tempo real.

Em uma fábrica onde há vários produtos para serem produzidos, há vários processos que envolvem conjuntos diferentes de funcionalidades, isto é, os processos são compostos por um conjunto de atividades a serem realizadas até se chegar ao produto final.

Apresenta-se um algoritmo de tomada de decisões que utiliza a heurística derivada da observação do comportamento de formigas (DORIGO,M.; MANIEZZO,V.; COLORNI,A.;1991). Para melhor compreensão desse algoritmo apresenta-se primeiro uma visão de um sistema de formigas (Ant System).
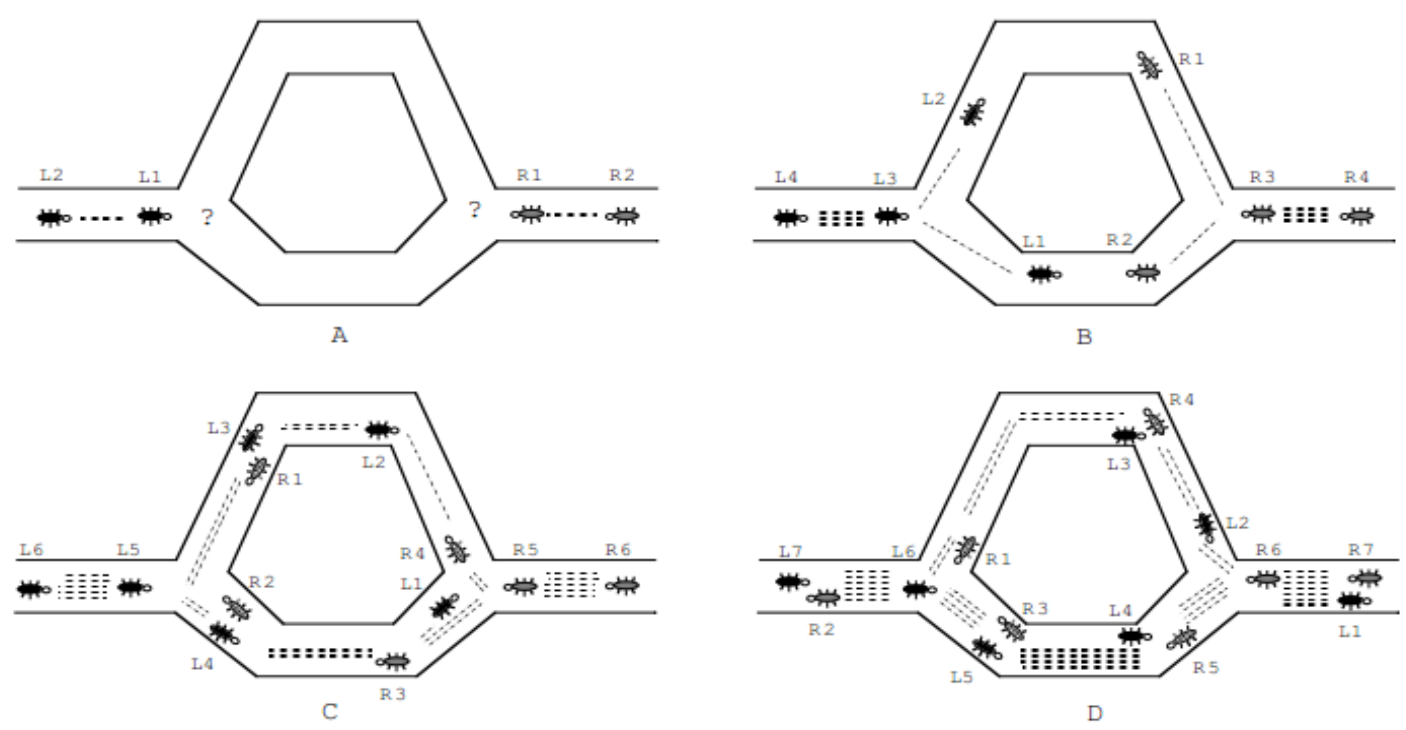

Figura B1 - Representação do caminho das formigas (DORIGO, 1991). 
Na figura B1 (A), ilustram-se as formigas chegando a um ponto de decisão, isto é, se prosseguem no caminho superior ou inferior. Na figura $B 1(B)$, as primeiras formigas escolhem seus caminhos de modo aleatório; na figura B1 (C), considerando que formigas andam a uma velocidade constante, as formigas que escolheram 0 caminho inferior alcançam o objetivo mais rapidamente e retornam para buscar mais alimento. Na figura B1 (D), o feromônio (secretado pelas formigas) acumula-se mais rapidamente no caminho inferior devido o maior número de formigas que transita por ele. Dessa forma, outras formigas que chegarem esse ponto decidem pelo caminho inferior devido ao maior acúmulo de feromônio que sinaliza que este é o caminho indicado. $O$ feromônio é representado na Figura B1 pelas linhas tracejadas. (Adaptado de DORIGO, M.; GAMBARDELLA, L. M. 1997).

\section{Sistema de Formigas (Ant System)}

Esse algoritmo foi o primeiro inspirado no comportamento real das formigas, que procuram o menor caminho da fonte do alimento para o formigueiro. As formigas utilizam a deposição de feromônio (substância química secretado pelas formigas) ao longo do caminho por onde passam, formando trilhas de feromônios que demarcam um caminho. Ao se depararem com várias trilhas de feromônios, elas (as formigas), através do olfato, escolhem a trilha com maior quantidade de feromônio depositado. Caso seja a primeira vez que a formiga passa por esse ponto, a decisão é feita de forma aleatória. Como o feromônio é depositado a cada passagem de cada formiga e a velocidade de locomoção das formigas é praticamente constante, o menor caminho entre a fonte de alimento e o formigueiro vai apresentando cada vez mais feromônio, assim atraindo mais formigas para a trilha em questão, até que todas as formigas usem esse caminho, garantindo que o menor caminho seja utilizado. Como o feromônio é uma substância volátil que ao longo do tempo evapora, trilhas pouco utilizada são apagadas. 
A escolha do caminho é feita com base na probabilidade $p(r, s)$, [onde $r$ : ponto de origem e s: ponto de destino] que pondera a informação heurística e informação vinda do feromônio (DORIGO,M.; MANIEZZO,V.; COLORNI,A.,1991).

A probabilidade de a formiga percorrer um caminho $(r, s)$. (Onde $r$ é origem e $s$ é o destino) corresponde à razão entre o caminho $(r, s)$ e a somatória de todos os caminhos $(r, u)$ que pertencem à vizinhança conforme equação (1).

$$
P(r, s)=\frac{[T(r, s)]^{\alpha} \cdot[\rho(r, s)]^{\beta}}{\sum u[T(r, s)]^{\alpha} \cdot[\rho(r, s)]^{\beta}}
$$

$P(r, s)=$ onde:

- $T(r, s)$ é a quantidade de feromônio do caminho (do ponto $r$ até o ponto $s$ ).

- Os parâmetros $\alpha$ e $\beta$ (ambos entre 0 e 1) são valores empíricos.

- $\rho(r, s)$ é uma função heurística que associa valor ao componente.

Seguindo com a analogia biológica, há também a deposição de feromônio, chamada de Regra de Atualização Global do Feromônio. Após todas as formigas terem feito seus caminhos, aplica-se essa regra, que utiliza a seguinte fórmula:

$$
T(r, s)=(1-T) \cdot T(r, s)+X(r, s)
$$

Onde: T é um parâmetro (entre 0 e 1) que retira a quantidade de feromônio simulando a evaporação do mesmo. 


$$
X(r, s)=\left\{\begin{array}{l}
1 / D_{k}, \text { se }(r, s) \in \text { caminho da formiga de número } k \\
0, \text { caso contrário }
\end{array}\right.
$$

O número de ciclos e de formigas também é definido por testes, para se saber quantas "formigas" devem ser usadas, por exemplo. Essa parte será tratada mais adiante.

\section{Sistema de Colônia de Formigas (Ant Colony System - ACS)}

A desvantagem em utilizar o algoritmo AS refere-se ao tempo necessário para encontrar soluções boas ou ótimas para problemas maiores, tornando o processo inviável. Por conta desse problema, desenvolveu-se o ACS (DORIGO,M.; MANIEZZO,V.; COLORNI,A.;1991). O método mantém a mesma linha de raciocínio do AS, porém com modificações para melhorar a eficiência do algoritmo.

A Regra Para Transição de Estado sofre uma modificação, com a inclusão de um teste: é definido um parâmetro q0 (um número entre 0 e 1), e é escolhido um número aleatoriamente (também entre 0 e 1), que vamos chamar de q. Com isso, a Regra de Atualização Global do Feromônio fica da seguinte forma (usando s como o destino final e $r$ como origem):

$\left\{\begin{array}{l}\text { Se } q \leq q o, \text { então } s=\text { arg. } \max _{u}\left\{[\mathrm{~T}(\mathrm{r}, \mathrm{s})]^{\alpha} \cdot[\rho(r, \mathrm{~s})]^{\beta}\right\} \\ \text { Caso contrário, é utilizado o método anterior. }\end{array}\right.$

Com essa inclusão, há um favorecimento para pequenos trechos com uma grande quantidade de feromônio, além de utilizar menos recursos computacionais. 
Em relação à Regra de Atualização Global do Feromônio, a modificação ocorre na definição de $X(r, s)$.

$$
X(r, s)=\left\{\begin{array}{c}
1 / D_{b}, \text { se }(r, s) \in \text { melhor caminho já encontrado } \\
0, \text { caso contrário }
\end{array}\right.
$$

Onde $D b$ é a distância do melhor caminho encontrado, ou seja, o menor caminho.

A regra de atualização do Global Feromônio continua sendo aplicada após todas as formigas de um ciclo terem feito seu caminho. 


\section{ANEXO C}

NORMAS

Neste anexo, apresentam-se informações referentes às normas IEC61131-3, IEC61499, ISA-S95 


\section{NORMA IEC 61131-3}

A padronização dos Controladores Lógicos Programáveis (CLP's) começou entre o final da década de 1970 e o inicio de 1980, Foi iniciada com a comunidade industrial internacional, uma equipe de trabalho atuando na comissão do IEC (International Electro-technical comission) voltado para o propósito de encontrar um padrão. Essa equipe tinha como objetivo analisar o projeto completo de CLP's, tanto o hardware, quanto instalação, testes, documentação, programação e comunicações.

Essa equipe designou oito frentes de trabalho para desenvolver diferentes partes do padrão para uso do CLP's. A primeira parte do padrão foi publicada em 1992 (General Information - conceitos e definições de terminologias básicas). A parte 3, referente às linguagens de programação, foi publicada em 1993; portanto, a partir da Norma IEC 61131-3, tornou-se um padrão global para programação de controle industrial.

Uma interface de programação padrão permite que se desenvolva $\circ$ programa (software) em várias fases do projeto, como, a especificação, implementação, teste, instalação e manutenção.

As linguagens padrão incluem: Lista de Instrução (IL), Diagrama Ladder (LD), Diagrama de blocos de funções (FBD) e Texto Estruturado (ST).

\section{Linguagens de Programação}

Programa Sequential Function Chart (SFC): descreve graficamente o comportamento sequencial de um programa de controle, estrutura a organização decompõe um problema de controle em partes gerenciáveis, mantém-se uma visão global da solução do problema. É formado por um conjunto de steps, ligados a 
blocos de ação e transições. Cada step representa um estado do sistema de controle. A transição está associada com uma condição e, se for verdadeira, desativa o step anterior, e ativa o step posterior. Cada elemento pode ser programado em qualquer linguagem IEC, inclusive o próprio SFC. É possível a implementação de sequências paralelas.

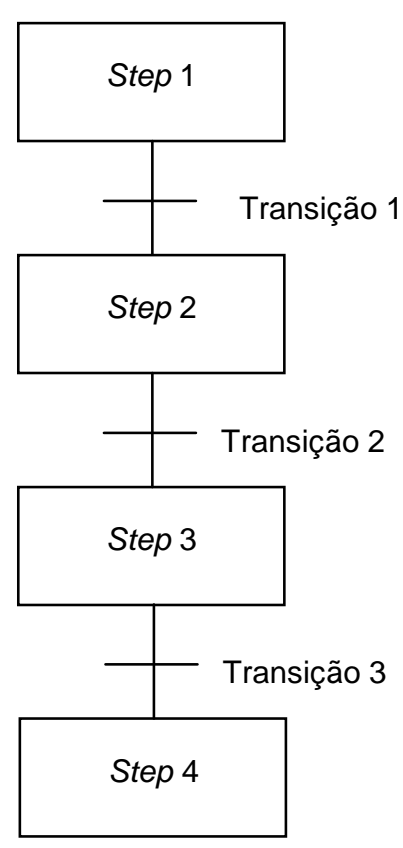

Figura C1 - Exemplo de programa SFC

- Diagrama Ladder (Ladder Diagram - LD)

- Blocos de Função (Function Block Diagram - FBD)

\section{Textuais}

- Lista de Instruções (Instruction List - IL)

- Texto Estruturado (Structured Text - ST)

Lista de Instruções (IL)

\begin{tabular}{|ll|}
\hline LD & A \\
AND & B \\
ST & E \\
\hline
\end{tabular}

Texto Estruturado (ST)

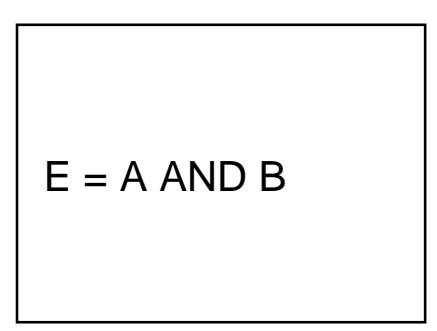


Blocos de Função (FBD)

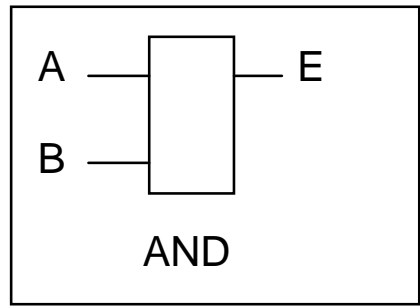

Diagrama Ladder (LD)

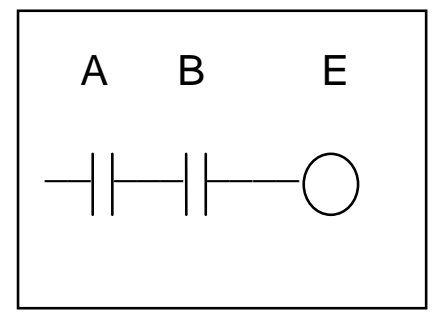

Figura C2 - Exemplos de implementação dos códigos nas linguagens IEC

O diagrama Ladder (LD) possui a representação gráfica baseado na lógica de relés e tem sua origem nos Estados Unidos.

Lista de instruções (IL) possui a linguagem textual e é semelhante ao assemble e tem sua origem na Europa.

Diagrama de blocos (FBD) é uma forma de programar o sistema por meio de um conjunto de blocos gráficos interconectados que representa o fluxo dos sinais entre os elementos de processos.

Texto estruturado (ST) é uma linguagem de programação muito utilizada e pode ser implementada em blocos de funções.

\section{Tipos de dados}

Os dados são do tipo booleano, inteiro, real, byte e word, e string. Baseado nestes tipos, é possível também se definir um tipo de dado próprio, como sendo um canal de entrada analógica.

As variáveis podem ser atribuídas para endereços de entrada e saída do hardware e configurações do programa. Desta forma, as variáveis possuem uma independência 
do hardware, o que possibilita a reutilização. O uso dos nomes das variáveis é normalmente limitado à variavel que foi declarada; e podem, portanto, serem reusadas sem conflito, permitindo que seja uma variável global, ou local.

\section{Configuração, recursos e tarefas}

Para entender melhor esses conceitos, vamos nos referenciar à figura $\mathrm{C} 1$, que mostra o modelo de software proposto pelo padrão IEC 61131-3.

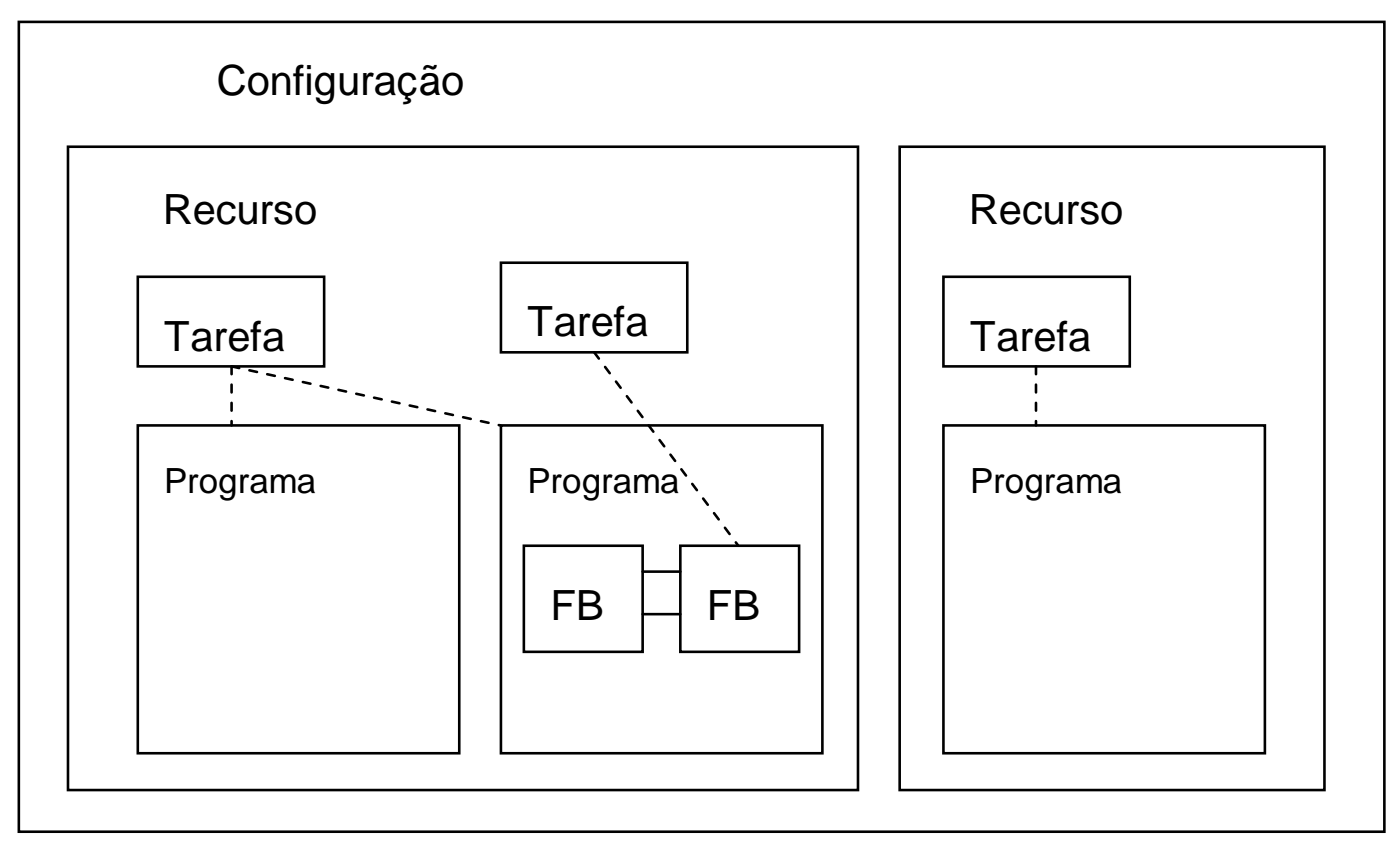

Figura C3 - Modelo de software padrão IEC 61131-3

Configurações: corresponde ao software necessário a um CP ou conjunto de CP's para que esse(s) cumpra $(\mathrm{m})$ suas funções de controle. A configuração define todos os elementos interagentes com suas configurações individuais e uma configuração total dada pelo resultado das diversas configurações.

Recursos: qualquer elemento com capacidade de processamento dentro de uma configuração, capaz de executar programas. O recurso pode existir fisicamente (CPU do processador, interfaces de operação IHM) capaz de executar programas 
baseados no padrão IEC. Para um dado recurso uma ou várias tarefas podem ser definidas.

Tarefas: controlam a execução de um conjunto de programas e/ou blocos de função. Podem ser executadas periodicamente ou na ocorrência de algum evento (trigger), como, por exemplo, a mudança de uma variável para uma região limite.

Programas: construídos a partir de elementos diferentes de software, escritos em linguagem definida pelo padrão IEC.

CLP convencional: contém pelo menos um recurso, executa uma única tarefa, controlando um único programa, executado em malha fechada.

\section{Blocos de funções (Functions blocks diagrams - FBD)}

São equivalentes a circuitos integrados, representando uma função de controle especializada. Contém os dados e algoritmo, o que equivale a dizer que possuem memória passada (o que consiste em uma das diferenças entre uma FBD e uma função). Como um $\mathrm{Cl}$ ou uma caixa preta, eles possuem uma interface bem definida. Permitem separar bem os níveis de programação e manutenção.

Os programas são tipicamente, um programa que consiste em uma rede de funções (functions) e blocos de função (function blocks), que podem trocar dados. Funções e blocos de funções são blocos de construção, básicos, contendo uma estrutura de dados e um algoritmo. 


\section{NORMA}

\section{IEC 61499}

Normas de Sistema de Controle 


\section{NORMA IEC 61499}

A norma IEC 61499 possui aplicação em controladores programáveis em sistemas de controle. Essa norma é uma contribuição para expansão da flexibilidade dos controladores, com a vantagem econômica aos usuários.

Apresentam-se as normas sugeridas pela IEC para geração de algoritmos de controle.

Aplicação dos Blocos Funcionais na modelagem de sistemas produtivos

Segundo a IEC 61499, o bloco funcional, é uma maneira efetiva de realizar a modelagem e criação do algoritmo de controle para sistemas de controle, é distribuído conforme figura C4.

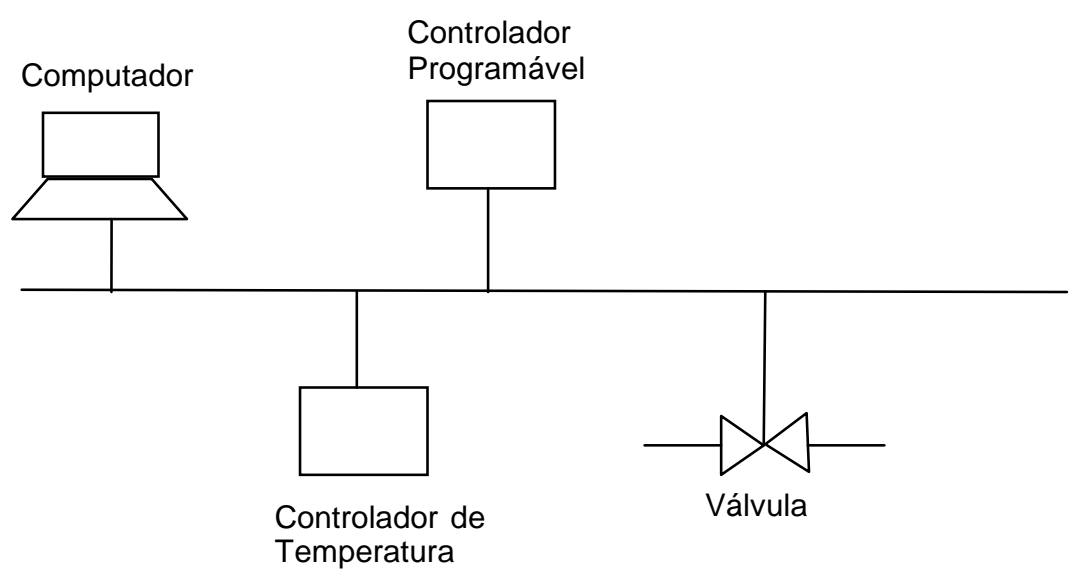

Figura C4 - Exemplo da interconexão dos equipamentos de um sistema de controle distribuído segundo a IEC

A IEC 61499 define sistemas distribuídos de controle como sendo um sistema de processamento de recursos que efetua o controle de um processo através de uma rede de comunicação, contendo, computadores, controladores programáveis, medidores e dispositivos de controle interconectados como no exemplo da figura C4. 


\section{Estrutura básica de um bloco funcional}

Segundo a norma IEC 61499, um bloco funcional básico é constituído de duas partes:

Parte superior: Representa o recebimento e o envio dos sinais de controle do bloco na forma de eventos, em que os sinais de entrada possuem o objetivo de ativar ou desativar o algoritmo do bloco funcional e os sinais de saída do bloco indicam o término de seu processamento.

Parte inferior: representa o algoritmo de controle associado ao bloco funcional, em que esse algoritmo pode ser programado, utilizando-se qualquer uma das linguagens padronizadas pela IEC 61131-3. São recebidos e/ou enviados sinais das variáveis utilizadas no algoritmo do bloco funcional que podem ser gerados e/ou recebidos por outros blocos funcionais situados no mesmo programa ou por elementos externos ao sistema.

A figura C5 apresenta o esquema básico de um bloco funcional padronizado pela IEC 61499.

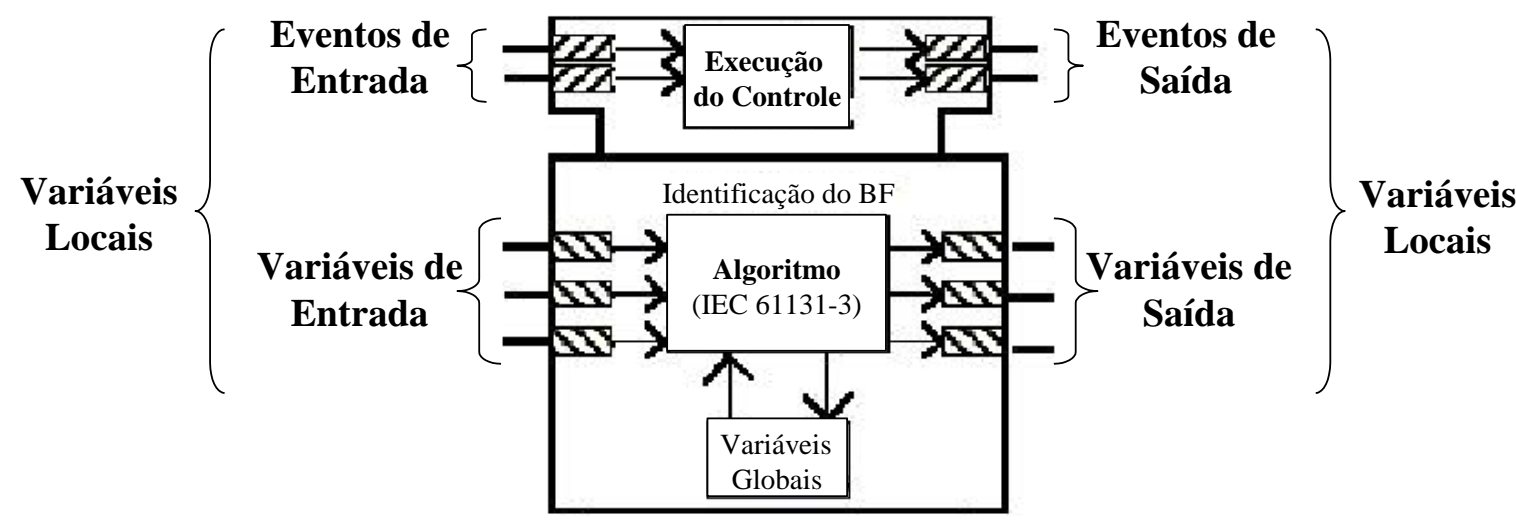

Figura C5 - Esquema básico de um Bloco Funcional padronizado pela IEC 61499 
A norma também permite a composição de blocos funcionais. Isso significa que um bloco funcional pode ser constituído de vários blocos funcionais menores. Os blocos que são criados a partir da composição de outros blocos; são chamados blocos componentes. Portanto, todo o bloco funcional do tipo componente, possui uma estrutura hierárquica. Essa hierarquização pode ser observada na figura C6.

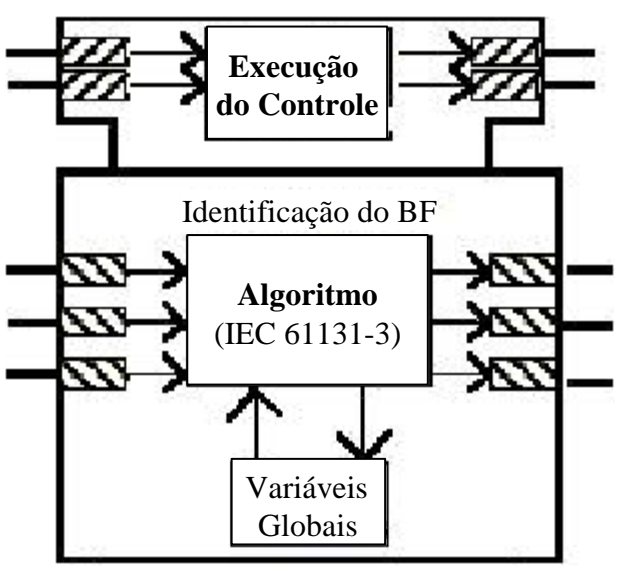

Construção Modular

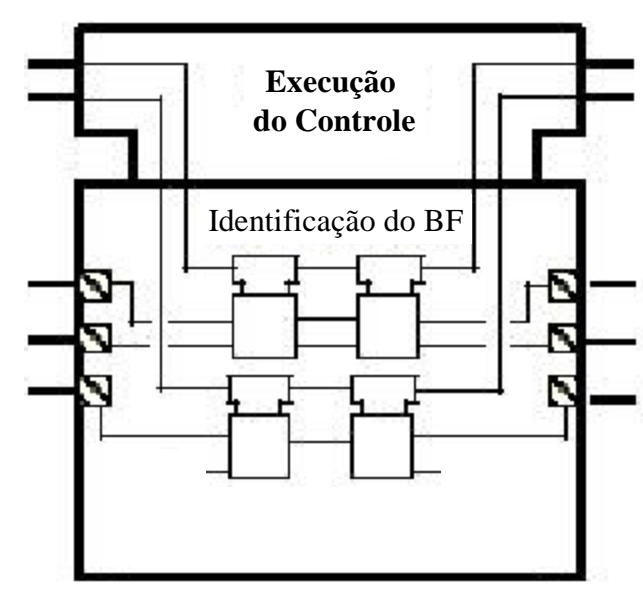

Construção Hierárquica

Figura C6 - Modularização dos Blocos Funcionais (CAVALHEIRO, A.)

Dependendo da necessidade, o bloco funcional pode trocar informações com dispositivos externos ao sistema conectados aos cartões de E/S dos controladores programáveis. As variáveis conectadas a esses cartões são convertidas em variáveis globais internas ao controlador, em que são disponibilizados para o sistema os seus valores possibilitando que qualquer bloco funcional possa processar essa informação.

Os blocos que necessitam trocar informações com dispositivos externos, são nomeados pela norma IEC 61499 como blocos de interface. Assim, o bloco de interface permite que o sistema interaja com os elementos externos fazendo a integração desses elementos com o sistema de controle. 
Esses elementos externos ao sistema podem ser desde dispositivos de atuação, tais como válvulas, motores, etc. até dispositivos de monitoração, tais como monitores, impressoras, etc.

A aplicação do MFG na norma IEC 61499

A diferença básica entre o bloco funcional proposto pela IEC 61131-3 e o bloco funcional proposto pela IEC 61499 é a padronização de como os sinais devem se comportar para que haja troca de informações entre os blocos funcionais, de forma estruturada, ou seja, o protocolo de troca de dados entre os blocos funcionais e a forma como esses blocos funcionais são processados dentro de um programa.

Portanto, o que deve ser utilizado da norma 61499 para que o MFG se adapte a essa, é a forma de como os sinais gerados e recebidos pelo algoritmo de controle devem ser apresentados para que este possa ser considerado como um algoritmo padronizado conforme a norma IEC 61499.

Para efetuar a construção dos modelos MFG estruturados seguindo a norma IEC 61499 , foi proposto o seguinte procedimento:

- Cada evento de entrada, ou seja, o sinal de controle do bloco funcional deve ser conectado à respectiva transição de entrada do algoritmo que se pretende controlar, através de um arco habilitador ou inibidor, e esse arco é nomeado de arco de evento de entrada;

- Cada evento de saída, ou seja, o sinal de término de processamento do algoritmo do bloco funcional gerado pelo box de saída do algoritmo utilizado para fazer o controle de outro bloco funcional, deve ser conectado a uma saída de evento do bloco funcional, através de um arco de sinal de saída, e esse arco é nomeado de arco de evento de saída; 
- Cada variável de entrada do bloco funcional utilizada no processamento do algoritmo designado a este, deve ser conectada à respectiva transição do algoritmo que utiliza esse sinal para efetuar sua lógica de controle, através de um arco habilitador ou inibidor, onde esse arco é nomeado de arco de evento de entrada;

- Cada variável de saída gerada por um box do algoritmo de controle utilizado em outro bloco funcional, deve ser conectado à uma saída de variável do bloco funcional, através de um arco de sinal de saída, onde esse arco é nomeado de arco de variável de saída;

- Cada elemento externo ao sistema que gera um sinal que será utilizado internamente pelo algoritmo de controle do bloco funcional deve ser ligado, diretamente, à respectiva transição do algoritmo de controle através de um arco habilitador ou inibidor, onde esse arco é nomeado de arco de variável externa de entrada.

- Cada elemento externo ao sistema que recebe um sinal gerado internamente pelo algoritmo de controle do bloco funcional, deve ser ligado, diretamente, ao respectivo box do algoritmo de controle através de um arco de sinal de saída, onde esse arco é nomeado de arco de variável externa de saída.

A Figura C7, segundo Cavalheiro (2004) apresenta uma sugestão para a padronização dos módulos MFG. 


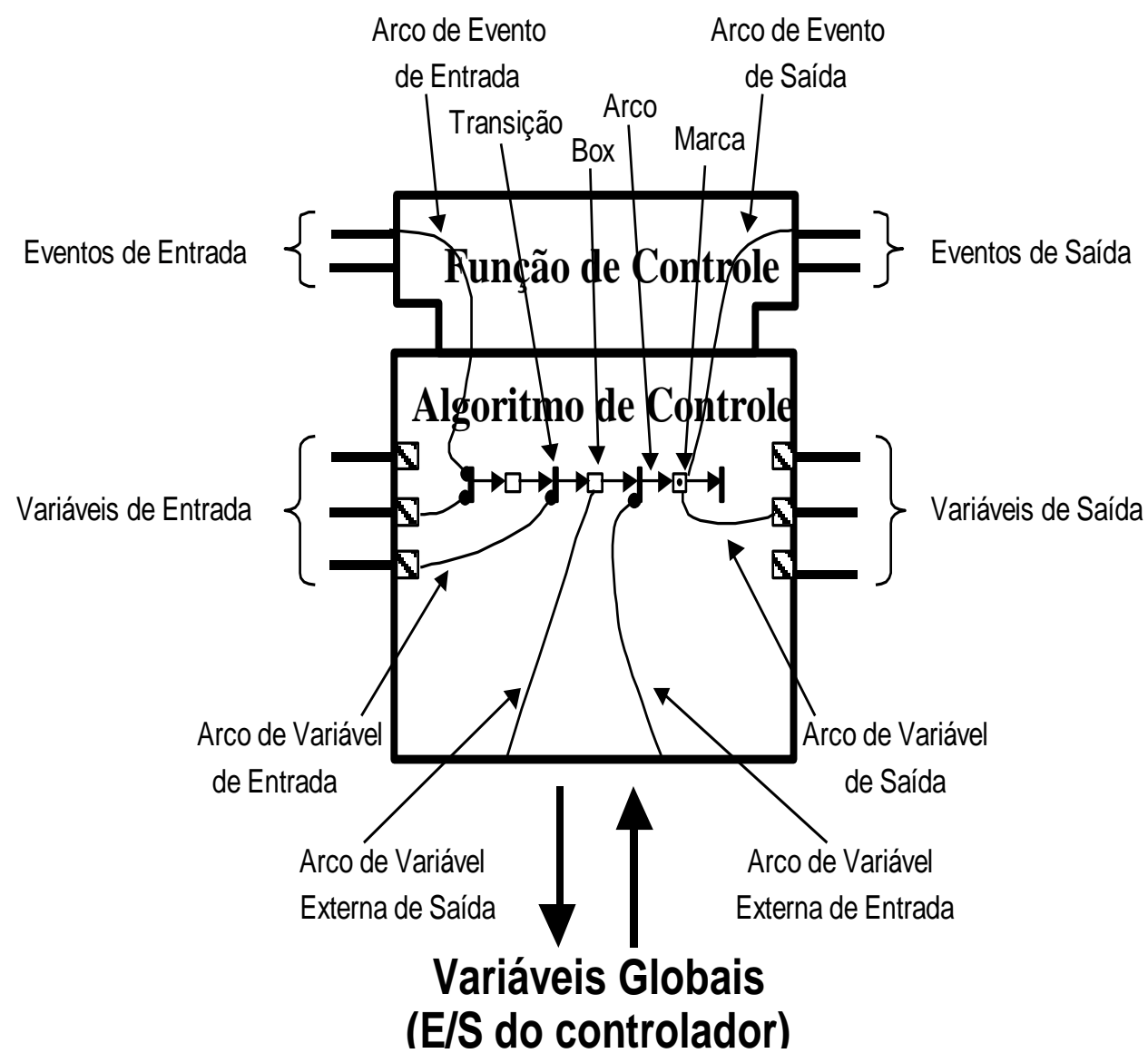

(llustração - Cavalheiro, 2004)

Figura C7 - Exemplo de um bloco funcional utilizando bloco estruturado sequencial do MFG 


\section{NORMA ISA-S95}

American National Standards Institute / International Society of Automation 95 


\section{ANSI/ISA-S95}

A norma ANSI/ISA-S95 (American National Standards Institute / International Society of Automation 95) trata da comunicação entre dados dos sistemas de gestão de negócios e sistema de operações de manufatura. Para que essas interfaces de comunicação sejam mais eficientes alguns pontos importantes são tratados pela Norma ANSI / ISA-S95, como, por exemplo, o uso de uma terminologia padronizada, a padronização de funções ou atividades a serem desempenhadas pelos diferentes sistemas, a distribuição dessas funções numa hierarquia e a padronização das interfaces de troca de dados entre essas funções.

Modelos e Terminologias para as Interfaces de Sistemas de Manufatura

A ANSI/ISA-S95 é uma norma mundialmente aceita, que foi desenvolvida para fornecer terminologias consistentes, as informações e os modelos operacionais são como base para esclarecer a funcionalidade da aplicação e o uso de informação (DOBREV 2008).

De acordo com Dobrev (2008), a norma ANSI/ISA-95 ou simplesmente ISA95 é baseada num conjunto de normas internacionais amplamente utilizadas, e estabelece modelos e terminologia para definir as interfaces entre os sistemas de negócios de uma empresa e seus sistemas de controle de manufatura. Os modelos e terminologias definidos nesse padrão servem para: a) enfatizar as boas práticas de integração dos sistemas de controle com sistemas corporativos durante o ciclo de vida dos sistemas; b) podem ser usados para melhorar as capacidades de integração existentes de sistemas de controle de manufatura com os sistemas corporativos, e c) podem ser aplicadas independentemente do grau de automação. A ISA95 foi desenvolvida para as indústrias de manufatura para ser aplicada em todos os setores industriais e em todos os tipos de processos produtivos, como fabricação em lotes, processos contínuos ou processos repetitivos. 
A ISA95 foi concebida para fornecer os seguintes benefícios:

- Reduzir os tempos que as empresas levam para alcançar níveis de produção plena de novos produtos;

- Habilitar os fornecedores para desenvolver e oferecer ferramentas adequadas para a implementação da integração de sistemas de controle para sistemas corporativos;

- Permitir que as empresas identifiquem melhor suas necessidades;

- Reduzir os custos de automatizar os processos de manufatura;

- Otimizar as cadeias de fornecimento;

- Reduzir os esforços do ciclo de vida de engenharia.

Os modelos são baseados no Modelo de Referência Purdue para Manufatura Integrada por Computador (CIM), no Modelo Funcional internacional da MESA (Manufacturing Enterprise Solutions Association) e, o modelo de hierarquia de equipamento da norma IEC 61512-1 (ANSI/ISA- 88,01-1995). Possuem quatro partes da norma que estão disponíveis: (1) ANSI/ISA-95.00.01-2000, (EnterpriseControl System Integration, Part 1: Models and Terminology), (2) ANSI/ISA-95.00.022001, (Part 2: Object Model Attributes), (3) ANSI/ISA-95.00.03-2005, (Part 3: Activity Models of Manufacturing Operations Management) e (4) ANSI/ISA-95.00.05-2007, (Part 5: Business to Manufacturing Transactions). As Partes 4 (ISA Draft 95.00.04, (Part 4: Object Models and Attributes of Manufacturing Operations Management) e 6 (ISA Draft 95.00.06, (Part 6: Manufacturing Operations Management Transactions)

A ANSI/ISA-S95 parte 1 descreve as funções relevantes da empresa e o domínio de controle e quais objetos são trocados entre esses domínios. A parte 1 trata da interface do nível 4 com o nível 3.

A ISA95 parte 1 e 2 enfocam nas interfaces de produção-para-negócios com base em quatro modelos: (1) modelos de hierarquia funcional, (2) modelo de hierarquia de equipamentos, (3) modelo funcional de fluxo de dados e (4) modelo de objetos. 
O modelo de hierarquia funcional fornece uma estrutura para as atividades de uma empresa de manufatura.

A ISA95 identifica e estabelece um modelo de atividades e fluxos de dados das informações, denominado de diagrama de hierarquia funcional e mostra os diferentes níveis de hierarquia do modelo funcional.

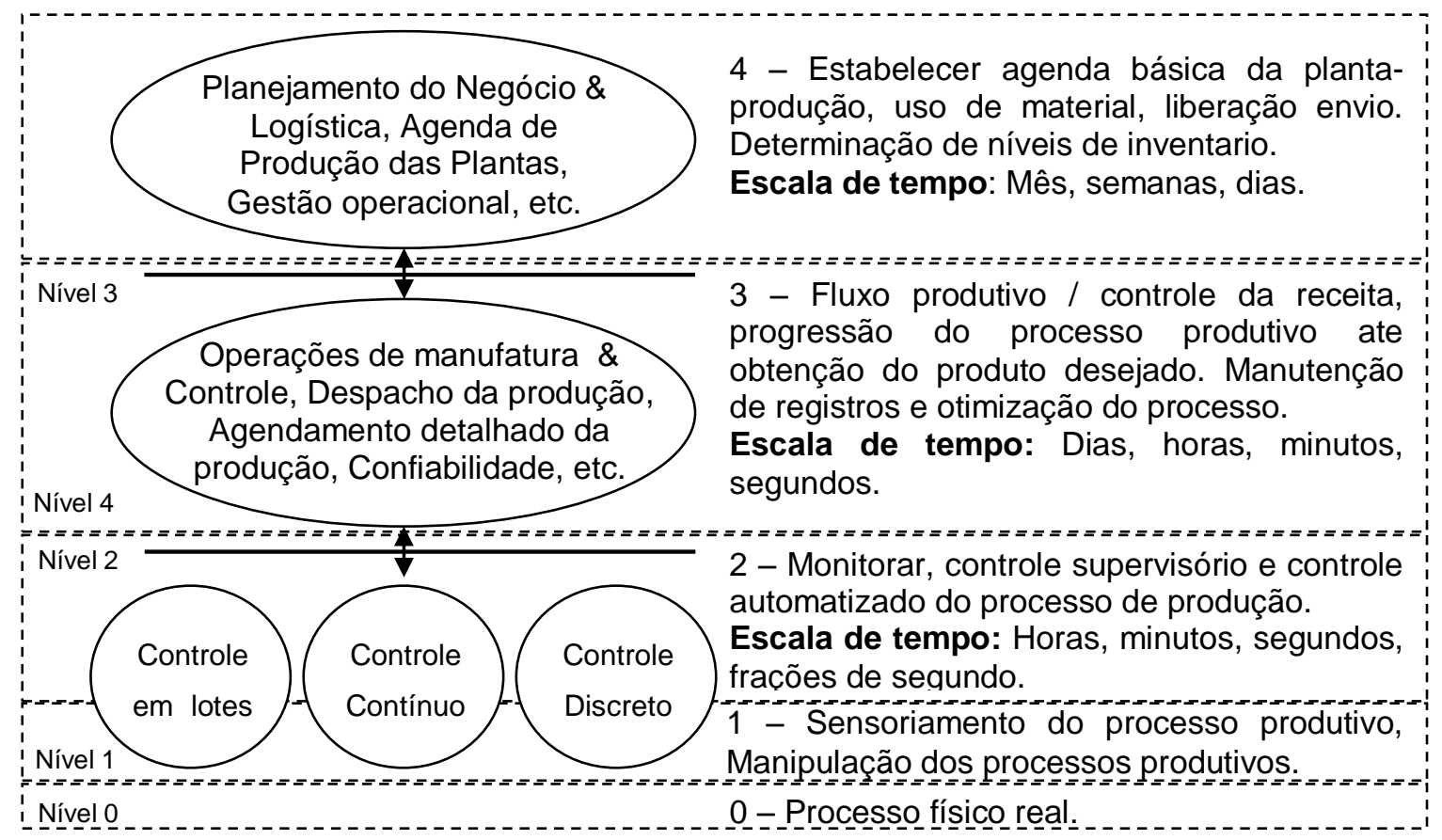

Figura C8 - Diagrama de hierarquia funcional

(Tradução adaptada de AMERICAN NATIONAL STANDARD, 2005)

Cada nível fornece funções especializadas e tem tempos de resposta característicos. A ISA95 nas partes 1 e 2 descreve os modelos de objetos e atributos de objetos das informações que são compartilhadas entre os níveis 3 e 4 da Figura C8 Seus modelos de objeto são representados usando a notação UML (Unified Modeling Language).

A parte 3 define os modelos de atividades do gerenciamento das operações de manufatura que possibilita que o sistema da empresa controle o sistema de integração. O escopo da ISA95, parte 3, é limitado: a) ao modelo das atividades associadas ao gerenciamento de operações de manufatura, funções do nível 3 da 
Figura ISA95, e b) a identificação de alguns dos dados trocados entre as atividades de nível 3 Figura ISA95. O foco da ISA95 parte 5 é a interface entre os sistemas de empresa/negócio e os sistemas de manufatura. Esta parte define a troca de conteúdos entre interfaces através da definição de transações. As transações podem ser utilizadas em relação aos objetos que são trocados entre o nível 4 e nível 3 da Figura ISA95.

Os pontos que nortearam a elaboração da norma foram (NAKAMOTO, 2008):

- Necessidade de identificação das interações envolvidas;

- Necessidade de distinção entre os processos de negócio e os processos de manufatura;

- Necessidade de independência entre os sistemas de negócios e os sistemas de manufatura.

A ISA95 contém os modelos e as terminologias para a definição das interfaces entre o sistema de estratégias de negócio da empresa e o sistema de controle da manufatura. O foco está na redução de riscos operacionais mediante a caracterização do grau de dificuldade de integração e interoperabilidade entre o planejamento e o sistema de controle

Basicamente, o diagrama de hierarquia funcional identifica os seguintes níveis (NAKAMOTO, 2008):

- Nível 0: Corresponde às funções relacionadas com o processo físico real;

- Nível 1: Corresponde às funções relacionadas com as atividades envolvidas na coleta de sinais e manipulação dos processos físicos, operando tipicamente dentro da escala de tempo das grandezas de interesse, ou seja, em segundos ou menos;

- Nível 2: Corresponde às funções relacionadas com as atividades de monitoração e controle local dos processos físicos, operando dentro da escala de tempo da ordem de minutos, segundos ou suas divisões. $O$ 
nível 2 tipicamente trata de um equipamento dentro de um centro de trabalho, conforme a hierarquia proposta pela ISA-S95;

- Nível 3: Corresponde às funções relacionadas com as atividades que realizam a progressão dos processos para gerar os produtos finais. Inclui as atividades de manutenção de registros e coordenação dos processos. O nível 3 opera tipicamente dentro da escala de tempo de dias, turnos, horas, minutos e segundos, sobre áreas de centros de trabalho;

- Nível 4: Corresponde às funções relacionadas com as atividades do negócio necessárias para manter o sistema de manufatura. Entre as atividades relacionadas com a manufatura estão os estabelecimentos do planejamento da produção, determinação de níveis de inventário e garantia de que os materiais são liberados em tempo e no lugar certo para produção. O nível 4 opera tipicamente dentro da escala de tempo de mês, semanas e dias. 


\section{APÊNDICE}

CÓDIGO DE PROGRAMAÇÃO

Neste apêndice, apresenta-se o programa referente ao segundo exemplo de aplicação. 
PROGRAM MainPrg 51

VAR

INA : BOOL;

A1 : BOOL :

$\mathrm{H} 1:$ BOOL

ARC2 : BOOL;

A1_1 : BOOL ;

C1 : CTD ;

$\mathrm{ZZ}: \mathrm{BOOL}$;

BUFFER1 : WORD

LC1 : BOOL;

$\mathrm{H} 2: \mathrm{BOOL}$

ARC4 : BOOL;

$\mathrm{A} 2$ : BOOL;

$\mathrm{H} 3: \mathrm{BOOL}$

ARC6 : BOOL ;

A2_1: BOOL;

$\mathrm{H} 4$ : BOOL;

ARC8 : BOOL ;

A3 : BOOL;

H5 : BOOL;

ARC10 : BOOL ;

A3_1 : BOOL ;

$\mathrm{H} 6$ : BOOL;

H7 : BOOL;

$\mathrm{H} 8$ : BOOL;

ARC16 : BOOL ;

ARC12 : BOOL ;

ARC14 : BOOL ;

A4 : BOOL :

A4_1 : BOOL ;

A5 : BOOL;

ARC15 : BOOL ;

ARC13 : BOOL ;

ARC11 : BOOL ;

ARC9 : BOOL ;

ARC7 : BOOL;

ARC5 : BOOL;

ARC3 : BOOL;

ARC1 : BOOL ;

INB : BOOL;

B1 : BOOL

J1 : BOOL;

ARC17 : BOOL ;

ARC18: BOOL ;

B1_1 : BOOL ;

$\mathrm{J} 2: \mathrm{BOOL}$;

J3 : BOOL ;

J4 : BOOL :

J5 : BOOL ;
J6 : BOOL ;

$\mathrm{J} 7$ : BOOL ;

J8 : BOOL ;

B2 : BOOL ;

B2_1 : BOOL ;

B3 : BOOL ;

ARC24 : BOOL ;

ARC22 : BOOL ;

ARC20 : BOOL ;

$A Z: B O O L$.

BZ: BOOL;

OUTA : BOOL ;

LC2 : BOOL ;

BUFFER2 : WORD ;

ARC19 : BOOL :

ARC21 : BOOL ;

ARC23 : BOOL;

OUTB : BOOL ;

INC : BOOL ;

$C:$ BOOL

C1_1: BOOL ;

C2 : BOOL;

C2_1 : BOOL;

C3 : BOOL :

K1 : BOOL;

ARC26: BOOL ;

K2 : BOOL;

ARC29: BOOL ;

K3 : BOOL ;

ARC30 : BOOL ;

K4 : BOOL;

ARC32 : BOOL ;

C_1 : BOOL;

LC3 : BOOL;

$\mathrm{CZ}: \mathrm{BOOL}$;

OUTC : BOOL;

IND : BOOL;

D1 : BOOL ;

D1_1 : BOOL ;

D2 : BOOL ;

D2_1: BOOL ;

D3 : BOOL ;

L1 : BOOL ;

L2 : BOOL ;

L3 : BOOL;

L4 : BOOL;

ARC34 : BOOL ;

ARC46 : BOOL ;

ARC38 : BOOL

ARC36 : BOOL ; 


\begin{tabular}{|c|c|c|c|}
\hline 101 & ARC40 : BOOL ; & 151 & N6 : BOOL ; \\
\hline 102 & L1_1 : BOOL ; & 152 & N1_1 : BOOL ; \\
\hline 103 & LC4 : BOOL ; & 153 & OUTG : BOOL ; \\
\hline 104 & BUFFER4 : WORD ; & 154 & OUTE : BOOL ; \\
\hline 105 & ARC33 : BOOL ; & 155 & GZ : BOOL ; \\
\hline 106 & OUTD : BOOL ; & 156 & ARC49 : BOOL ; \\
\hline 107 & ARC35 : BOOL ; & 157 & ARC51 : BOOL ; \\
\hline 108 & ARC37 : BOOL ; & 158 & ARC53 : BOOL ; \\
\hline 109 & ARC39 : BOOL ; & 159 & ARC55 : BOOL ; \\
\hline 110 & INE : BOOL ; & 160 & ARC57 : BOOL ; \\
\hline 111 & E1 : BOOL ; & 161 & ARC59 : BOOL ; \\
\hline 112 & E1_1:BOOL ; & 162 & BUFFER6 : WORD \\
\hline 113 & E2: BOOL; & 163 & LC6 : BOOL ; \\
\hline 114 & E2_1:BOOL; & 164 & C111111: CTD ; \\
\hline 115 & E3 : BOOL ; & 165 & ARC54 : BOOL ; \\
\hline 116 & M1 : BOOL; & 166 & ARC56 : BOOL ; \\
\hline 117 & M2 : BOOL; & 167 & ARC58 : BOOL; \\
\hline 118 & M3 : BOOL; & 168 & ARC60 : BOOL ; \\
\hline 119 & M4 : BOOL; & 169 & END_VAR \\
\hline 120 & M1_1: BOOL; & & \\
\hline 121 & LC5 : BOOL ; & & \\
\hline 122 & BUFFER5 : WORD ; & & \\
\hline 123 & ARC42 : BOOL ; & & \\
\hline 124 & ARC44 : BOOL ; & & \\
\hline 125 & ARC48 : BOOL ; & & \\
\hline 126 & C11 : CTD ; & & \\
\hline 127 & C111 : CTD ; & & \\
\hline 128 & C1111 : CTD ; & & \\
\hline 129 & C11111 : CTD ; & & \\
\hline 130 & ARC47 : BOOL ; & & \\
\hline 131 & ARC45 : BOOL; & & \\
\hline 132 & ARC43 : BOOL ; & & \\
\hline 133 & ARC41 : BOOL ; & & \\
\hline 134 & ING : BOOL ; & & \\
\hline 135 & G1 : BOOL ; & & \\
\hline 136 & G1_1:BOOL ; & & \\
\hline 137 & G2: BOOL; & & \\
\hline 138 & G2_1: BOOL ; & & \\
\hline 139 & G3 : BOOL ; & & \\
\hline 140 & M5 : BOOL; & & \\
\hline 141 & M6 : BOOL; & & \\
\hline 142 & ARC50 : BOOL ; & & \\
\hline 143 & ARC52 : BOOL; & & \\
\hline 144 & G3_1:BOOL ; & & \\
\hline 145 & G4: BOOL; & & \\
\hline 146 & N1: BOOL; & & \\
\hline 147 & N2 : BOOL; & & \\
\hline 148 & N3 : BOOL; & & \\
\hline 149 & N4 : BOOL; & & \\
\hline 150 & N5 : BOOL; & & \\
\hline
\end{tabular}




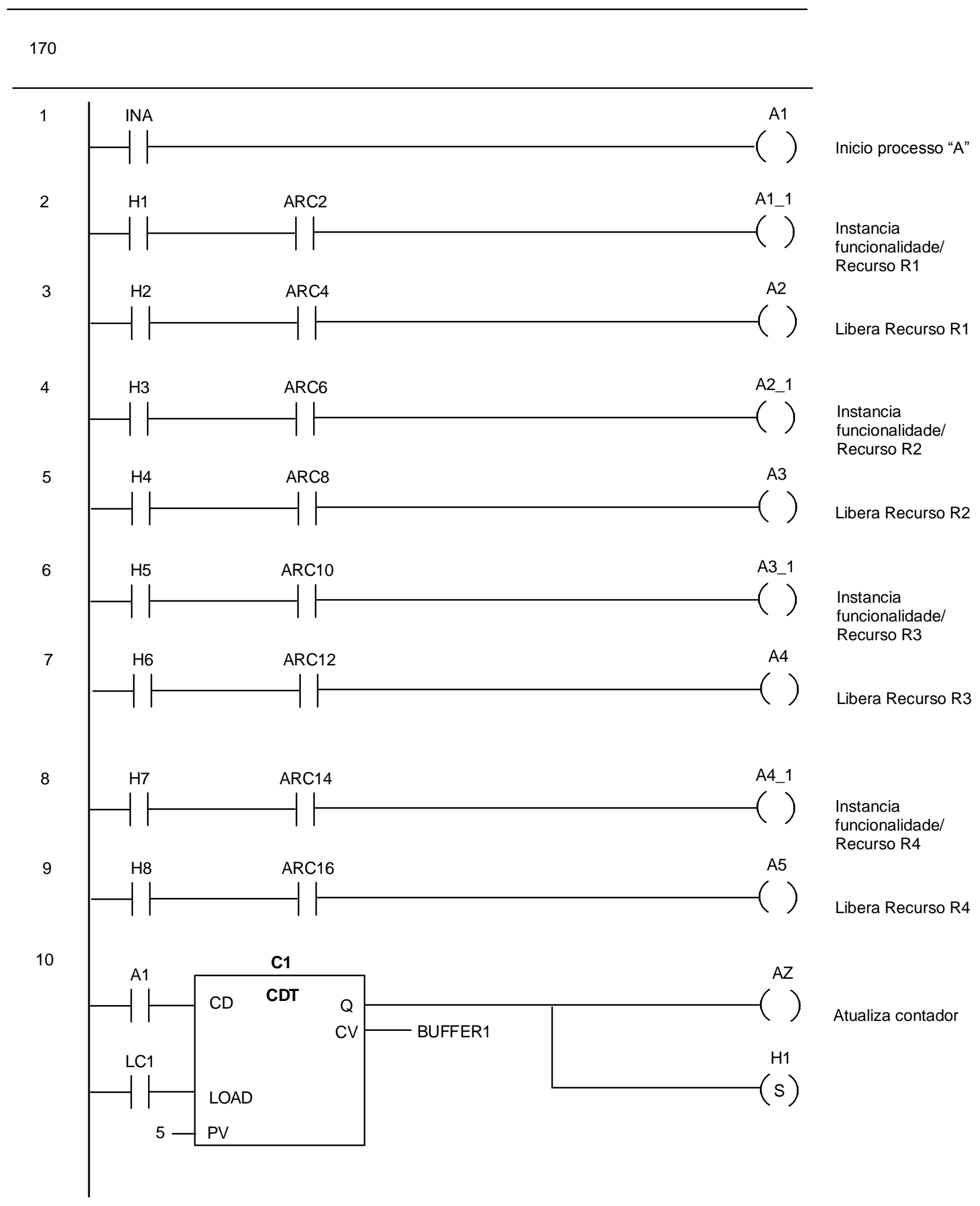




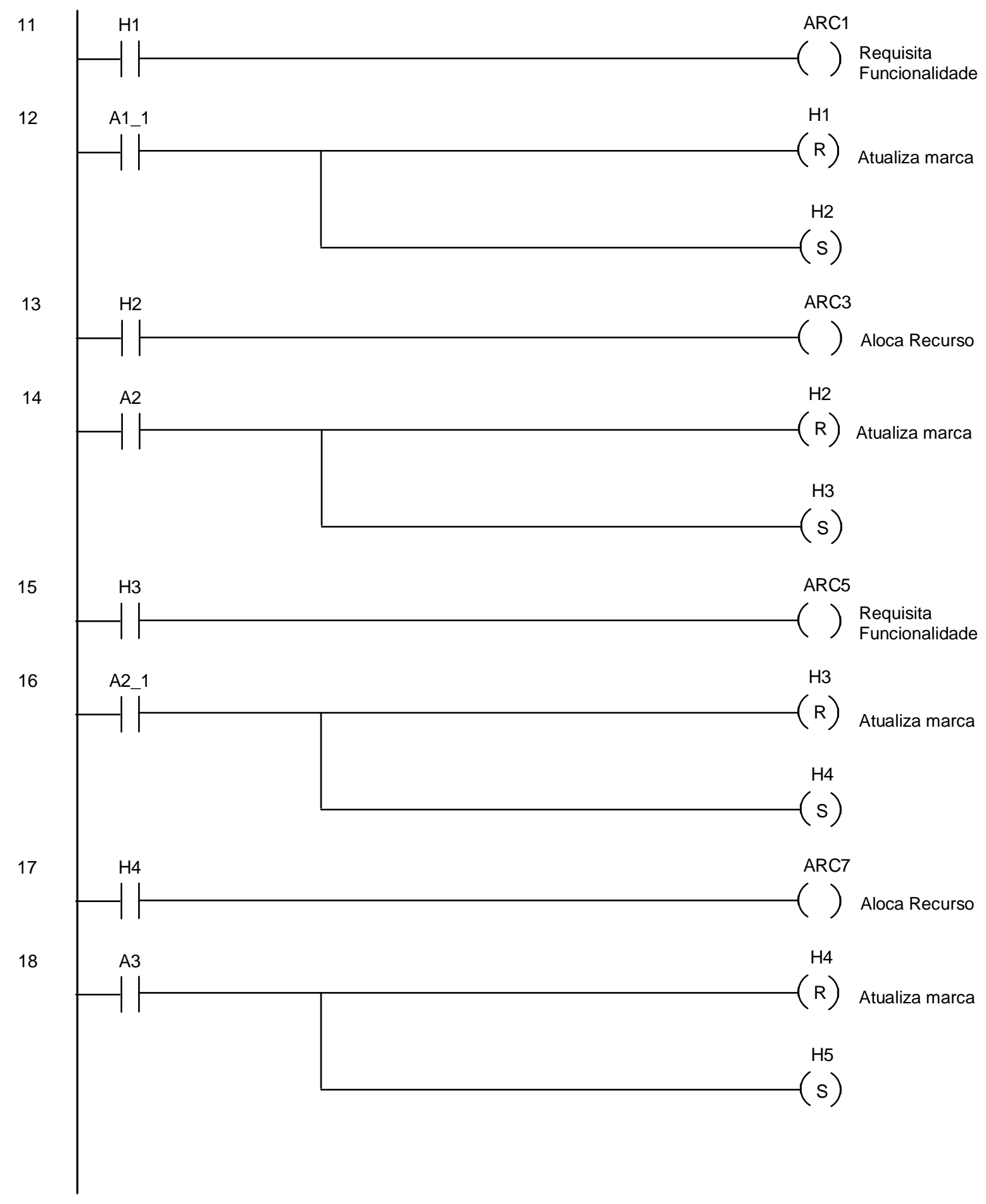




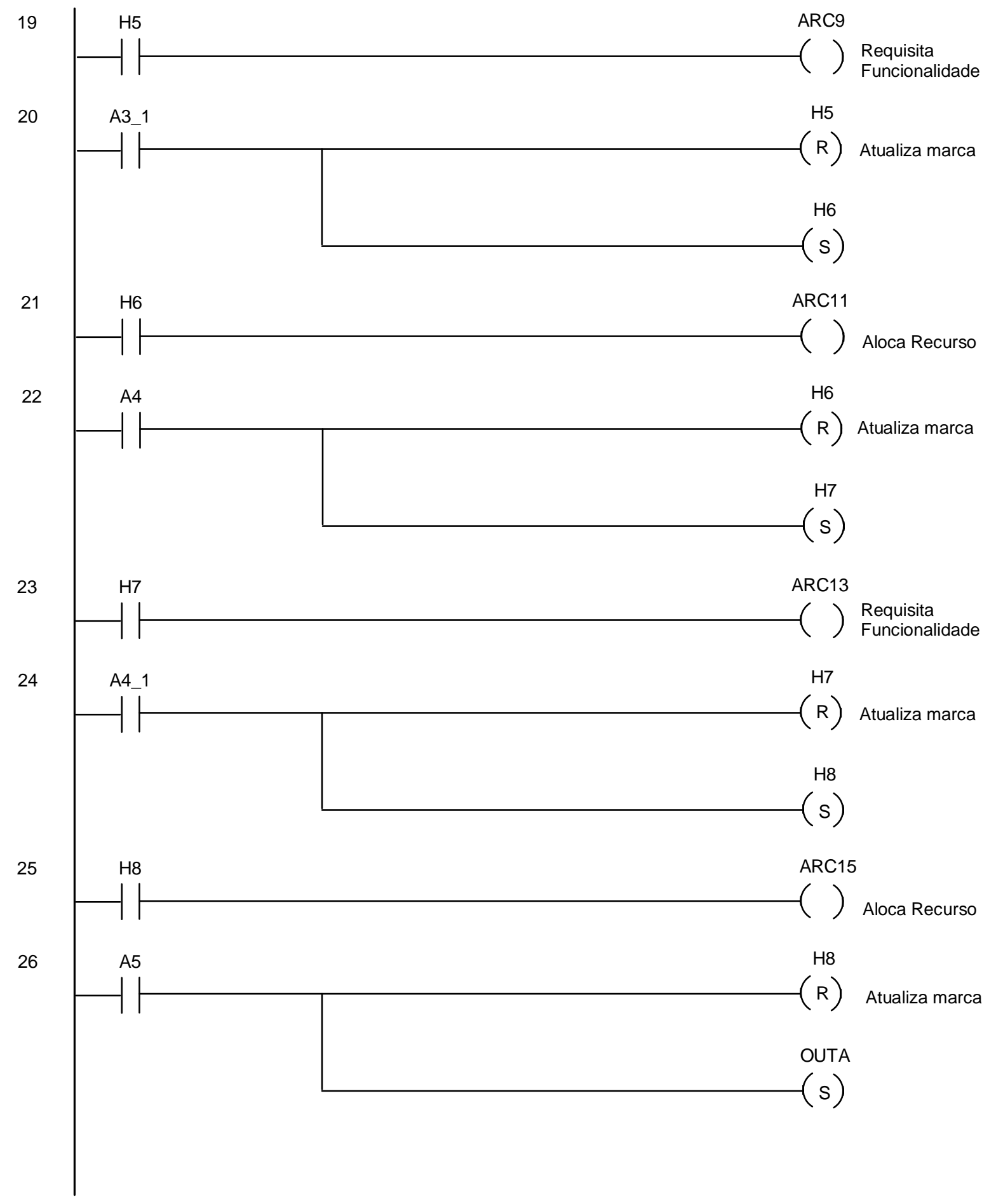




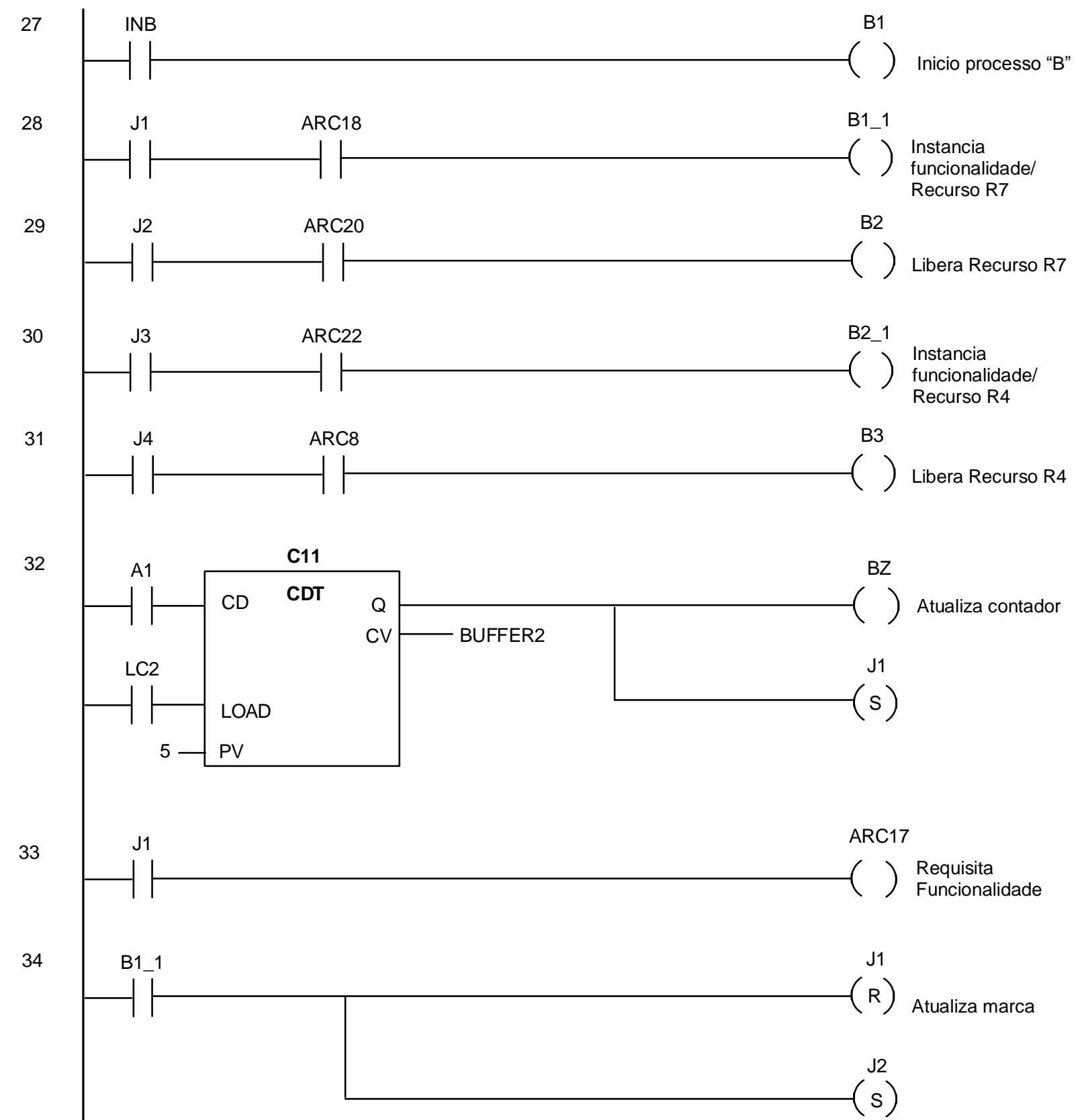




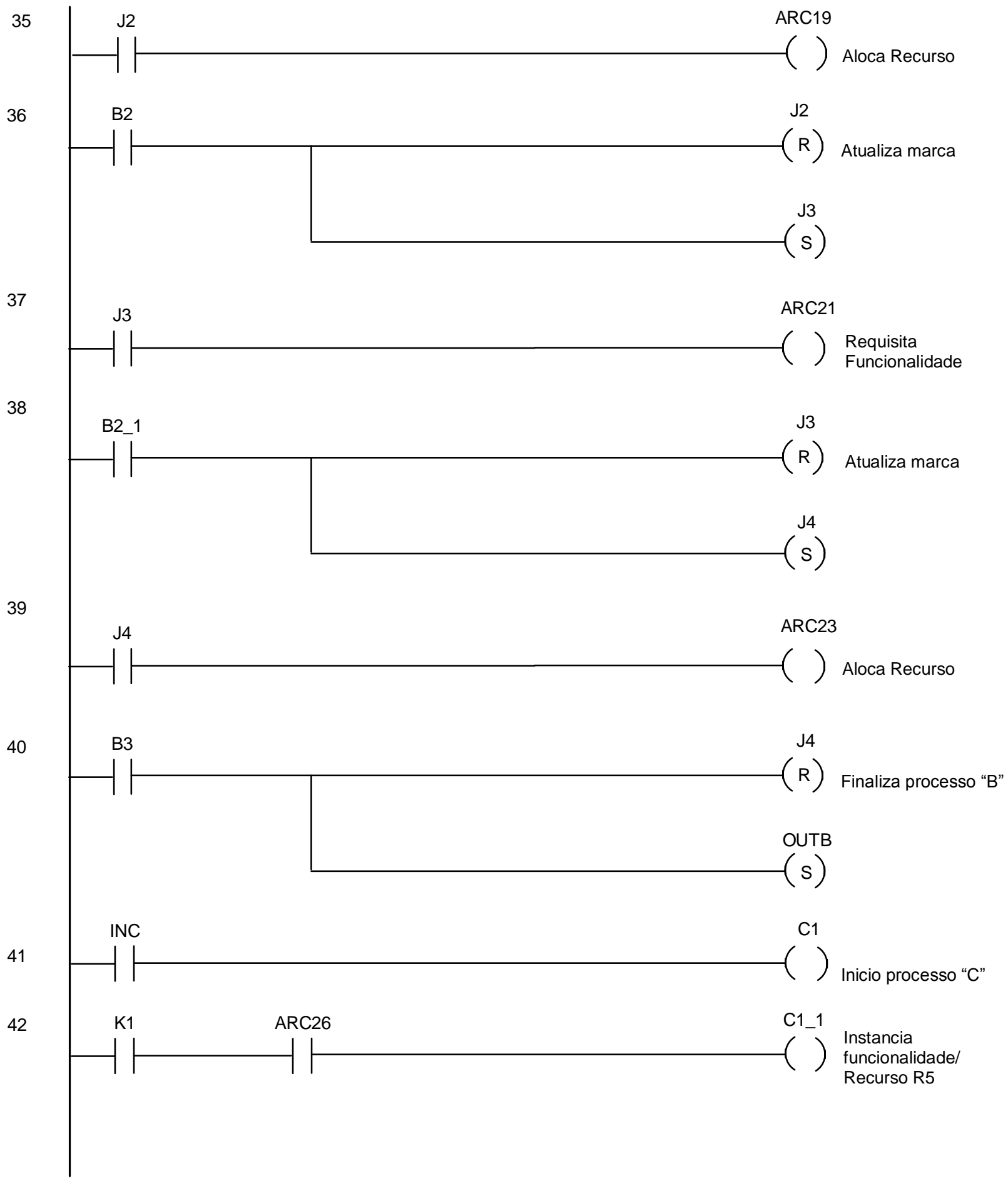




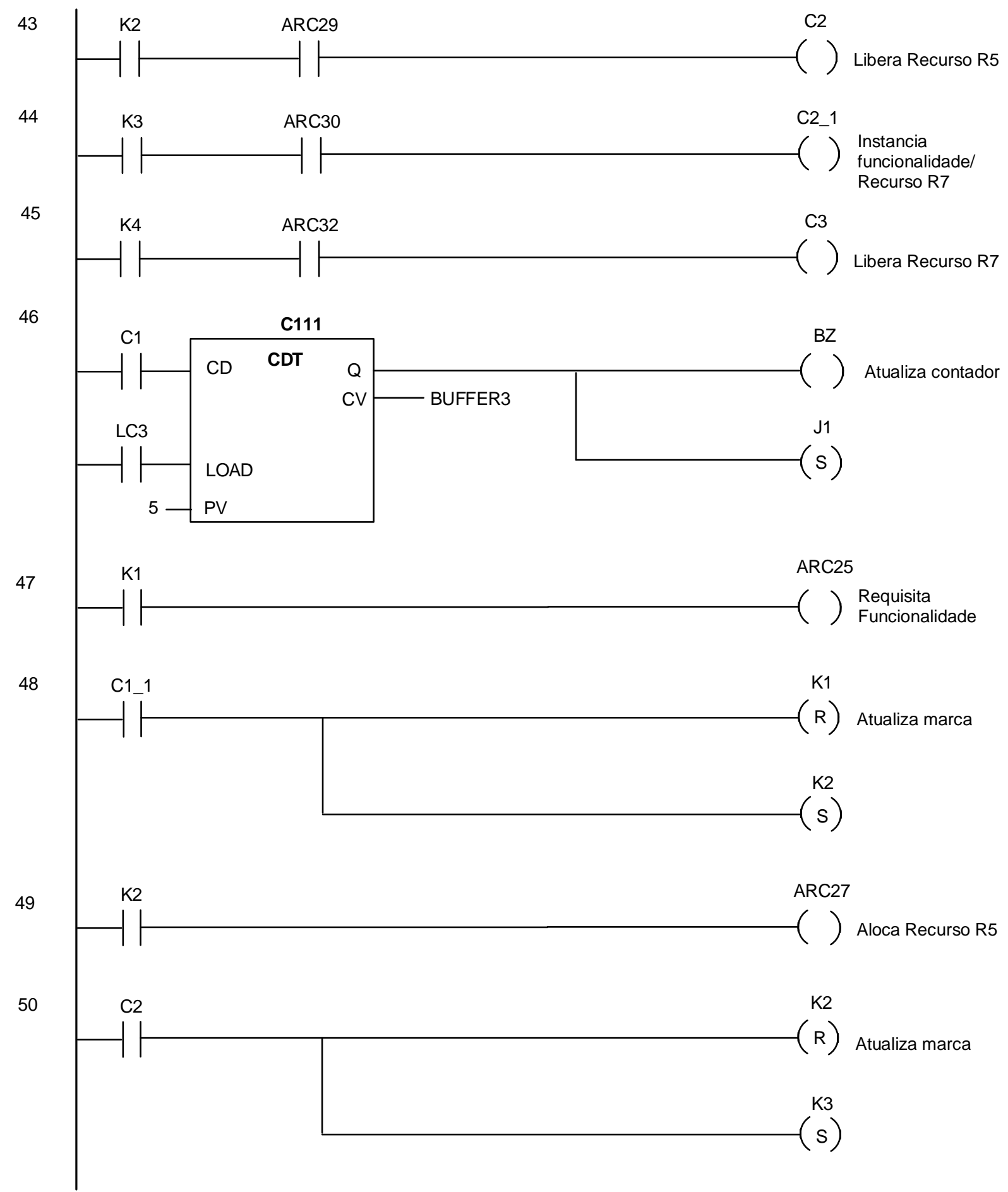




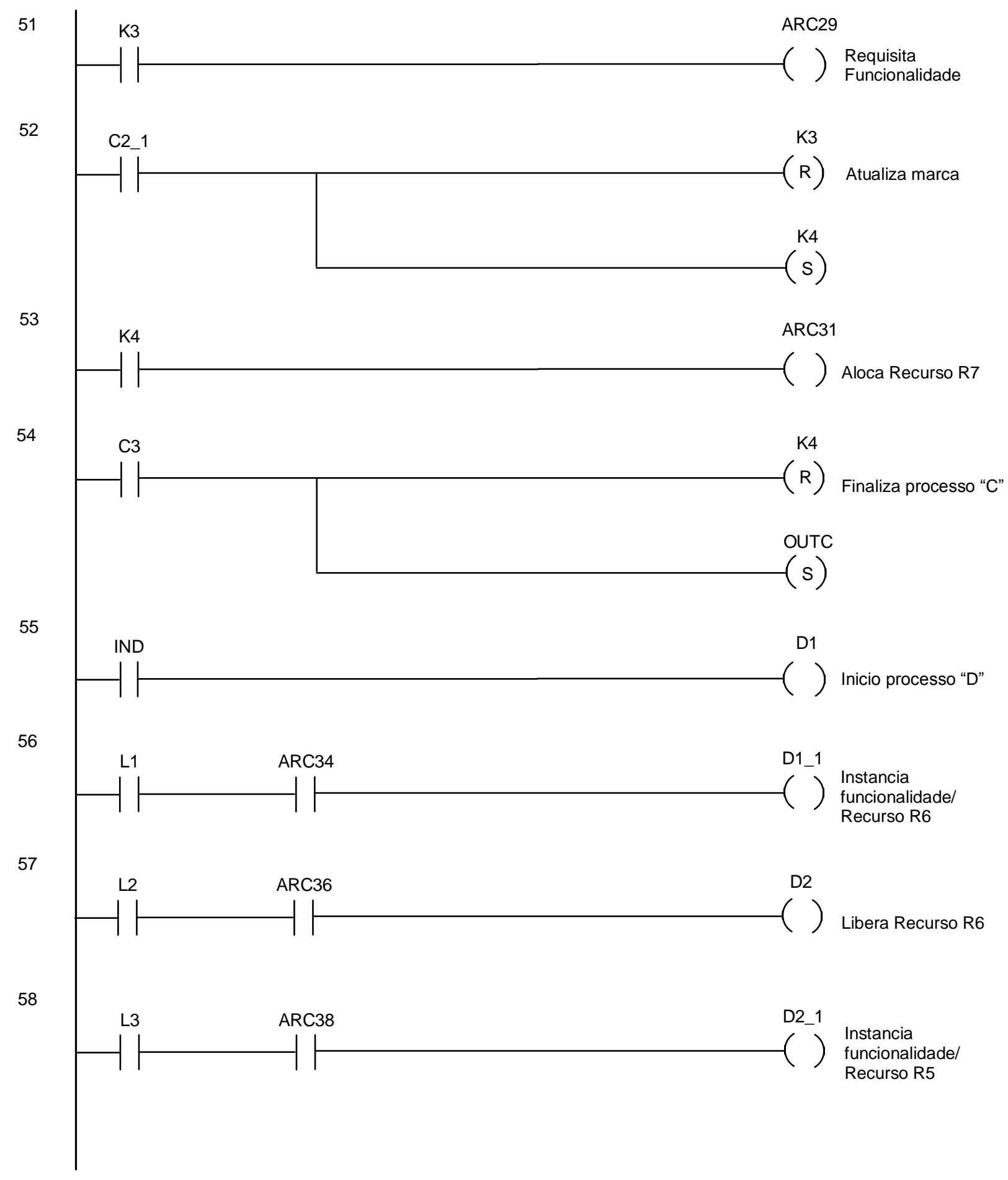




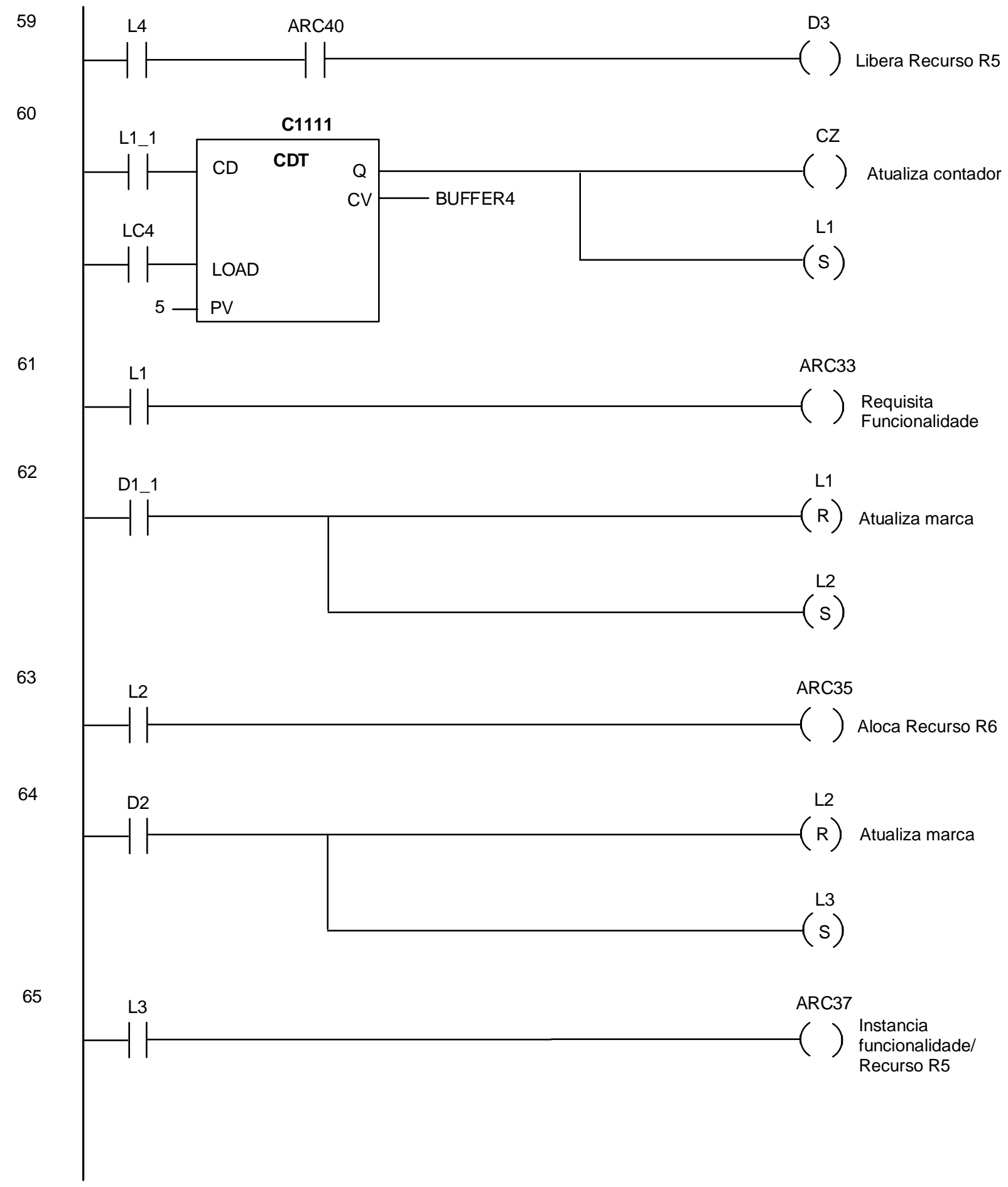




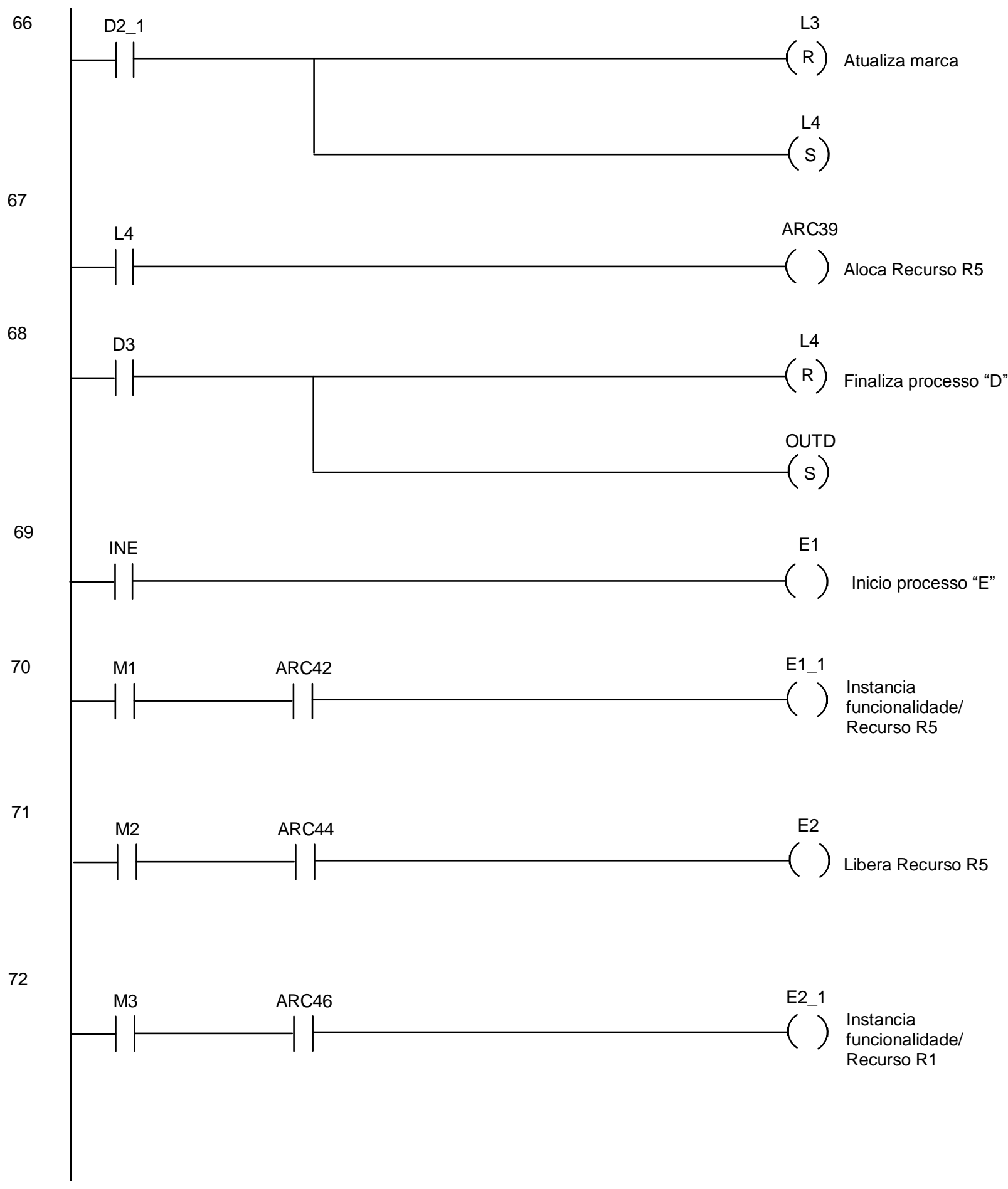




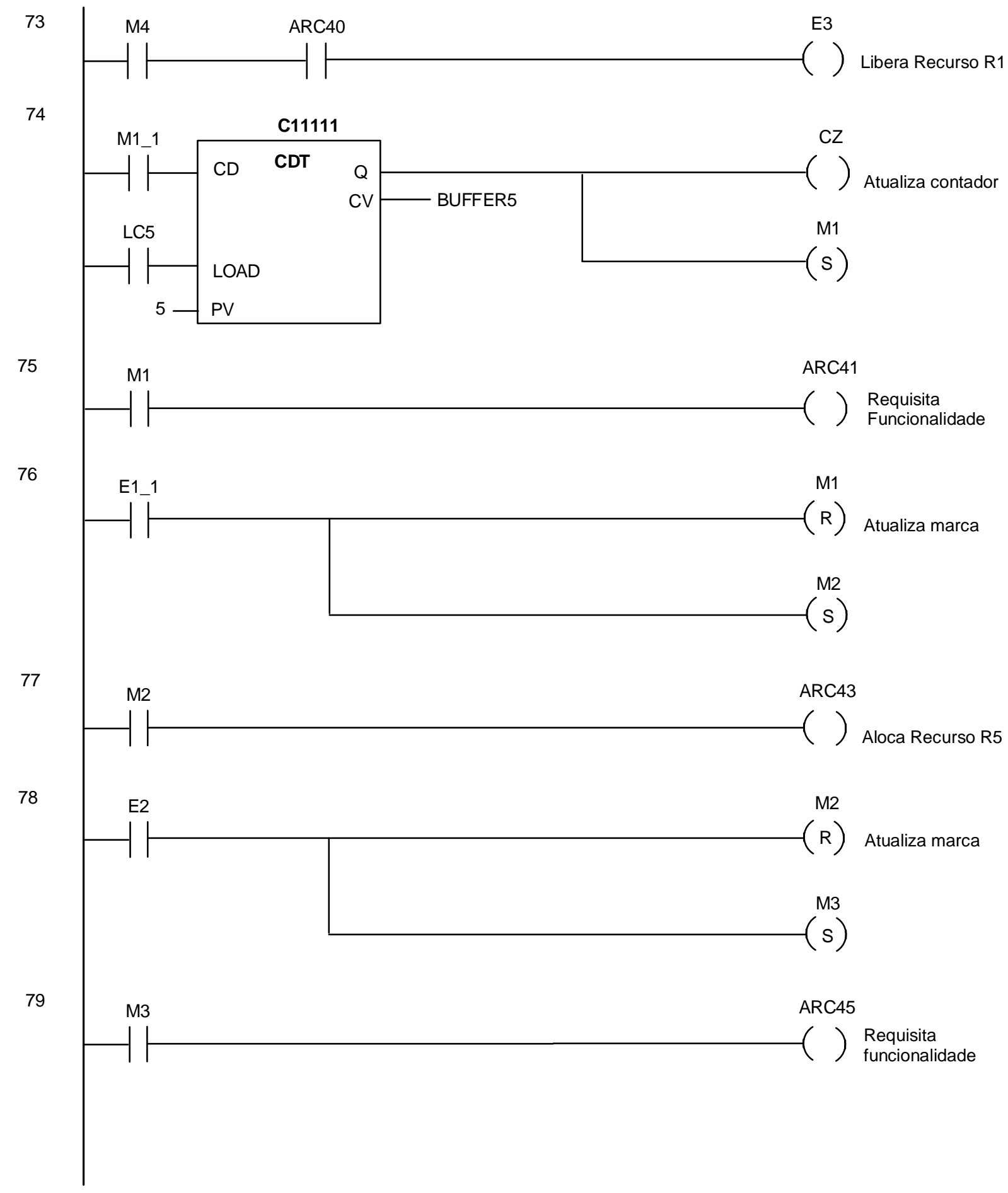




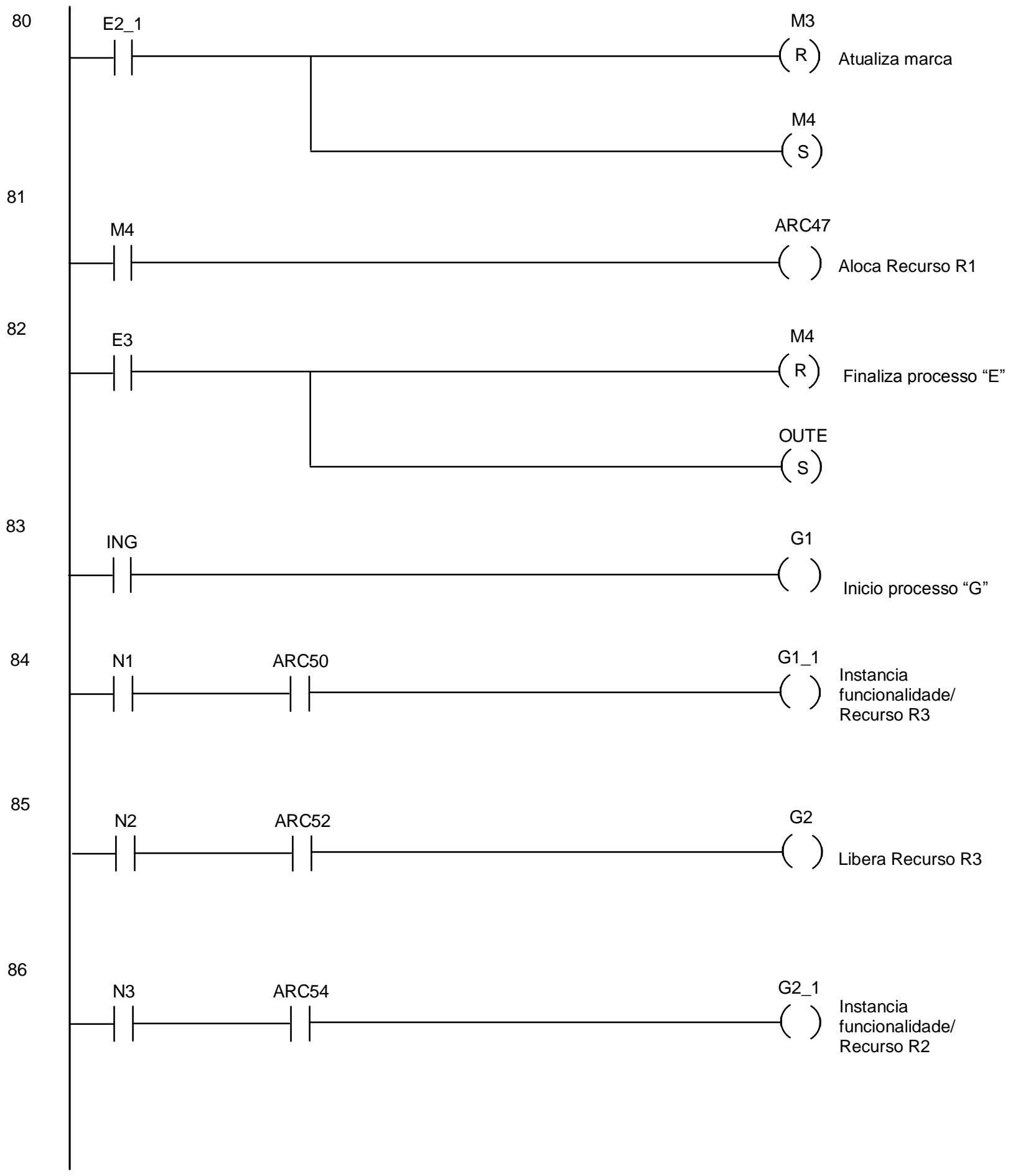




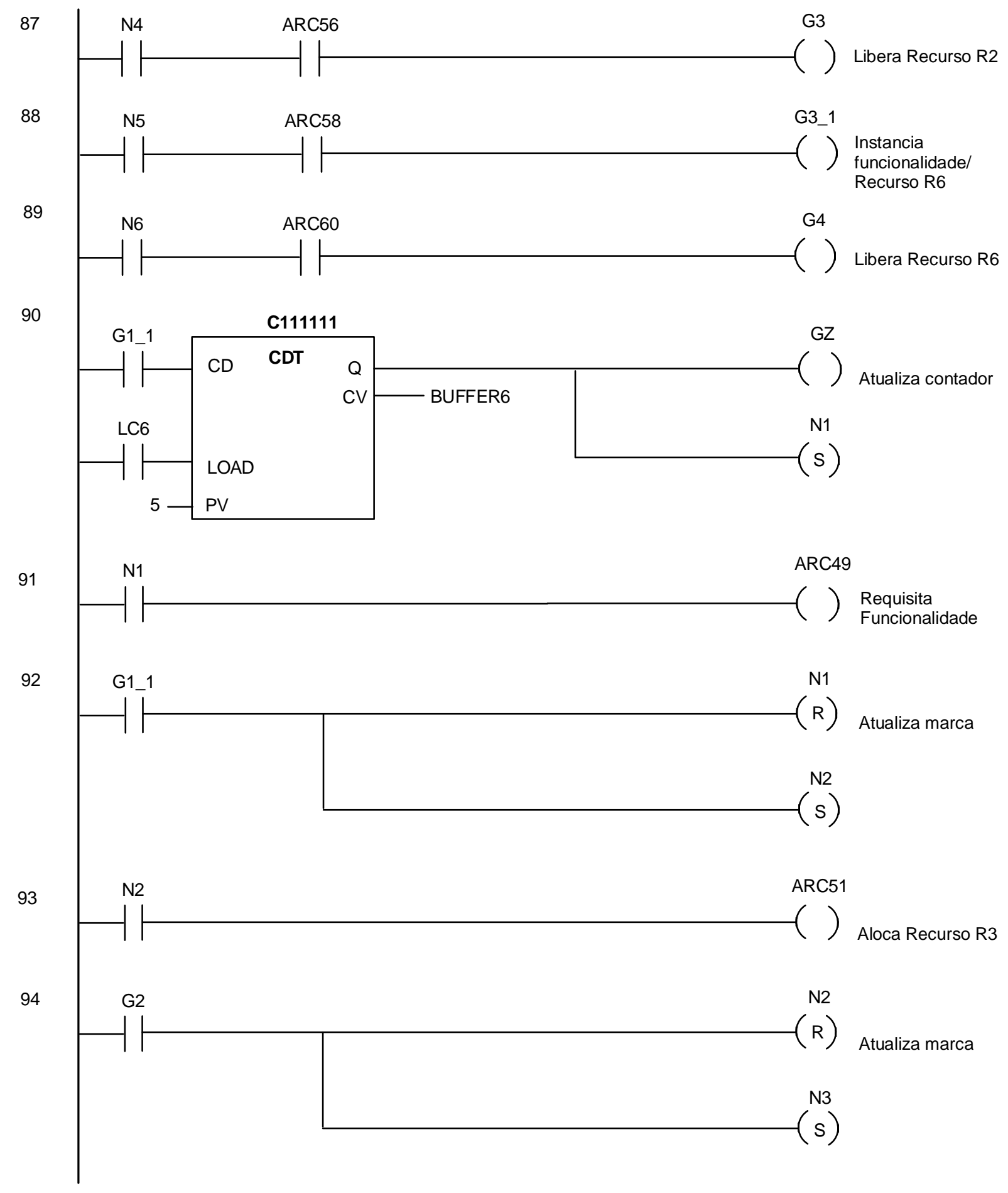


95

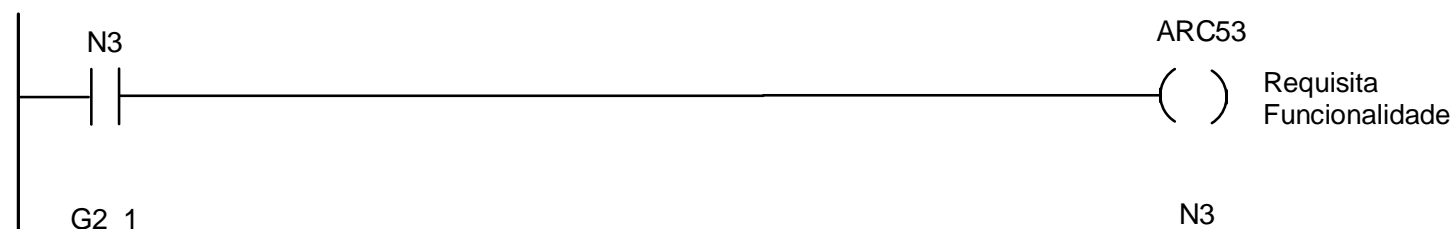

96

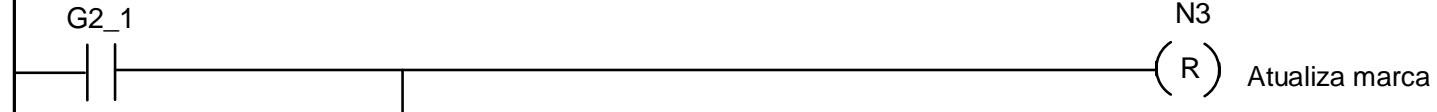

97

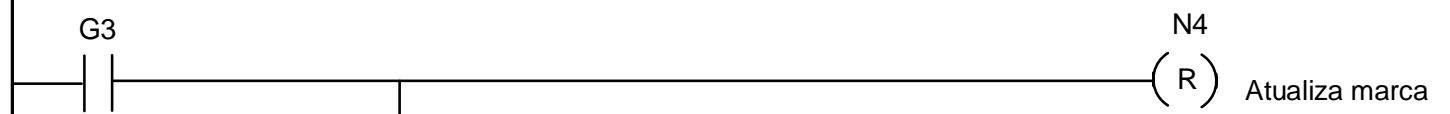

99

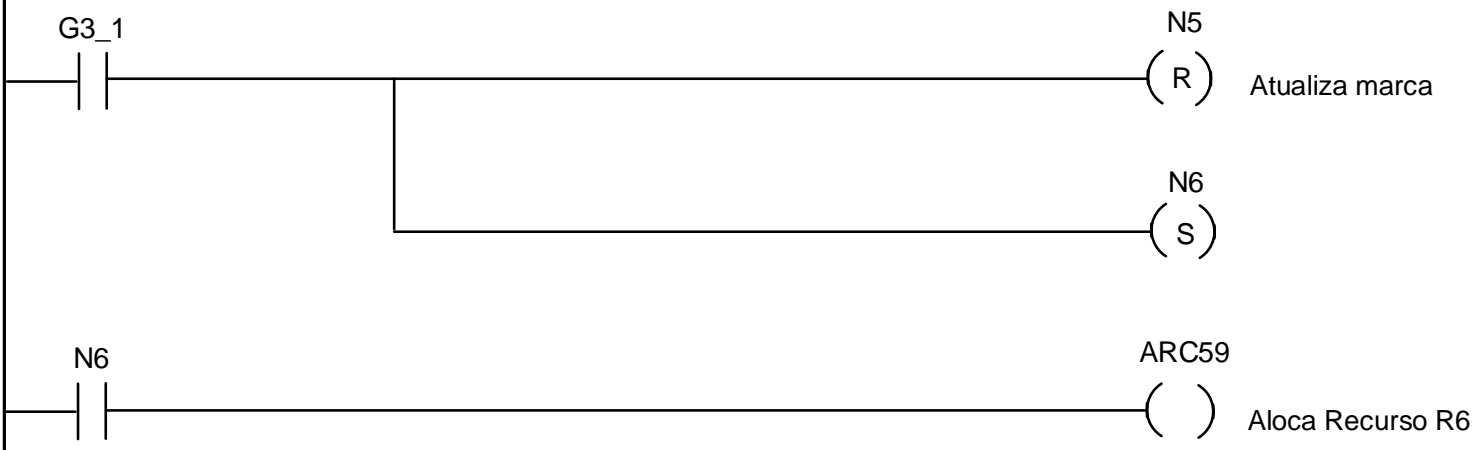




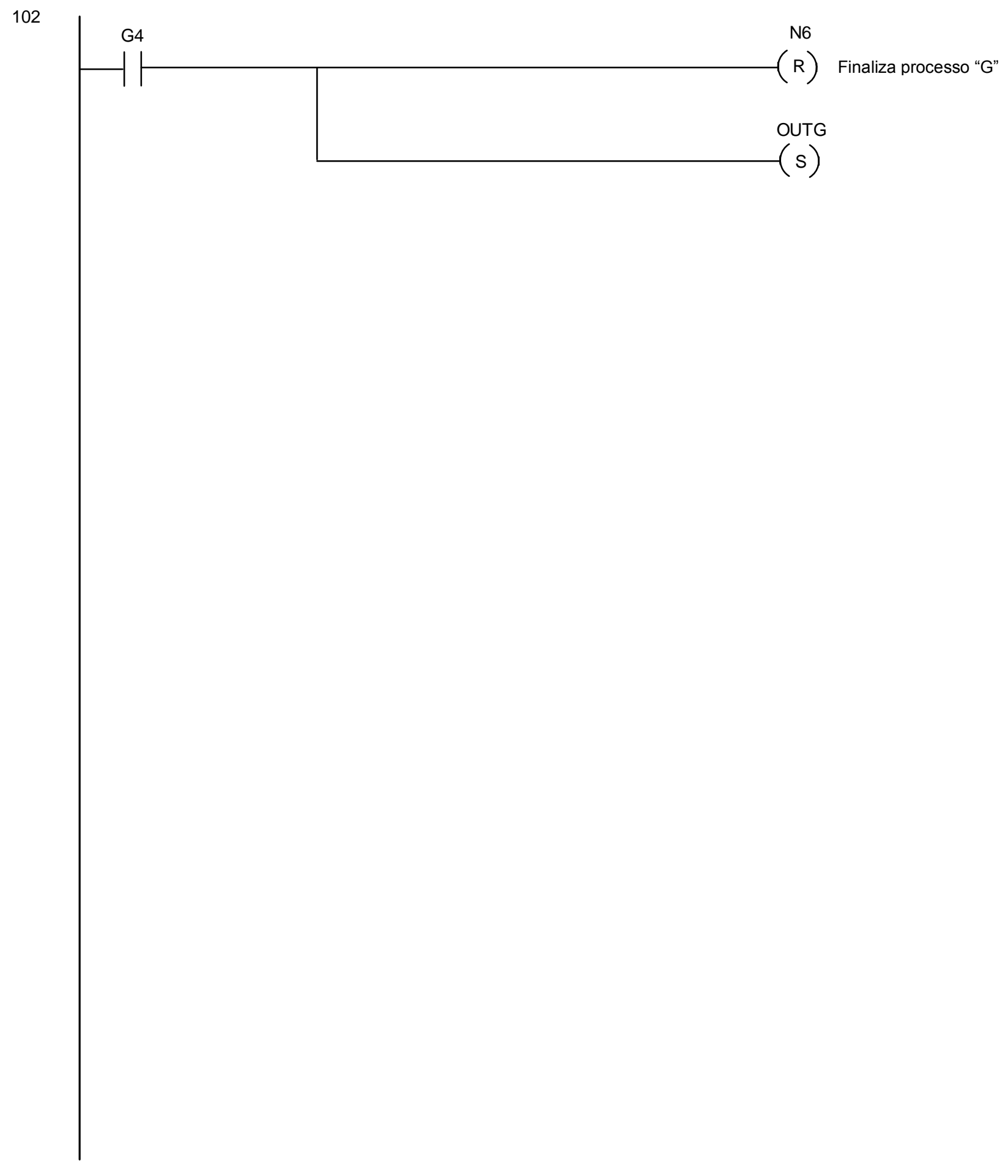

